\title{
EFFECTS OF A MULTITOUCH KEYBOARD ON WRIST POSTURE, TYPING PERFORMANCE AND COMFORT
}

\author{
A Thesis \\ Presented to the Faculty of the Graduate School \\ of Cornell University \\ In Partial Fulfillment of the Requirements for the Degree of \\ Master of Science
}

by

Jennifer Thom-Santelli

August 2004 
(C) 2004 Jennifer Thom-Santelli 


\begin{abstract}
The design of computer keyboards is rapidly evolving as portable computing becomes increasingly ubiquitous due to wireless networking and the increased popularity of personal digital assistants and notebook computers. However, there is a balance between mobility and productivity, in terms of text-entry accuracy and speed, which needs to be maintained as computer keyboards become smaller and slimmer through the introduction of ultra low-profile designs. In addition, the ergonomic benefits, in terms of the reduction of awkward wrist postures and user comfort, of ultra-low profile designs are unclear.

This study tests a new prototype ultra-low profile MultiTouch keyless keyboard (MTK) that uses a MultiTouch surface to create an extremely thin typing environment that requires no force to register a keystroke and allows mousing and gestural input on the same surface. In this study, the MTK was tested against a conventional keyboard (CK) for typing speed, accuracy, wrist postures and user comfort. It was hypothesized that the lack of key travel would increase speed and accuracy, while the ultra-thin design would reduce the amount of wrist extension, which could decrease the risk of a wrist injury or other hand and wrist musculoskeletal disorder. Finally, it was hypothesized that there would be a significant short-term learning effect on typing speed and accuracy for the MTK.

A laboratory experiment was conducted with 6 males and 6 females typing using two QWERTY keyboard designs: a CK and a MTK. Subjects visited the lab for 1.5 hours for 2 non-consecutive days in the same week, for a total of 3 hours. Each visit consisted of eight randomly assigned 7.5-minute typing tasks of text passages of similar difficulty and identical length.
\end{abstract}


Quantitative measures of typing speed and accuracy were collected using Typing Quick and Easy 13.0 and qualitative measures of user preference and comfort were gathered by self-report questionnaires. A wrist glove electrogoniometer system was used to record right-hand wrist positioning data, which was analyzed to assess the risk of injury. The two keyboards were evaluated in a repeated measures withinsubjects factorial design.

Subjects, typed slower $\left(\mathrm{F}_{1,11}=41.86, \mathrm{p}=0.000\right)$ and less accurately $\left(\mathrm{F}_{1,11}=\right.$ 23.55, $\mathrm{p}=0.001$ ) on the MTK during the typing tasks. Subjects preferred the CK and reported a higher level of ease $\left(\mathrm{F}_{1,11}=49.732, \mathrm{p}=0.00\right)$ and enjoyment $\left(\mathrm{F}_{1,11}=51.129\right.$, $\mathrm{p}=0.00$ ) during its use.

Mean wrist extension was lower for the $\operatorname{MTK}\left(\mathrm{F}_{1,11}=10.205, \mathrm{p}=0.000\right)$ while radial and ulnar deviation did not differ significantly between the two keyboards. The MTK had a lower percentage of highest-risk wrist extension $\left(F_{1,11}=6.437, p=0.028\right)$, and conversely, a higher percentage of neutral wrist posture $\left(\mathrm{F}_{1,11}=12.947, \mathrm{p}=0.004\right)$.

A significant positive linear trend was observed across the within-subjects scores for speed $\left(\mathrm{F}_{1,11}=9.308, \mathrm{p}=0.011\right)$ and accuracy $\left(\mathrm{F}_{1,11}=11.903, \mathrm{p}=0.005\right)$ across tasks in the MTK condition.

Limitations to this study include practice effects, due to the naïve subjects' lack of training on the MTK and the limited duration of exposure to this novel keyboard. Fatigue effects may have also been a factor, even though the experimental conditions were spread out over two non-consecutive days in the same week.

Future research directions include additional testing of the unique mousing and gestural capabilities of the MTK. Other research suggests that practice and extended exposure to the MTK may raise performance to comparable levels associated with CK devices. 


\section{BIOGRAPHICAL SKETCH}

Before returning to graduate school for a Masters of Science in Human Factors and Ergonomics, Jennifer Thom-Santelli worked in film and web production in New York City and San Francisco. Ms. Thom-Santelli received her Bachelor of Science in Human Service Studies from Cornell University in 1997. She will be continuing her studies at Cornell University in the Ph.D program in the Department of Communication, where she will be furthering her academic interests in social computing and human-computer interaction. This thesis is the culmination of research conducted in partial fulfillment of the Masters of Science that Ms. ThomSantelli will receive in August 2004. 


\section{ACKNOWLEDGMENTS}

I'd like to thank the College of Human Ecology for supporting my research with a Graduate Student Research Award. In addition, thanks are also extended to Fingerworks for their donation of the MultiTouch keyboard prototype, Intel Corporation for the donation of the computer workstation, Sitmatic for their donation of the chair, and WorkRite and Linak for the electronic height adjustable workstation.

The past two years working with my Special Committee Chair, Professor Alan Hedge, have been especially rewarding and I thank him for his spot-on guidance and warm encouragement. I'd also like to express my thanks to my minor member, Professor Geri Gay, who has expanded my academic interests and has helped me find a new professional direction. In addition, Francoise Vermeylen of the Office of Statistical Consulting provided much-needed advice at crucial points of the research process.

My family, especially my parents and my sister, have been a great source of support over the years and they deserve my grateful thanks as well. Lastly, my husband Josh deserves an especially loud shout-out for his patience, good humor and helpful encouragement. 


\section{TABLE OF CONTENTS}

BIOGRAPHICAL SKETCH............................................................................ii

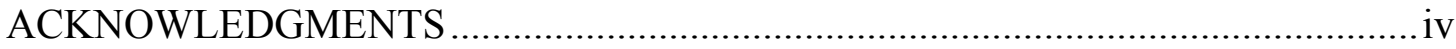

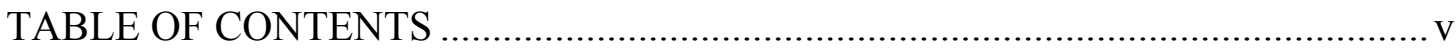

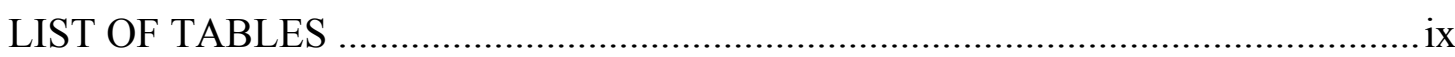

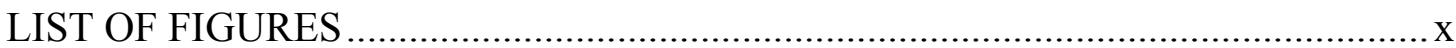

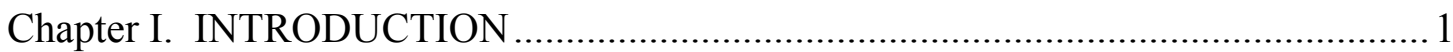

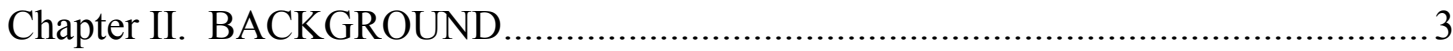

2.1 Ergonomic Properties of Computer Keyboards............................................... 3

2.1.1 Keyboard Layout................................................................................

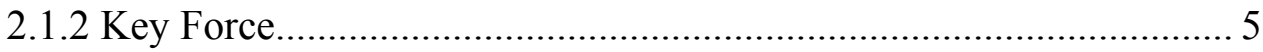

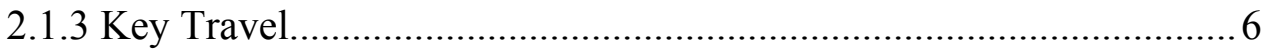

2.1.4 Key Layout........................................................................................

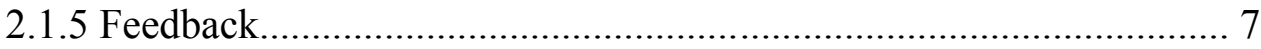

2.1.6 Keyboard Height............................................................................. 8

2.2 Evolution of Keyboard Design................................................................

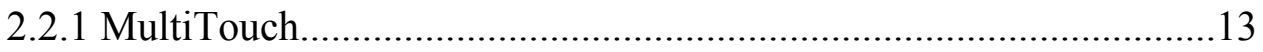

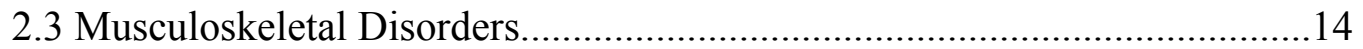

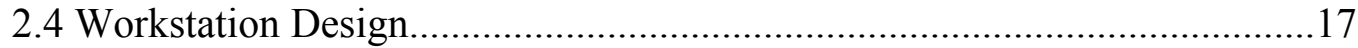

2.5 Time of Day Preference and Task Performance.............................................18

2.6 Research Rationale and Hypotheses.............................................................19

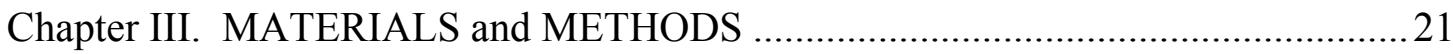

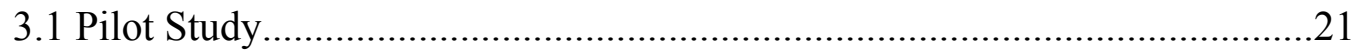

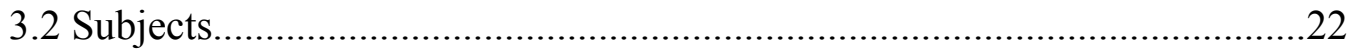




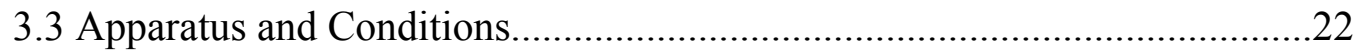

3.4 Experimental Tasks................................................. 25

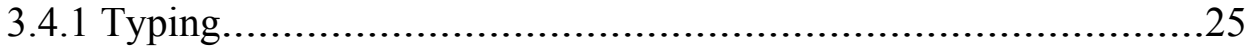

3.5 Questionnaires...........................................................25

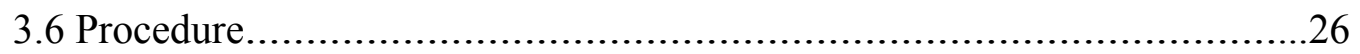

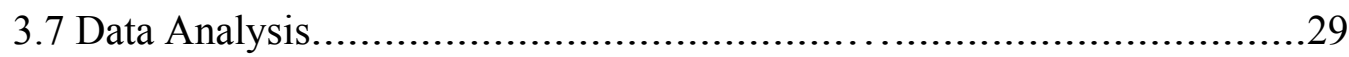

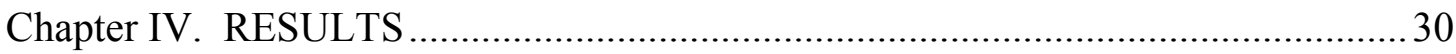

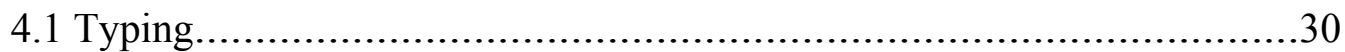

4.1.1 Speed and Accuracy................................................30

4.1.2 Learning Effects...............................................32

4.1.3 Wrist Posture........................................................35

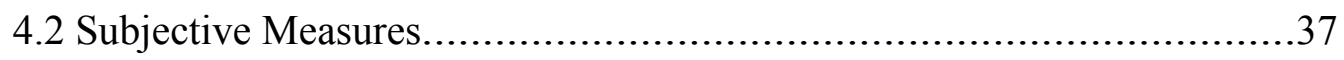

4.2.1 Enjoyment..................................................... 37

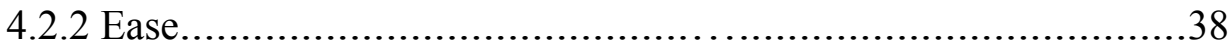

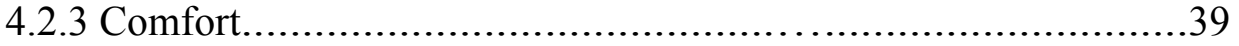

4.2.4 Fatigue..............................................................40

4.2.5 Subject Comments................................................43

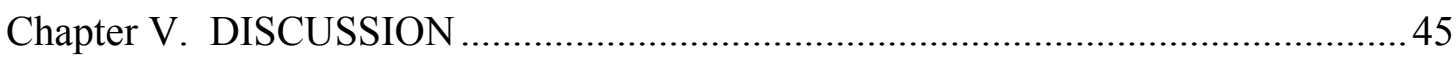

5.1 Key Travel and Key Force.................................................45

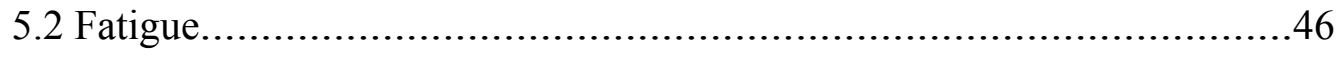

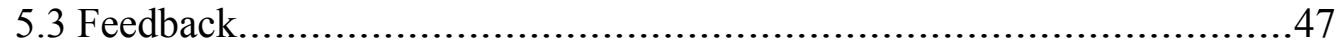

5.3.1 Visual Feedback.....................................................47

5.3.2 Auditory Feedback................................................48

5.3.3 Kinesthetic Feedback..............................................48

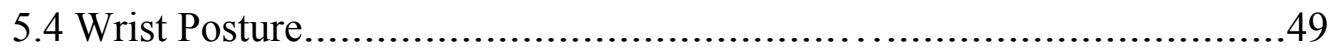

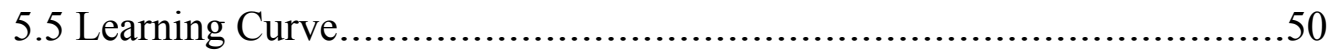


5.6 Limitations of Present Study....

5.7 Future Research and Design Directions...................................52

Appendix A. Experimental Setup with Conventional Keyboard Condition ...............55

Appendix B. Experimental Setup with MTK Condition ..........................................56

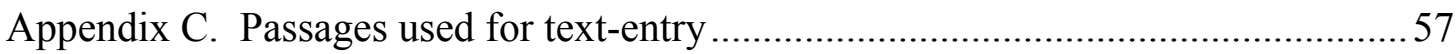

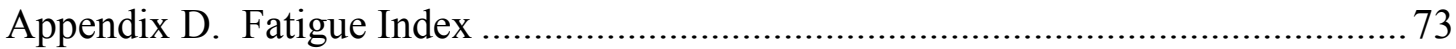

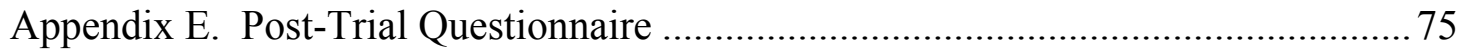

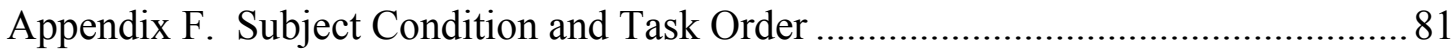

Appendix G. Raw Data: Typing Speed ......................................................... 82

Appendix H. Raw Data: Percent Accuracy ..................................................... 83

Appendix I. Raw Data: Wrist Data, CK Task 1 .................................................. 84

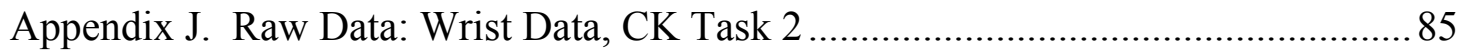

Appendix K. Raw Data: Wrist Data, CK Task 3 f................................................ 86

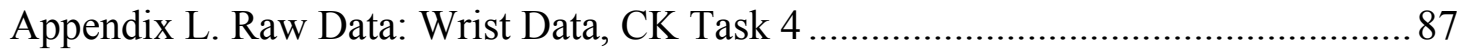

Appendix M. Raw Data: Wrist Data, CK Task 5 ................................................... 88

Appendix N. Raw Data: Wrist Data, CK Task 6.................................................. 89

Appendix O. Raw Data: Wrist Data, CK Task 7 .................................................... 90

Appendix P. Raw Data: Wrist Data, CK Task 8 ............................................... 91

Appendix Q. Raw Data: Wrist Data, MTK Task 1 ............................................ 92

Appendix R. Raw Data: Wrist Data, MTK Task 2 ................................................ 93

Appendix S. Raw Data: Wrist Data, MTK Task 3 ................................................ 94

Appendix T. Raw Data: Wrist Data, MTK Task 4 ................................................ 95

Appendix U. Raw Data: Wrist Data, MTK Task 5 ............................................. 96

Appendix V. Raw Data: Wrist Data, MTK Task 6 ............................................... 97 
Appendix W. Raw Data: Wrist Data, MTK Task 7 .............................................. 98

Appendix X. Raw Data: Wrist Data, MTK Task 8 .............................................. 99

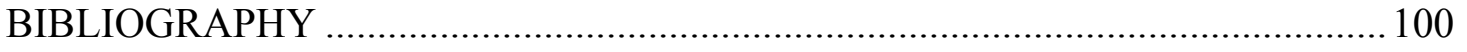




\section{LIST OF TABLES}

Table 3.1 Results from pilot study ..............................21

Table 3.2 Conventional keyboard description ......................24

Table 3.3 Keyless keyboard description ..........................24

Table 3.4 Experimental design.................................28

Table 4.1 Mean fatigue scores for CK......................... 41

Table 4.2 Mean fatigue scores for MTK ...........................42

Table 4.3 Effect of trial on fatigue levels......................... 43

Table 4.4 Subjects' comments..................................44 


\section{LIST OF FIGURES}

Figure 2.1 Maltron keyboard ................................... 10

Figure 2.2 Kinesis keyboard $\ldots \ldots \ldots \ldots \ldots \ldots \ldots \ldots \ldots \ldots \ldots \ldots \ldots \ldots 11$

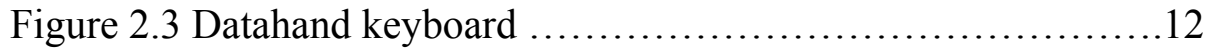

Figure 4.1 Typing speed in average words per minute...............30

Figure 4.2 Percent accuracy on typing tasks....................... 31

Figure 4.3 Typing speed across typing tasks.......................32

Figure 4.4 Accuracy across typing tasks.........................33

Figure 4.5 Regression of average wpm and typing trial...............34

Figure 4.6 Regression of percent accuracy and typing trial...........34

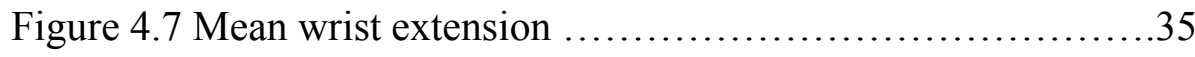

Figure 4.8 Percentage of flexion/extension wrist

postures in risk zones.................................. 36

Figure 4.9 Percentage of radial/ulnar deviated wrist

postures in risk zones ...................................37

Figure 4.10 Keyboard use enjoyment ..........................38

Figure 4.11 Keyboard ease of use ..................................

Figure 4.12 Self-report keyboard comfort ........................40 


\section{Chapter I. INTRODUCTION}

With the ongoing consumer acceptance of mobile computing products such as personal digital assistants and notebook computers, portability has emerged as a prevalent trend in computer hardware design. In addition to reducing the physical thickness of keyboards, attempts are being made to reduce typing forces by eliminating key travel and the normal forces required to reach the make point of an electromechanical key in order to reduce the risk of musculoskeletal disorders (MSDs) that have been associated with repetitive exertion, extreme wrist postures, and mechanical stress on soft tissue (Tittiranonda, Burastero, \& Rempel, 1999).

As a result, there has been an increase of computer keyboards that have been re-imagined with the concept of portability in mind. One recent novel development has been that of the MultiTouch keyboard which uses a capacitative sensor array to create a keying environment that is extremely thin and can be re-arranged in many configurations (Westerman, Elias, \& Hedge, 2001). Typing is registered by single finger contacts with the surface whereas cursor positioning is detected as two finger contacts, and other gestural commands can control other computer functions by use of a combination of finger movements on the surface. However, only split-design MultiTouch keyboards currently are commercially available, and many hunt and peck typists may be unable to perform at a satisfactory level with these designs.

Consequently, a prototype MultiTouch keyboard that resembles a single unit keyboard has been developed and this design was provided for experimental testing.

While a keyless keyboard design may allow for an extremely thin keyboard profile, the usability of such a keyboard, in terms of user preference and speed and accuracy during text-entry tasks, has not been fully examined. In addition, the effects of a very flat keying surface on comfort and the risks of musculoskeletal injuries need to be evaluated as well. 


\section{Objectives}

The purpose of the present research is to evaluate the technology of a MultiTouch keyboard in terms of performance and usability as compared to the conventional keyboard.

The following issues were explored:

1. Is text-entry faster and more accurate for the keyless keyboard because it does not require key travel?

2. Does a flat keyboard design improve wrist posture during typing, which can reduce the risk of injury?

3. How much of a short-term learning effect is there on the accuracy and speed of text-entry tasks on the keyless keyboard? 


\section{Chapter II. BACKGROUND}

\subsection{Ergonomic Properties of Computer Keyboards}

With the world's increasing dependence on computing and its associated technologies, the usability and the efficacy of the keyboard is one that must be examined in order to get a clearer picture of its prevalence through the years. In addition, the keyboard is a data input device with a design and function strongly rooted in historical precedence.

The main function of a computer keyboard is to enter text and numerical information when needed in a variety of computing situations, from data entry to word processing. This function, as well as task performance, user posture and health, is intimately connected with the design of the keyboard. The following sections discuss the ergonomic literature on the conventional computer keyboard and proposed alternative designs.

\subsubsection{Keyboard Layout}

Keyboard layout is an important design factor influencing the ergonomics and performance of the computer keyboard. The conventional computer keyboard utilizes the QWERTY layout, which evolved from the mechanical typewriter, and named for the six letter keys in the upper-left hand portion of the keyboard. Since its introduction in 1873 by the Sholes brothers, the conventional keyboard design with a parallel arrangement of rows is still the most prevalent American English layout (Norman \& Fisher, 1982). Its dominance owes to the widespread experience and familiarity that makes re-training a huge barrier to the acceptance of alternative layouts (Hanes, 1975).

Whether the QWERTY arrangement is the most favorable layout is still a matter of debate. The Dvorak Simplified Keyboard, developed in 1936, was designed 
to accommodate for the frequency of use of letters and sequences of letters in the English language (Hanes, 1975). Throughout the years, there has been much interest in this layout as an alternative to QWERTY as it has been proposed to be easier to learn, less likely to cause error and fatigue and superior in speed of entry (Alden, Daniels, \& Kanarick, 1972). However, a 1956 study conducted for the U.S government found that an average of 100 hours was needed to retrain typists in order to achieve original levels of productivity, which the researchers felt did not justify the adoption of the Dvorak layout (Hanes, 1975). For expert typists, Norman and Fisher (1982) used a simulation model to test a number of layouts, the QWERTY, the Dvorak, four alphabetic layouts and a diagonal layout, and found that the layout of keys makes little difference in terms of typist performance.

The alphabetic keyboard, a 3-row letter arrangement in alphabetic order, has also been proposed as an alternative. Michaels (1971) compared the QWERTY to the alphabetic with 30 subjects, ranging in typing skill from none to secretarial, and found that performance was better on the QWERTY for those who were semi-skilled or skilled typists. In fact, the alphabetic layout substantially slowed the skilled typists in mean keying rates. However, with the unskilled typists, the performance was essentially equal. Even after a period of practice, there was no indication that the learning curve for the alphabetic layout would be less steep than for the QWERTY (Michaels, 1971). Michaels improves on Hirsch's (1970) investigation of the alphabetic keyboard as Hirsch compared two groups of non-typists. Norman and Fisher (1982) revisit the alphabetic layout with 12 novice typists and found that the alphabetic keyboard made a slight difference in performance over a completely random keyboard layout but those with a slight familiarity with the QWERTY had a $67 \%$ greater achieved speed than the alphabetic. 
In light of touch screens and personal digital assistants, the predictive keyboard has been raised as an alternative to a traditional full QWERTY layout. By displaying only the most used keys at one time using tables of letters' transitional probabilities, a predictive keyboard will be able to conserve screen real estate (Lewis, Allard, \& Hudson, 1999). An investigation concerning the design of the predictive keyboards focused on the frequency that a user might have to often press a button for a new set of predictive keys, therefore slowing down performance (Lewis et al., 1999). In addition, increasing the number of keys displayed would cut down on the frequency of searching for a new set of buttons (Lewis et al., 1999), which would seem to contradict the benefit of conserving screen real estate. However, an exhaustive investigation of performance issues with a constantly changing set of key layouts has not yet been conducted.

\subsubsection{Key Force}

The design of individual keys must be considered as a factor affecting user performance. Greenstein and Arnaut (1987) note that key design has largely been based on design convention rather than past scientific and empirical.

However, key activation forces, defined by the BSR/HFES 100 guidelines (BSR \& HFES, 2002) as the "maximum force immediately prior to the switch closure", have been shown to have different preference levels from users. Key activation forces should be between 0.25 to $1.47 \mathrm{~N}$, according to Alden et al. (1972) and echoed in the BSR/HFES 100 (2002) guidelines. However, these parameters, within certain limits, have little effect on experienced typists (Alden et al., 1972). According to the BSR/HFES 100 (2002) guidelines, users prefer forces from 0.4 to 0.8 $\mathrm{N}$ but tend to use more force than required (Armstrong, Foulke, Martin, Gerson \& Rempel, 1994). To counteract the use of unneeded force and limit key activation 
forces below $0.8 \mathrm{~N}$, the BSR/HFES 100 (2002) standard recommends a range of 0.5 to $0.6 \mathrm{~N}$.

Key displacement, the distance the key moves vertically, is linked closely to key activation forces. According to the BSR/HFES 100 (2002) guidelines, vertical key displacement shall be from 1.5 and $6.0 \mathrm{~mm}$ and the preferred key displacement should be between 2.0 and $4.0 \mathrm{~mm}$.

\subsubsection{Key Travel}

Key travel can be defined as the area traveled by the fingers when pressing on keyboard keys. Convention and previous research support a guideline of centerline distances between adjacent keys shall be between 18 and $19 \mathrm{~mm}$ horizontally and 18 and $21 \mathrm{~mm}$ vertically (BSR \& HFES, 2002). These guidelines hold true for functional groups of keys only.

Keyboard geometry, which encompasses the issues of key sizes and inter-key spacing, has been shown to affect travel, movement time and user performance. By altering key geometry to reduce finger travel between keys, it can be hypothesized that movement time may decrease and user performance in terms of typing speed may increase. To validate Drury and Hoffman's model for movement time on keyboards, Hoffman, Tsang and Mu (1995) devised a set of simulated keyboards varying in center spacing of the keys, inter-key spacing, and key size. The smallest movement times were found in the instances when the inter-key spacing was approximately the same as finger-pad size while movement time increased with a larger amount of keys moved (Hoffman, Tsang \& Mu, 1995). 


\subsubsection{Key Layout}

Cultural issues may determine the key design of a computer keyboard as well. First, the standards of a particular region, its historical precedents, and application requirements must be considered, and language and other cultural variations, as well as inconsistent standards, can complicate this task (Hanes, 1975). For a single and well-defined cultural group, these guidelines should be kept in mind. According to the ISO 9241 (1998) standards, the characters and number of keys need to be determined, arrangement of keys according to frequency, follow historical precedent and established standards, group frequently used keys in touch area, put common functions together and group logically. Again, these guidelines seem consistent with the issues discussed above.

\subsubsection{Feedback}

Auditory, kinesthetic, and visual key feedback are also mentioned in the Alden et al. (1972) research as factors influencing computer keyboards and user performance. Visual feedback is important when learning how to touch type due to maintaining home row position and may play a role in self-detecting typing errors (Klemmer, 1971).

Building on the importance of individual key design, Brunner and Richardson (1984) investigated performance effects due to kinesthetic key feedback by studying user preferences and performance on three different keyboards with three different key action mechanisms. Each had the same layout but differed in the tactile and auditory feedback (Brunner \& Richardson, 1984). Two groups, expert and occasional typists, spent a full day in testing and completed a subjective questionnaire measure for each keyboard (Brunner \& Richardson, 1984). Lower error rates were found with the keyboards with elastomer key action rather than those with a linear-spring mechanism 
(Brunner \& Richardson, 1984). In addition, tactile feedback at multiple points of each keystroke improved performance (Brunner \& Richardson, 1984).

The performance effects on low profile and membrane keyboards and numerical keypads, such as ones found on telephones, were studied in the late 70 s and early 80 s. With the advent of membrane keyboards, there was concern that the lack of adequate auditory and kinesthetic feedback would adversely affect user performance in text-entry tasks.

In an examination of no-travel membrane and capacitative telephone keypads, error rates were significantly worse and mean keying times were significantly different, but by increasing kinesthetic feedback by adding a 25-30-millisecond lockout to depressions on a keypad, error rates were reduced (Pollard \& Cooper, 1979). In Roe, Muto and Cooper (1984), the addition of metal domes for kinesthetic feedback, embossed keys for key discrimination, and a $1000 \mathrm{~Hz}$ tone for auditory feedback to a membrane keyboard yielded the best performance and preference scores.

The current BSR/HFES 100 guidelines (2002) specify that key actuation needs to be accompanied by tactile or auditory feedback. Auditory feedback should occur at the same point of key displacement for all keys and this feedback volume should be adjustable (BSR \& HFES, 2002). Highly detailed specifications have been difficult to establish because effectiveness has been related to feedback mode, user skill, keyboard layout and task demands (BSR \& HFES, 2002).

\subsubsection{Keyboard Height}

Keyboard height was investigated as one of the design components that could have a possible effect on typist performance. In Burke, Muto and Gutmann (1984), skilled typists used 8 eight low profile keyboards that were placed on platforms to simulate keyboard heights of $64 \mathrm{~mm}, 84 \mathrm{~mm}$, and $104 \mathrm{~mm}$. Following a typing 
session that included a pre and post-test and a long-run or short-run task, the subjects were given a semantic differential questionnaire regarding their preference. While performance did not really vary in terms of accuracy and speed, the subject preferred the keyboard at $84 \mathrm{~mm}$ (Burke et al., 1984)

Past research has considered the close relationship between keyboard height and keyboard slope. The BSR/HFES 100 guidelines (2002) maintain that the slope of a conventional keyboard shall be between 0 and 15 degrees but that alternative designs may exceed that slope range. Personal user preference has been determined as a major factor influencing keyboard slope (Burke et al., 1984) but the design recommendation to keep wrists as straight as possible remains in place. Further research outlined in a later section of this thesis will discuss the relationship between keyboard design and the resulting keyboard slope.

\subsection{Evolution of Keyboard Design}

Throughout the years, there have been a number of alternative keyboard designs suggested and researched as an ergonomic alternative to the conventional flat keyboard. The following section will review a selection of keyboards that attempt to reduce awkward wrist postures, decrease the learning curve associated with acquiring typing skills and increase portability.

Splitting the keys into different configurations was thought to be a way to decrease deviation of the forearms, hands and wrists. Nakaseko, Grandjean, Hunting, and Gierer (1985) while investigating the biomechanical effects of the split keyboards and large forearm wrist supports, found that subjects preferred a split keyboard that decreased ulnar deviation from 20 degrees to 10 degrees $(p<0.05)$. In terms of performance, an adjustable split keyboard may be more readily accepted by participating users than a fixed angle split keyboard (Cakir, 1995). 
Kroemer (2000) has assembled an exhaustive bibliography detailing the research concerning various alternative keyboard designs, which remains a valuable resource to designers and researchers. The Maltron keyboard, with split keys and a bowl-shaped typing area and Dvorak key layout had been proposed as a model for training new typists. Based on work by Lillian Malt, Hobday (1988) detailed the developments and benefits of the Maltron while admitting that converting experienced QWERTY users to this design might be difficult.

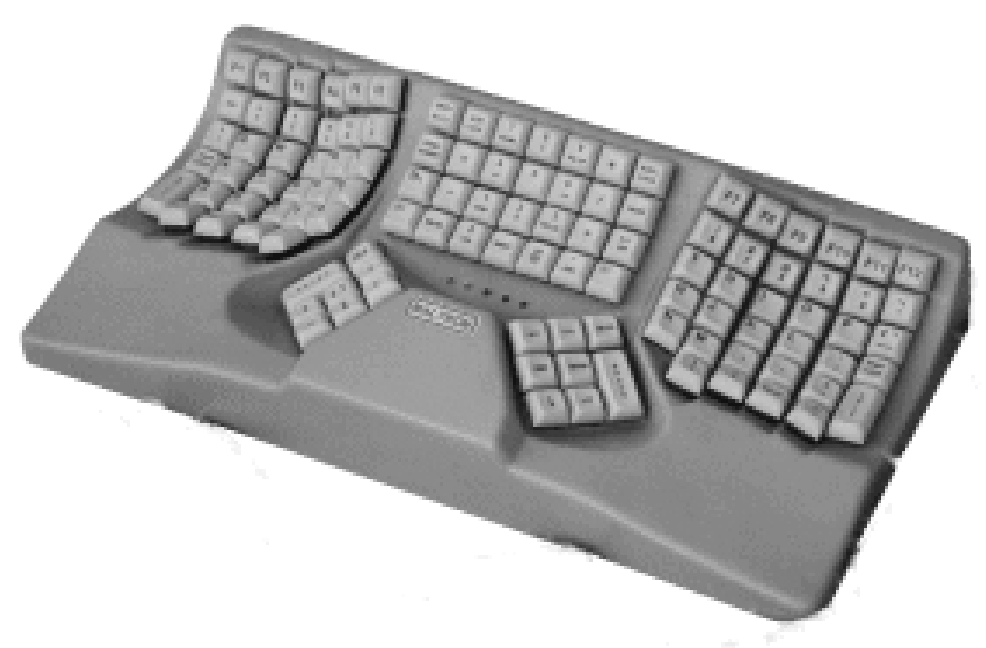

Figure 2.1. The Maltron keyboard. Note. From www.maltron.com by PCD Maltron LTD. Copyright 2004 by PCD Maltron LTD. Reprinted with permission.

Appearing remarkably similar to the Maltron is the Kinesis Ergonomic Computer Keyboard. Using a QWERTY layout, the training period on the Kinesis keyboard was relatively short, where accuracy of $97 \%$ was reached within 97 minutes and $72 \%$ of speed proficiency was reached within 115 minutes (Gerard, Jones, Smith, Thomas, \& Wang, 1994). In addition, EMG readings demonstrated that the resting posture with the Kinesis required less activity to maintain and reduced the muscular 
activity in the flexor carpi ulnaris, flexor digitorum sublimis, and the extensor digitorum communis (Gerard et al., 1994). Split keyboards and the Kinesis were found by Treaster and Marras (2000) to decrease tendon travel up to $11 \%$.

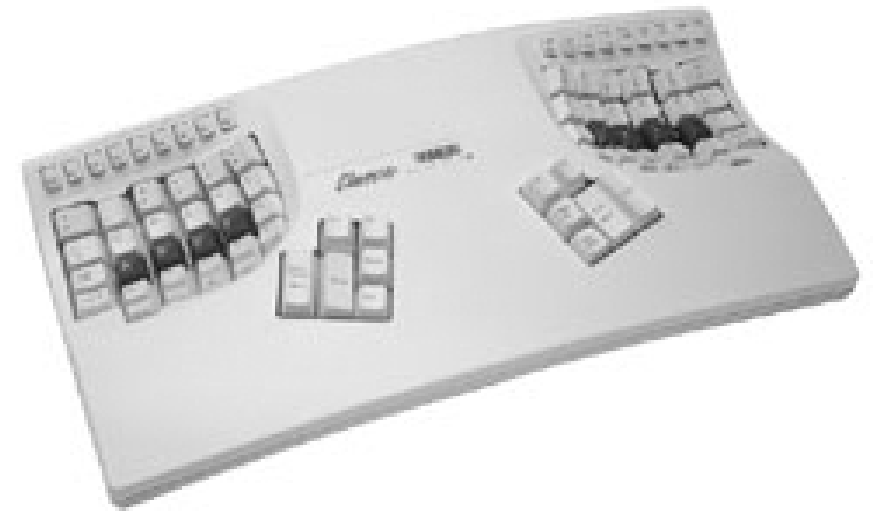

Figure 2.2. The Kinesis keyboard. Note. From www.kinesis-ergo.com by Kinesis Corporation. Copyright 2004 by Kinesis Corporation. Reprinted with permission.

The chord keyboard has been proposed as a portable alternative that may increase user performance in terms of typing speed. Rochester, Bequaert, and Sharp (1978) developed a working prototype that was a right-handed model with a 5x2 arrangement of square keys and 4 thumb keys. In addition, an automated training system was developed to teach people how to touch-type on the chord keyboard (Rochester et al., 1978), which helped to decrease learning time. Adding another chord design for consideration, Kroemer (1988) tested a chord keyboard with ternary, or three-state, keys activated horizontally instead of vertically.

With the advent of smaller computing spaces, keyboard designs that occupy less real estate have become more frequently discussed. Wiklund, Dumas and Hoffman. (1987) provided some parameters for a one-handed design that would accommodate a terminal cradled between the elbow crease and the hand. A Half- 
QWERTY keyboard, small enough to wear on the wrist, has been developed where one half of the letters used by one hand are present and the other half are typed by depressing the space bar, while pressing the keys (Matias, MacKenzie, \& Buxton, 1994). In preliminary study, typing rates were 2 to 3 times faster than compact keyboards and were faster than handwriting speeds as well (Matias et al., 1994).

A radical change from the conventional keyboard, the Datahand is composed of 2 separate units that allow the user to rest their hand over the 4 finger holes and recessed thumb area. While Knight and Retter (1989) observe in preliminary testing that the Datahand can be learned in relatively few hours, this device would seem to present a challenge for the users who are deeply familiar with conventional keyboards and the QWERTY layout.

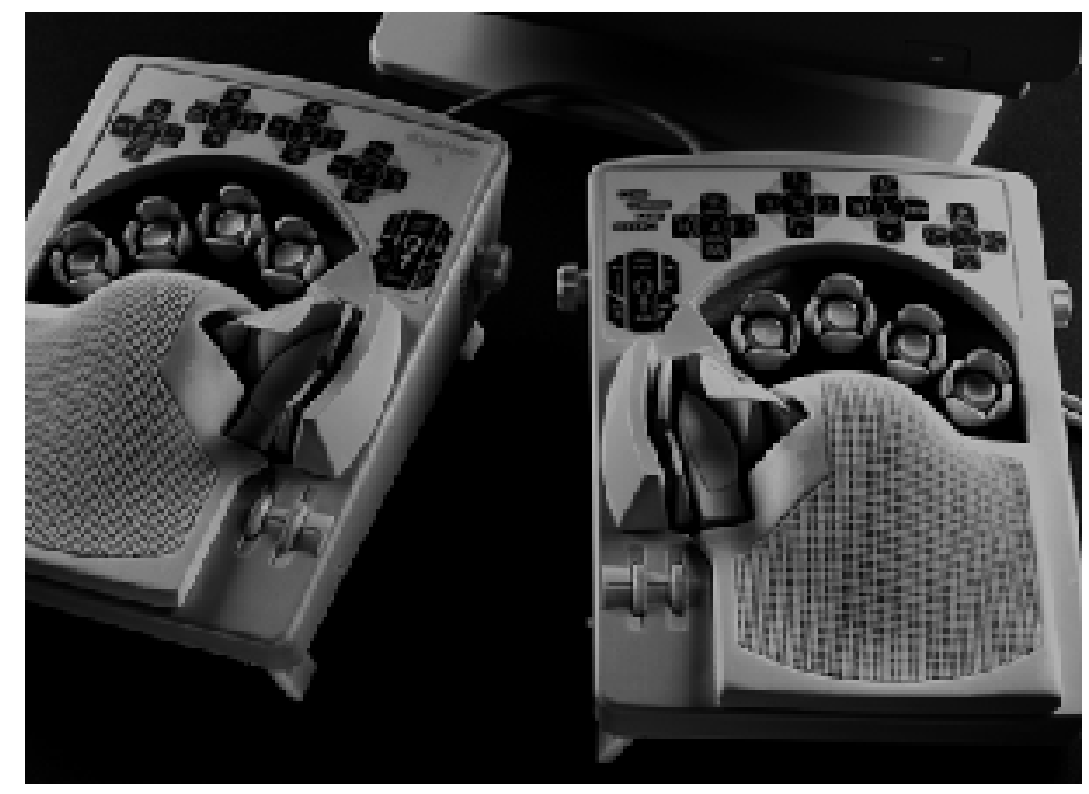

Figure 2.3. The Datahand keyboard. Note. From www.datahand.com by Datahand Systems. Copyright 2004 by Datahand Systems. Reprinted with permission. 
Pen-based inputs have become more prevalent as of later with the rise of PDAs, the introduction of the tablet PC, and the widespread use of graphic editing software. Additionally, pointing tasks do not seem to be well supported by the current design of the keyboard, and with the development of alternative input devices, there was some early research gathered to assess their benefits. As a result, Hashimoto and Togasi (1995) developed a virtual oval keyboard on a Wacom tablet to mimic the natural movement of the wrist while using a pen. For cursor positioning, lightpens and lightguns were four to five times faster for arbitrary cursor positioning, sequential cursor positioning and check reading (Goodwin, 1975).

\subsubsection{MultiTouch}

A gestural interface is another alternative in the user and input device relationship. The combination of pointing and typing capabilities of such an interface may prove useful when considered with current computing needs, and the reduced key force needed may help to reduce risk of MSDs. The gestural interface also holds promise for multi-lingual users as typing functions are not necessarily limited by a physical character set.

An example of this type of interface is the MultiTouch, described by Westerman, Elias, and Hedge (2001) as a robust input surface that is very thin yet not limited in size. MultiTouch uses a "two-dimensional sensor array that produces images of fingers and hands near or touching its surface (Fingerworks, 2004).” A software component then interprets, recognizes and tracks the hand and finger movements (Fingerworks, 2004). MultiTouch recognizes a single finger touch as a typing keystroke command while a two fingertip touch points, and a thumb and forefinger motion is a gesture command (Fingerworks, 2004). 
Limited research has been conducted on the MultiTouch surface. A test of a MultiTouch numberpad found that the input surface produced faster cursor positioning time but slightly longer data-entry times than on the conventional electromechanical keypad (Shanis, 2002). A previous usability test of MultiTouch as compared to a standard keyboard and mouse was inconclusive due to the input surface leaning curve even though typing took significantly longer $(\mathrm{p}<0.0001)$ on the MultiTouch (Detwiler, Hun An, \& Choi, 2000). The MultiTouch surface has been incorporated into a children's finger-painting device that can be used as for collaborative artwork (Browne, Bederson, Druin, Sherman, \& Westerman, 2000).

\subsection{Musculoskeletal Disorders}

Musculoskeletal disorders (MSDs) have emerged as an important and costly health issue in the United States, accounting for "nearly 70 million physician office visits annually and 130 million total health care encounters, including outpatient, hospital and emergency room visits (National Academy of Sciences, 2001).” Defined as soft tissue injuries that involve nerve, tendon and muscle damage, MSDs affect the upper extremities, defined as the neck, shoulder, elbow, hand, wrist, and fingers, as well as the back and lower back. Substantial research has indicated a higher incidence rate of MSDs of the upper extremities as computer use, combined with posture issues and repetitive motion, has increased (National Academy of Sciences, 2001). Awkward posture, force application and repetitive tasks are noted as the major risk factors contributing to the development of MSDs (NIOSH, 1997).

Carpal Tunnel Syndrome (CTS) is a MSD of the upper extremities that commonly occurs in frequent computer users. However, a causative relationship between computer use and CTS is still a matter of debate. Based on a review of relevant epidemiological literature, there is evidence that highly repetitive work may 
cause a higher incidence of CTS, and exposure to the combined factors of risk (e.g. force and repetition, force and posture) has a positive relationship to the development of CTS (NIOSH, 1997). The opposing viewpoint names confounding factors, such as age, gender, and outside non-job related characteristics that may weaken the stated relationship between computer use and CTS (National Academy of Sciences, 2001).

Extension, or dorsiflexion, is the wrist deviation most commonly associated with the increased risk of injury (NIOSH, 1997). The carpal tunnel contains 9 flexor tendons, which connect the fingers and thumb to the forearm flexor muscles that control finger movement, the radial artery and the median nerve. When the wrist is flexed or extended repeatedly, the sheaths surrounding the flexor tendons can swell, constricting the carpal tunnel, which presses into the median nerve (Sanders \& McCormick, 1993).

To decrease the incidence of risk, a neutral wrist angle of zero degrees of pronation, extension/flexion and radial/ulnar deviation is hypothesized to be the most favorable wrist posture (Zecevic, Miller, \& Harburn, 2000). However, Rempel, Bach, Gordon and Tal (1998) found that minimal carpal tunnel pressure did not occur in a neutral position but at $45^{\circ}$ metacarpophalangeal pronation and $2^{\circ}$ flexion, which should be taken into account when assessing the design of input devices.

Work-related MSDs have been one of the great incentives in ergonomic keyboard redesign, for health and productivity reasons. A 1987 survey of Massachusetts clerical workers revealed that those workers with repetitive duties were at increased risk of developing discomfort related to musculoskeletal issues as well as headaches and vision problems (Rossignol, Morse, Summers, \& Pagnotto, 1987). More recently, a survey of 12,262 regular keyboard users found that regular keyboard use was significantly associated with pain in the shoulders, wrist and hands (Palmer, 2001). 
Using an objective measure of electromyography, Gilad and Harel (2000) used flat, negative, Tony, described as an architecture for a split keyboard with a positive tilt angle in the sagittal plane, and an apart design, and apart keyboard geometry's to determine muscular effort in the following muscle groups: flexor carpi ulnaris, extensor carpi ulnaris, the deltoid and trapezius. The flexor muscles used less effort $(\mathrm{p}<0.05)$ when keying was undertaken on a negative slope keyboard (Gilad \& Harel, 2000). In addition, there is a relatively recent review of the literature detailing the relationship between cumulative trauma disorders and keyboard use (National Academy of Sciences, 2001) that suggests that further research should be done on the relationship between force and repetition.

The issue of physiological strain and its measurement, as related to keyboard use, holds some importance as subjective measures of strain do not measure muscle activity. Electromyography, EMG for short, has been found to be one of the most widely used objective measures of different types of strain.

In an assessment of hand abduction at typewriters, Zipp, Haider, Halpern, and Rohmert (1983) used electromyography to record muscle action potentials and used the muscle load information to conclude that a split keyboard may contribute to less detrimental muscle activity during a longer typing task. Stasser, Fleischer, and Keller (2000), in their investigation of a split, ergonomic keyboards, utilized EMG to record the effort of 8 muscle groups simultaneously to determine that the test keyboard led to less muscle strain, as demonstrated by muscle activity differences.

In addition to muscle group effort, EMG has measured discomfort in many cases as well. Hagberg and Sundelin (1986) used EMG to reliably correlate muscular load to subjective measures of discomfort, such as Borg scales of perceived exertion, on the upper trapezius muscle for 6 female VDT workers. Lowe, Moore, Swanson, Perez, and Alderson (2001) investigated the relationship between upper limb muscle 
loading, reported discomfort and keyboard use and found that EMG measures of upper limb loading did not predict MSDs as well as the presence of existing symptoms.

\subsection{Workstation Design}

While it can be difficult to eliminate repetitive typing tasks in a computing environment, the workstation may be controlled to reduce postural risk factors that may cause MSDs.

Keyboard slope and keyboard height, varied by workstation design, have also been examined for their relationship to MSDs of the wrist. Hedge, Morimoto and McCrobie (1999) compared a keyboard on a downward tilting keyboard tray to a conventional keyboard placed on a desktop and a keyboard on a conventional, adjustable keyboard tray. The downward tilting keyboard tray helped to reduce wrist extension $(\mathrm{p}=0.026)$ and $67 \%$ of the wrist movements were in a neutral zone (Hedge et al., 1999).

Simoneau and Marklin (2001) varied keyboard slope to $+15,+7.5,0,-7.5$ and 15 degrees and the height of the keyboard so that subjects' wrists were at the same height as their elbows, above the elbows and four $\mathrm{cm}$ below the elbows. As slope of the keyboard tilted negatively, the mean wrist extension decreased 13 degrees (Simoneau \& Marklin, 2001). Mean wrist extension was lowest at 7.3 degrees when the keyboard was higher than elbow height (Simoneau \& Marklin, 2001).

Keyboard slope and its relationship to wrist and seated postures have been cited as possible factors contributing to musculoskeletal discomfort. One approach taken was to vary the slope of the keyboard itself. Hedge and Powers (1995) investigated 2 systems, one with full motion forearm supports and the other with a negative slope keyboard support system. The negative slope keyboard system was found to reduce average dorsal wrist extension to -1 degree (Hedge \& Powers, 1995). 
Simoneau and Marklin (1999) extended this research by pre-determining a set of angles that the keyboards would be set at during the typing observation. As a result, mean wrist extension decreased from 22.5 degrees in a 15-degree positive slope keyboard to 7.8 degrees in the negative slope keyboard condition $(\mathrm{p}<0.01)$ (Simoneau \& Marklin, 1999).

Extending the research on alternative keyboard designs, Muss and Hedge (1999) examined the vertical split-keyboard, the use of forearms supports and traditional keyboards. While typing performance was slightly reduced, subjects using the vertical split-keyboard spent a greater proportion of the time with wrists in a neutral position $(\mathrm{p}<0.01)$ (Muss \& Hedge, 1999). Kroemer (1972) used two groups, typists and non-typists, to evaluate the K-keyboard, first proposed in 1926, and found that performance was reduced but subjects reported less subjective discomfort.

Nelson, Treaster and Marras (2001) took a slightly different approach to assess the relationship between keyboard angles on tendon travel and wrist and finger joint kinematics. Lightweight goniometers were attached to the subjects' fingers at each joint and flexible monitors developed in the Biodynamics Laboratory at Ohio State were used to monitor the wrists (Nelson et al., 2001). The study found that there was a tradeoff between wrist extension and finger position (Nelson et al., 2001).

\subsection{Time of Day Preference and Task Performance}

Individual differences in circadian rhythms, specifically "morningness" and "eveningness", have long been of interest in terms of their effect on task performance. To evaluate morningness and eveningness, Horne and Ostberg (1976) devised an English-language questionnaire that assessed a person's affinity into three categories: a morning type, an evening type, and an intermediate type. This questionnaire was validated using the circadian variation in oral temperatures (Horne \& Ostberg, 1976) 
and has been used since as a reliable English-language assessment tool of time of day preference.

Different types of cognitive performance have been found to follow circadian cycles and the mediation of individual differences, such as morningness and eveningness, have also been investigated as well. Folkard (1979) used a measure of immediate recall of digit sequences presented from an audio recording to demonstrate that performance improved from early in the day (approximately 8:00AM) until midmorning (10:30AM) but then declined for the rest of the day with the lowest point in the evening at 9:00PM.

While there is no research on the direct effect of time of day on keyboarding, performance on a typing task can be likened to past work on cognitive and manual task performance. Time of day effects on performance tasks of varying cognitive loads are somewhat inconclusive. Circadian type did not interact with task performance, where there was no significant difference between scores on a highdemand analogy task and a repetitive digit recall (Green \& Morgan, 1985). In a delayed recall task of lecture material, Marks and Folkard (1988) found that subjects were more likely to remember more important lecture information if they heard the lecture in the late afternoon rather than the morning. In terms of manual task performance, Hill, Cureton and Collins (1989) demonstrated faster ergometer test times from athletes who trained in the morning and were tested in the morning and athletes who trained in the afternoon and were tested in the afternoon $(\mathrm{p}<0.05)$, which suggested an adaptation effect to the time of day the task was performed.

\subsection{Research Rationale and Hypotheses}

Based on the review of existing literature, keyboard height, key design and feedback were selected as the main points of interest in the present research. This 
study was designed to examine the relative performance effects and user reactions to two computer keyboards: a conventional keyboard and a MultiTouch keyless

keyboard. Quantitative measures of typing speed and accuracy, and wrist postures and qualitative measures of user preference and comfort were collected to assess the two keyboards in terms of performance, wrist extension during typing, and preference and ease of use.

A typing task was chosen to be representative of keyboard functions used most frequently and to demonstrate user performance. Each hypothesis was developed to represent different aspects of performance for each keyboard, and dependent measures were selected to properly assess those aspects of performance. The hypotheses of the present study are as follows:

1. Text-entry will be faster and more accurate for the MultiTouch keyless keyboard because it does not require key travel.

2. A flat, ultra low-profile MultiTouch keyboard design will improve wrist posture during typing, which can reduce the risk of injury.

3. There will be a significant short-term learning effect on the accuracy and speed of text-entry tasks on the MultiTouch keyless keyboard. 


\section{Chapter III. MATERIALS and METHODS}

\subsection{Pilot Study}

A pilot study was conducted with two female graduate students, both experienced touch typists, in order to finalize the transcription passages used in the typing tasks, to test the monitoring equipment and to clarify the language used in the questionnaires given before and after each typing task. Each pilot subject used the conventional keyboard on one day and the MultiTouch keyboard on a second day, and keyboard order was randomly assigned and balanced. On each day, the pilot subjects completed eight 7.5-minute typing tasks, which were also administered randomly. A post-trial questionnaire was given to assess preference and determine subject's internal circadian preferences. Each pilot subject was paid for her participation. The results are shown in Table 3.1 .

Table 3.1. Results from pilot study

\begin{tabular}{|l|l|l|l|l|l|l|}
\hline & $\begin{array}{l}\text { Average } \\
\text { wpm }\end{array}$ & Accuracy & $\begin{array}{l}\text { Mean RH } \\
\text { wrist } \\
\text { extension }\end{array}$ & $\begin{array}{l}\text { Mean LH } \\
\text { wrist } \\
\text { extension }\end{array}$ & $\begin{array}{l}\text { Mean RH } \\
\text { rad/uln } \\
\text { deviation }\end{array}$ & $\begin{array}{l}\text { Mean LH } \\
\text { rad/uln } \\
\text { devation }\end{array}$ \\
\hline $\begin{array}{l}\text { Conventional } \\
\text { Keyboard }\end{array}$ & 59.31 & $95.31 \%$ & 23.87 & 24.13 & 15.78 & 16.34 \\
\hline $\begin{array}{l}\text { MultiTouch } \\
\text { keyboard }\end{array}$ & 32.43 & $82.87 \%$ & 16.49 & $17.65^{*}$ & 12.54 & $14.26^{*}$ \\
\hline
\end{tabular}

*Data from one pilot subject

During the pilot study, it was found that the left wrist goniometer failed to function properly and as a result, only the right wrist goniometer was used for the full experiment. Statistical analysis conducted with the limited left-hand data available revealed no significant difference between the right-hand and left-hand wrist postures. 
Results from the pilot study helped to fine tune the main experiment, which was subsequently conducted.

\subsection{Subjects}

12 subjects, 6 men and 6 women undergraduate and graduate students, were recruited from Cornell University via e-mail and posted flyers. Subjects were asked to participate in the study as paid volunteers receiving $\$ 45$ as compensation. All subjects were right-handed and ranged in age from 20 to 28 years old. The sample size was determined in consultation with the College of Human Ecology Statistical Consulting Office on the basis of power, alpha level and variability.

Selected subjects were pre-screened as proficient touch typists, defined as the ability to type at least 45 words per minute, and had fingernails that did not interfere with their typing performance. Each subject was tested independently in the laboratory by the same experimenter, and subjects were required to come into the lab for 1.5 hours on 2 days (for a total of 3 hours), at the same time of day for each visit. Six of the subjects chose morning start times for their experimental visit while the other six subjects scheduled their participation for the afternoon.

\subsection{Apparatus and Conditions}

The experimental study was conducted in the Cornell University Human Factors and Ergonomics Laboratory. A computer workstation (Appendix A and B) was set up with an adjustable table (LINAK) and an ergonomic task chair (Sitmatic Boss Task.) Each subject was allowed to adjust the table and chair to his or her comfort on the first visit. The chair seat pan height and angle and the table height was recorded and replicated on the second day of testing. A Dell 20" computer monitor 
was placed on the adjustable table behind the computer keyboard. The same fluorescent overhead lights served to illuminate the room for each condition.

A wrist goniometer, a fingerless glove instrumented with sensors (Greenleaf Medical), recorded each subject's right-hand vertical and lateral deviations during typing at a sampling frequency of $10 \mathrm{~Hz}$. A conventional keyboard (CK: Dell AT101W) and the prototype of a MultiTouch keyboard (MTK: Fingerworks Ultra in silent mode) were tested. 
Table 3.2. Conventional Keyboard: Dell AT101W

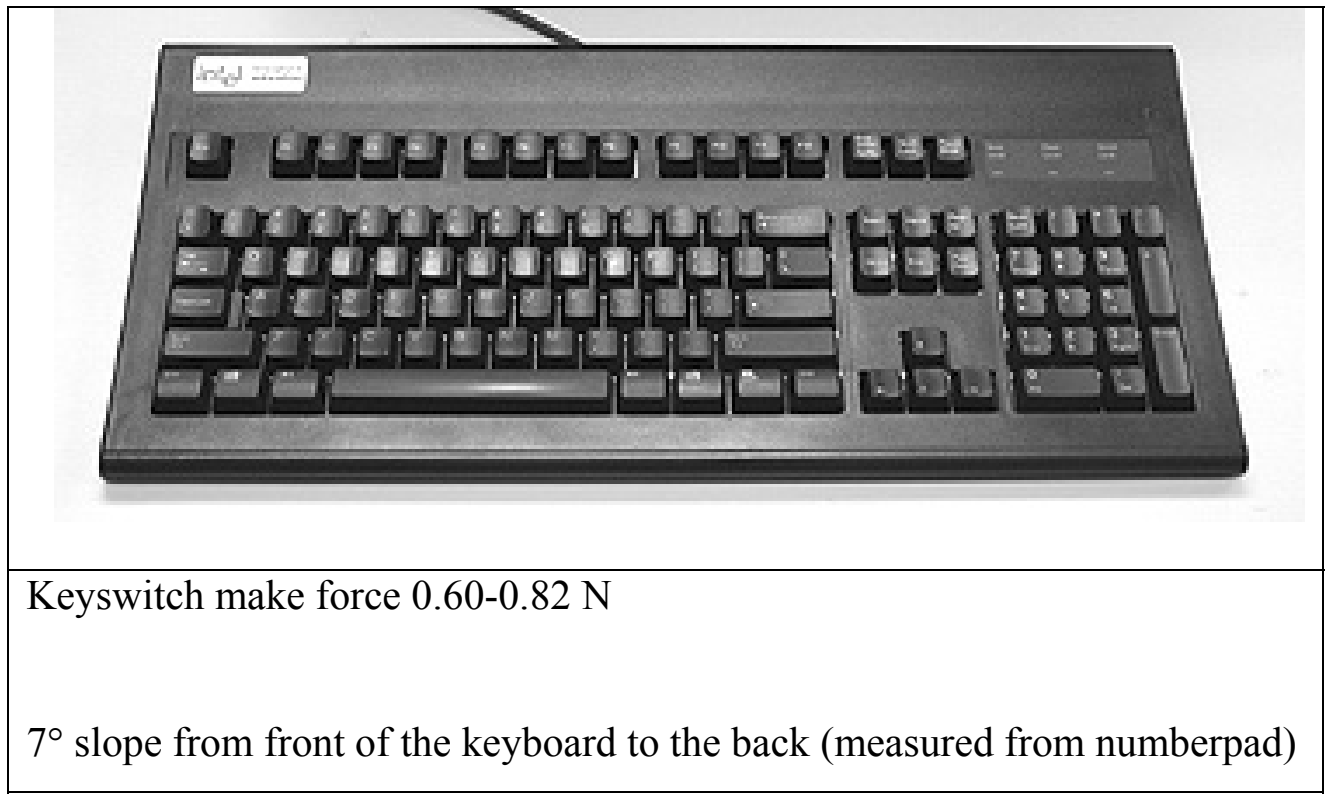

Table 3.3. MultiTouch Keyboard: Fingerworks Ultra

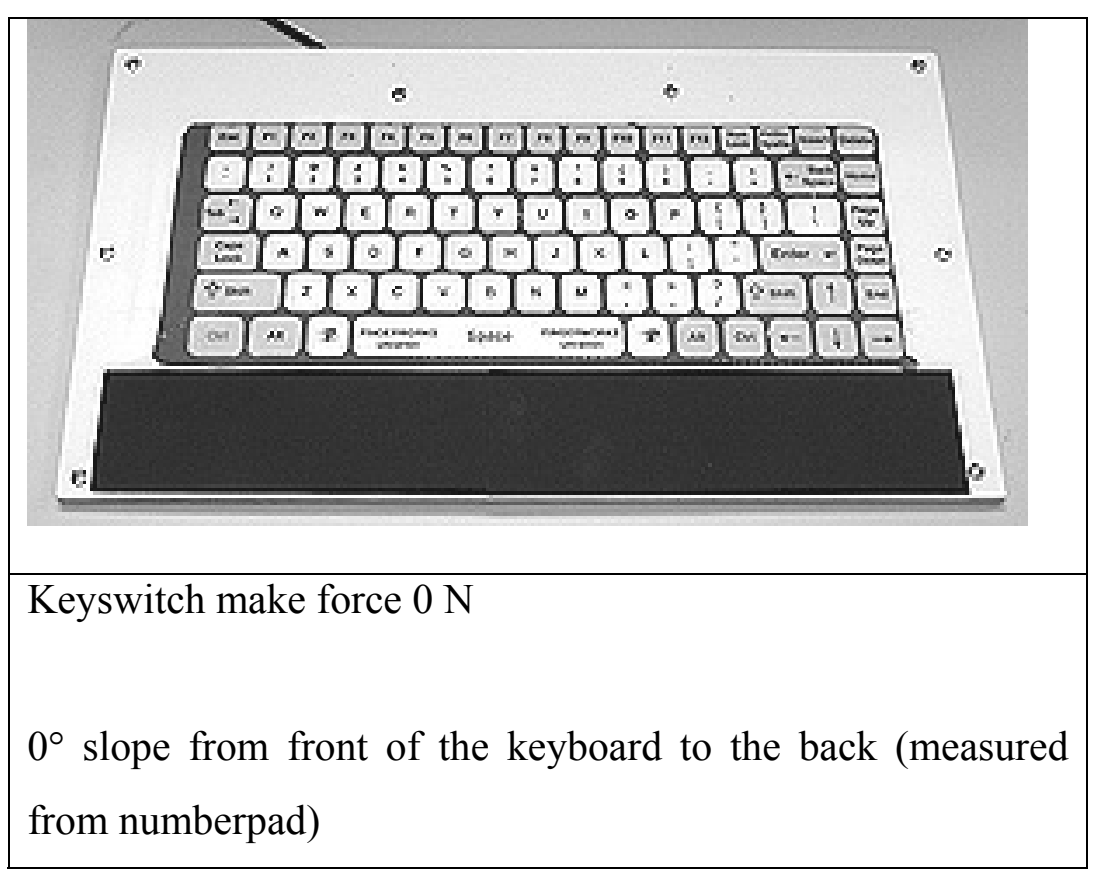




\subsection{Experimental Tasks}

\subsubsection{Typing}

On each visit, subjects performed eight 7.5-minute typing tasks consisting of 500-word passages selected from general interest magazine articles (Appendix C), selected for their similarity in length and Flesch-Kincaid Grade Level score of 12. The sixteen selected passages were used for both keyboard conditions and were administered in random order on both visits. These documents took longer than 7.5 minutes to type for a typing speed of 60 words per minute (i.e. they exceeded 450 words in length), and subjects typed for the 7.5-minute duration at which point the experimenter stopped the task.

Typing software (Typing Quick and Easy 13.0) was used to present the passages and record information about subjects' accuracy and speed. Subjects were encouraged to be as accurate as possible. Each typing task was timed by the experimenter using a stop-watch which was started as the first letter was typed and stopped after 7.5 minutes.

\subsection{Questionnaires}

Two different questionnaires were administered to subjects, one to measure fatigue (Appendix D) and a second questionnaire (Appendix E), which measured keyboard and circadian type, which was administered after the last typing task on the subjects' second day of the experiment.

On the fatigue questionnaire, subjects were asked to circle the appropriate choice on a 4-point Likert-type scale to indicate their present feeling of discomfort in the right hand, right wrist, right forearm, right upper arm, right shoulder, left hand, left wrist, left forearm, left upper arm, left shoulder, neck, upper back, and lower back. The fatigue questionnaire was given to subjects a total of 9 times during each visit, 
once before the first task to establish a baseline of fatigue, and then given again after each typing task was completed.

The post-trial preference questionnaire was administered after the $8^{\text {th }}$ task on the second day of testing and requested subjects to describe their enjoyment and comfort with each of the keyboards on a 10-point scale. Frequency of use of different computing devices, as well as split and conventional keyboards was collected on a 4point Likert-type scale on the post-trial questionnaire as well. In addition, a time-ofday questionnaire based on Horne and Ostberg's (1976) was also included on the posttrial questionnaire to assess subjects' circadian type.

\subsection{Procedure}

The study was conceived as a repeated measures design with each subject participating in two conditions containing the typing tasks using both a CK and the MTK. Both conditions took place in the same room on two separate days at approximately the same time of day to minimize any possible effects. Condition order and typing task order were counter-balanced and randomly-assigned to the subjects (Appendix F).

Upon entering the laboratory, each subject was asked to sit in an ergonomic chair and make him or herself comfortable by adjusting the chair height, which ranged from 18"-21". Table height was adjusted by subject according to preference on the first day, recorded by the experimenter, and then reset to the same height on the second day of typing tasks. Table heights ranged from $72 \mathrm{~cm}$ to $81 \mathrm{~cm}$ for both conditions. To minimize threats to external validity, each subject positioned the keyboard to his or her preference and could sit at the distance from the monitor and the keyboard that was most comfortable. 
The subject then filled out the consent form and assessed his or her level of fatigue by filling out the first comfort questionnaire. This survey was administered after each task to evaluate fatigue, as the conditions were tested. Next, the subject donned the wrist goniometer on his or her right arm, which served to measure wrist posture. The goniometer was then calibrated to obtain the most accurate readings possible.

The first 5 minutes was spent instructing each subject on the task, which was followed by a 5-minute practice typing task generated by the typing software so that subjects could become accustomed to the keyboard and the wrist goniometer. For the MTK condition, subjects were told that the MTK required no force but essentially functioned similarly to a $\mathrm{CK}$.

Each subject participated in eight 7.5-minute typing task trials using the CK and MTK on 2 separate days. Each trial passage was different and passage order was randomly assigned. The conditions and trials are as follows: 
Table 3.4. Experimental Design

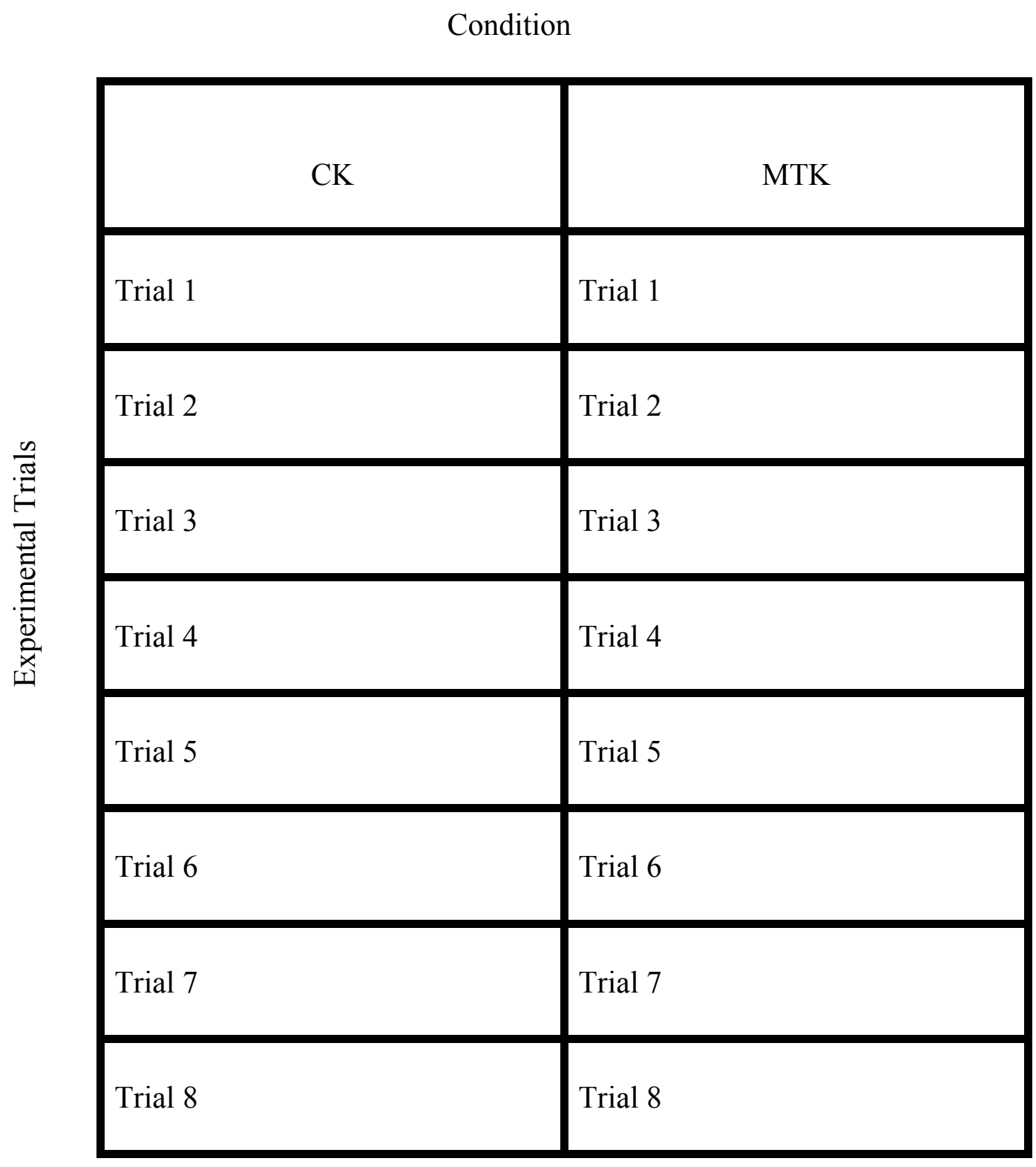




\subsection{Data Analysis}

Typing Quick and Easy was used to objectively measure the dependent variables of speed, by the words per minute per task, and accuracy (in percentage errors per document) in each typing task. The Typing Quick and Easy datasets from each test condition were compared with each other in order to examine trends in speed and accuracy to determine the existence of a learning effect.

To gather wrist posture data, a wrist goniometer (Greenleaf Medical) was used on the right hand and arm. The distribution of angular deviation of the right wrist (flexion and extension, and radial and ulnar deviation) was examined to determine to the proportion of times spent at various wrist angles and these data were compared between keyboards. Wrist posture, not EMG, was chosen as a measure to ascertain risk of injury as awkward postures have been linked to MSDs such as carpal tunnel syndrome. In addition, instrumentation to measure both EMG and wrist posture would require additional equipment on the upper extremities that would hinder subjects' typing performance.

The dependent variables of speed, accuracy, wrist posture, comfort and user preference were statistically analyzed using SPSS, Version 11 for Mac OS X. Repeated measures analysis of variance was used to determine within subjects differences between the two conditions. The Office of Statistical Consulting was contacted to verify the use of these tests and their outcomes. 


\section{Chapter IV. RESULTS}

The following results were gathered from statistical analysis of the measures of the dependent task and questionnaire variables.

\subsection{Typing}

\subsubsection{Speed and Accuracy}

There was no effect of order found on the average words per minute typed by the subjects. As a result, a 2 (keyboard) x 8 (trial) repeated measures GLM was conducted which uncovered an effect of keyboard on the average words per minute typed during the tasks $\left(\mathrm{F}_{1,11}=41.86, \mathrm{p}=0.000\right)$. Subjects had typed 39.14 percent faster on an average words per minute basis on the CK $(p=0.000)$ than the MTK (Figure 4.1). Gender differences and time of day preference were not found to have a significant effect on average words per minute typed.

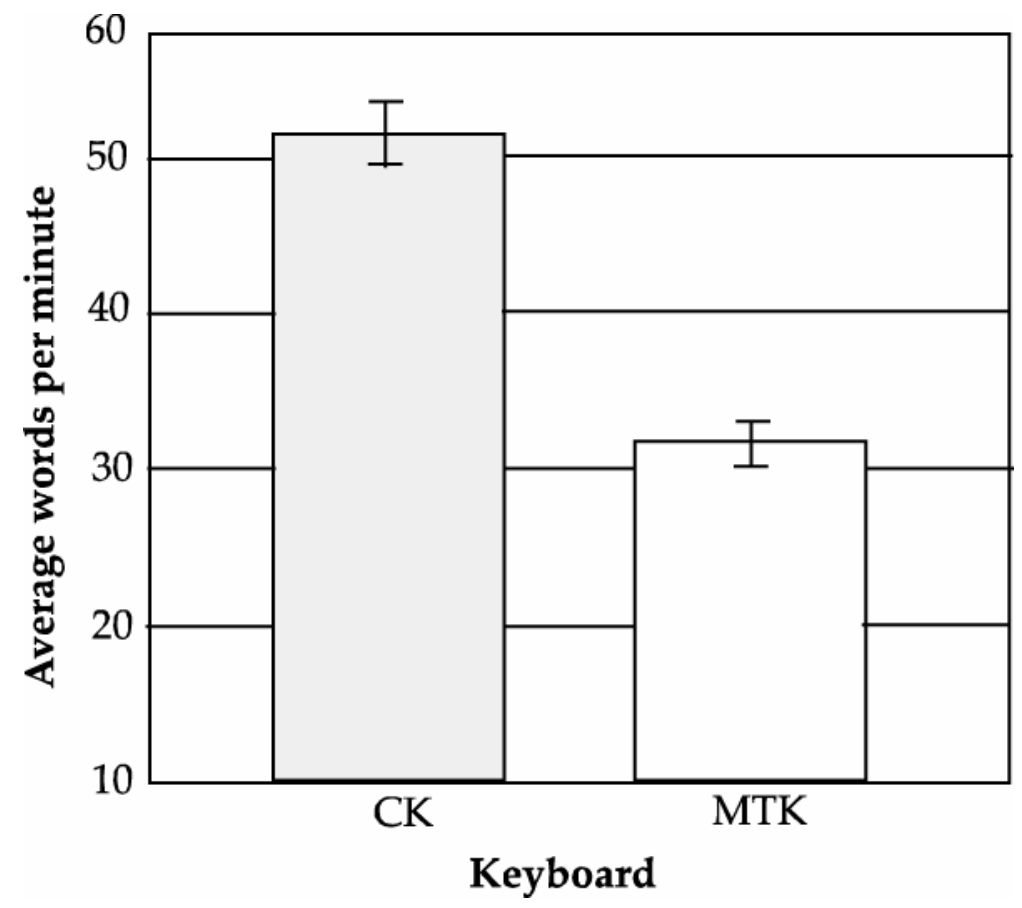

Figure 4.1. Typing speed in average words per minute (Mean \pm Standard Error) 
Again, order effects were tested, with no significant effect found on subjects' accuracy. However, the keyboard type had an effect on subjects' accuracy during the typing tasks $\left(\mathrm{F}_{1,11}=23.55, \mathrm{p}=0.001\right)$, which was also calculated using a $2 \times 8$ repeated measures GLM. Subjects were 16 percent more accurate when using the conventional keyboard to type (Figure 4.2). There was a marginally significant interaction between gender and keyboard type $\left(\mathrm{F}_{1,10}=4.80, \mathrm{p}=0.053\right)$, which indicated that females tended to score higher accuracy levels than males on the MTK. Again, time of day preference was tested and not found to have an effect on accuracy.

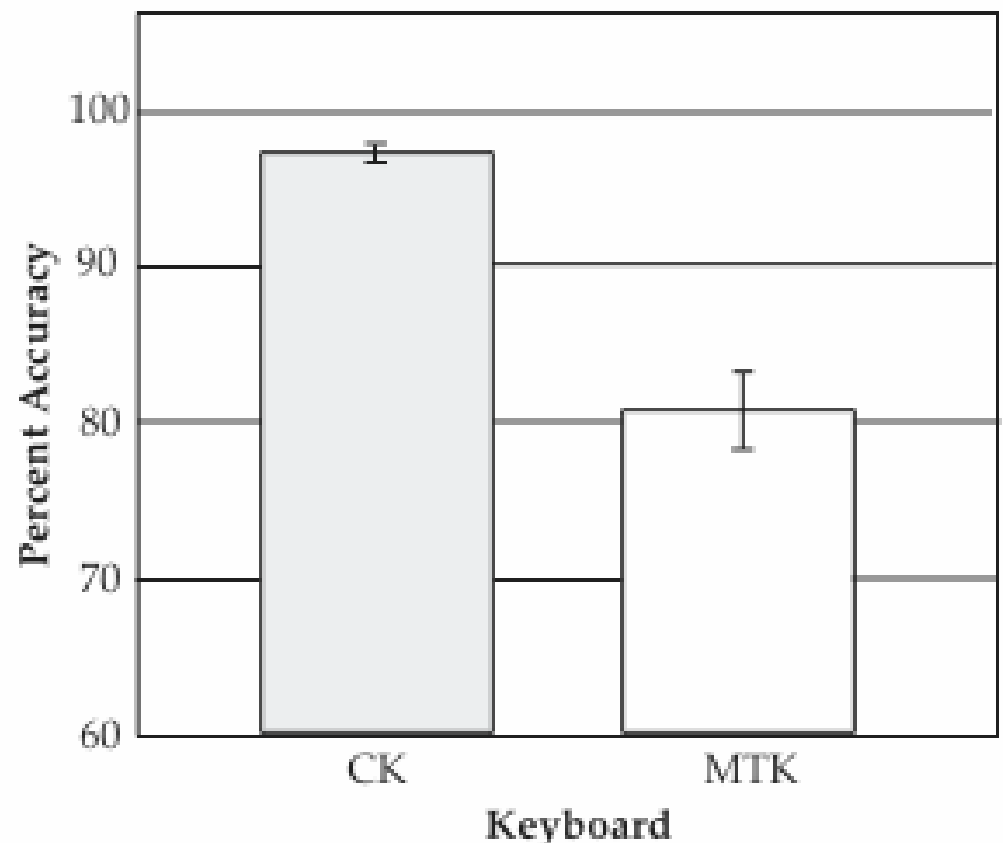

Figure 4.2. Percent Accuracy of Typing Tasks (Mean \pm Standard Error) 


\subsubsection{Learning Effects}

Tests of within-subject contrasts of the subjects' average words per minute typed showed a significant linear pattern with the interaction between keyboard and trial $\left(\mathrm{F}_{1,11}=9.308, \mathrm{p}=0.011\right)$. While the subjects' average words per minute typed on the conventional keyboard remained at the same level, the speed scores on the MTK were indicative of an upward trend, which suggested that subjects were improving with each trial (Figure 4.3).

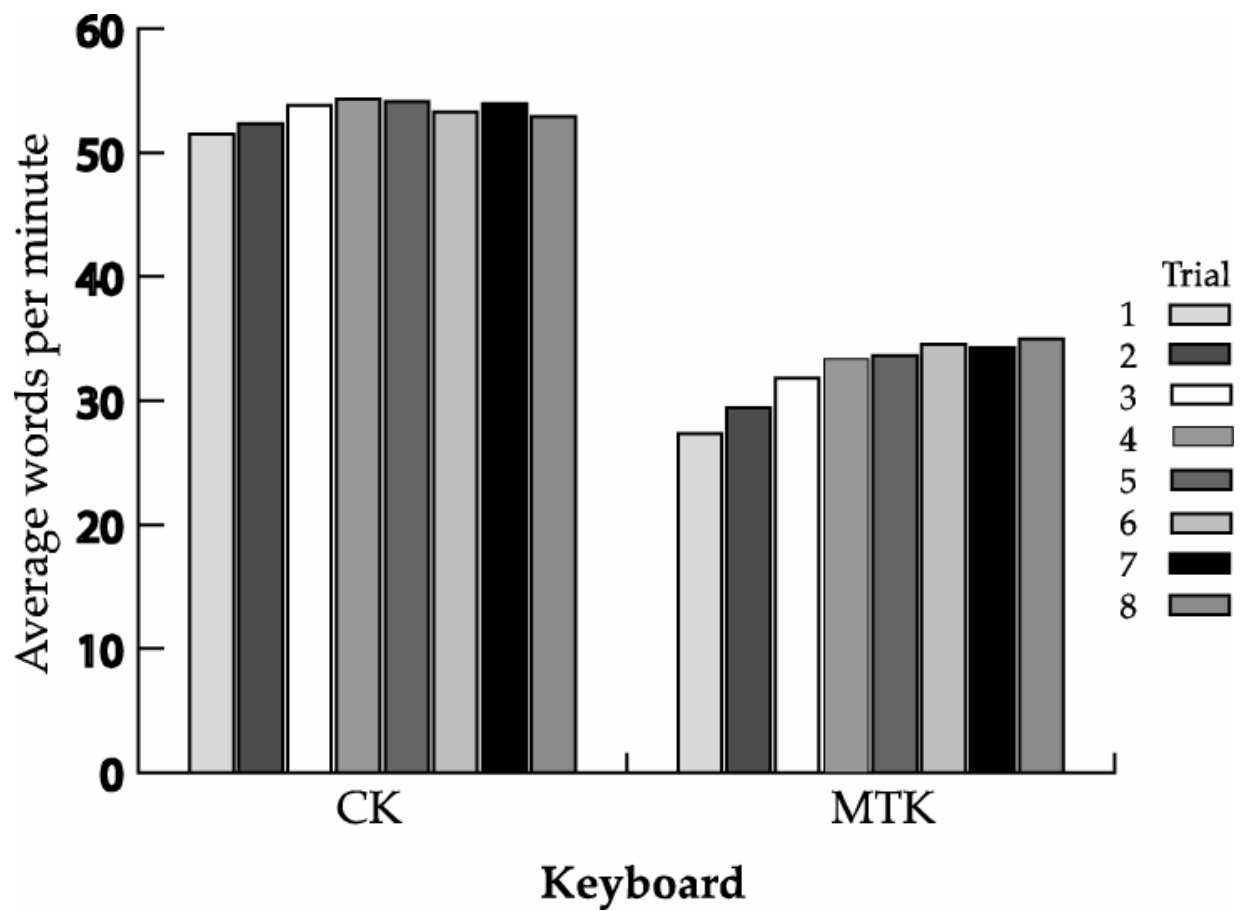

Figure 4.3. Typing speed across typing tasks

Subjects' accuracy scores, when analyzed by tests of within-subject contrasts, revealed a significant linear pattern in the interaction between keyboard and trial $\left(\mathrm{F}_{1,11}=11.903, \mathrm{p}=0.005\right)$. Again, the accuracy scores on the conventional keyboard 
remained constant while subjects' accuracy on the MTK improved through the progression of the typing tasks (Figure 4.4).

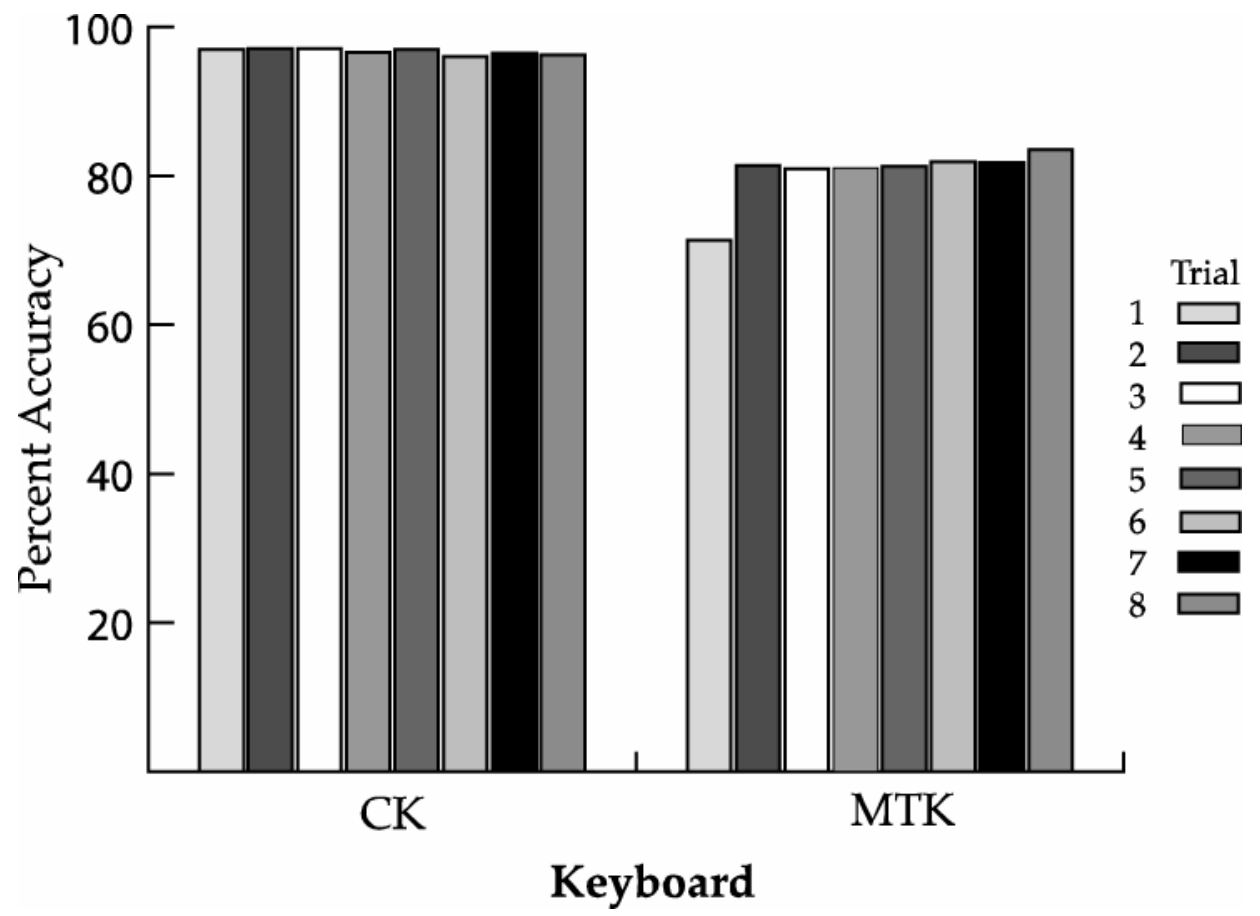

Figure 4.4. Percent accuracy across typing tasks

In order to further investigate the learning curve for both typing speed and accuracy, regression equations using each performance measure as a dependent variable and trial as an independent variable were calculated (Figure 4.5 and Figure 4.6). 


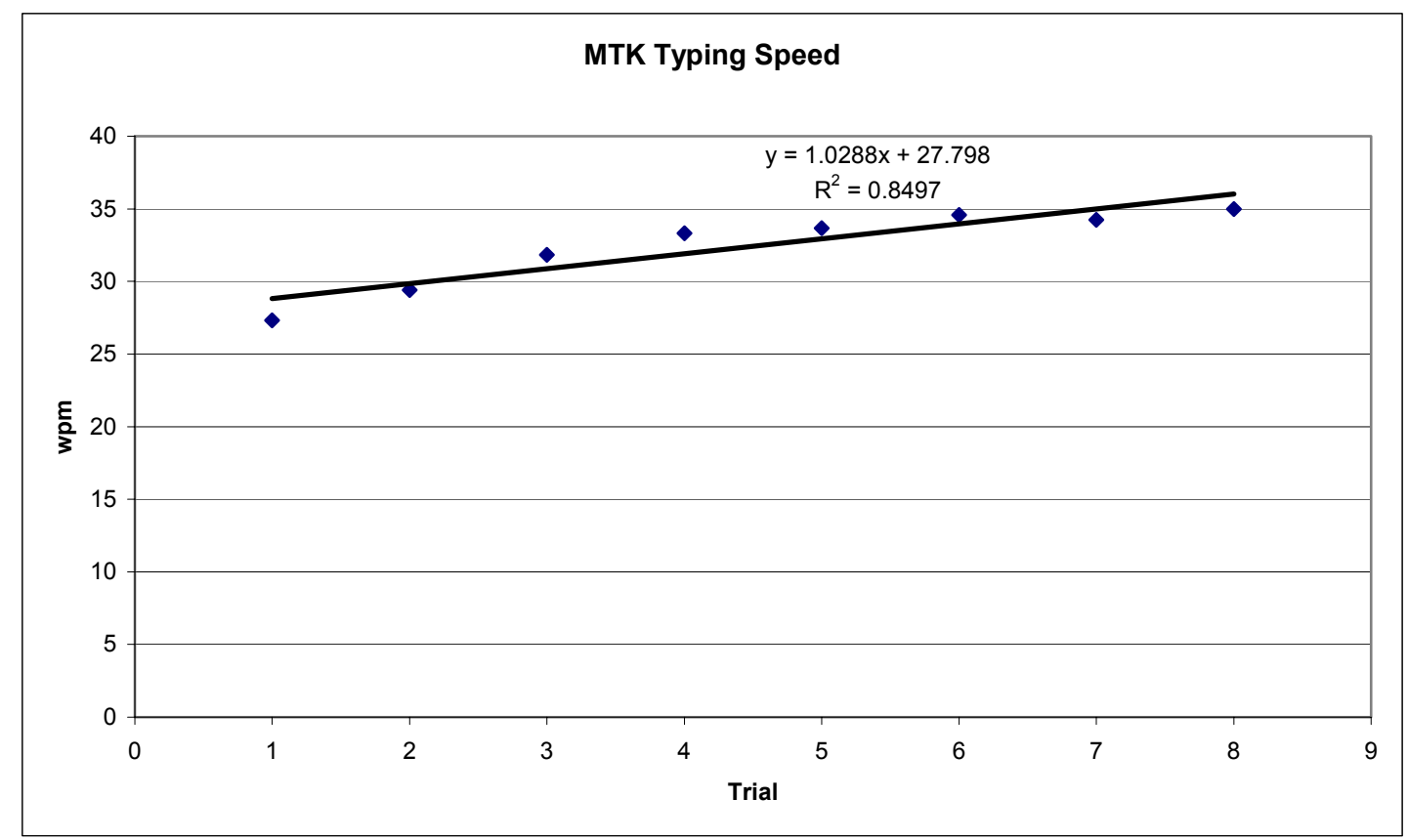

Figure 4.5. Linear regression of average wpm and typing trial

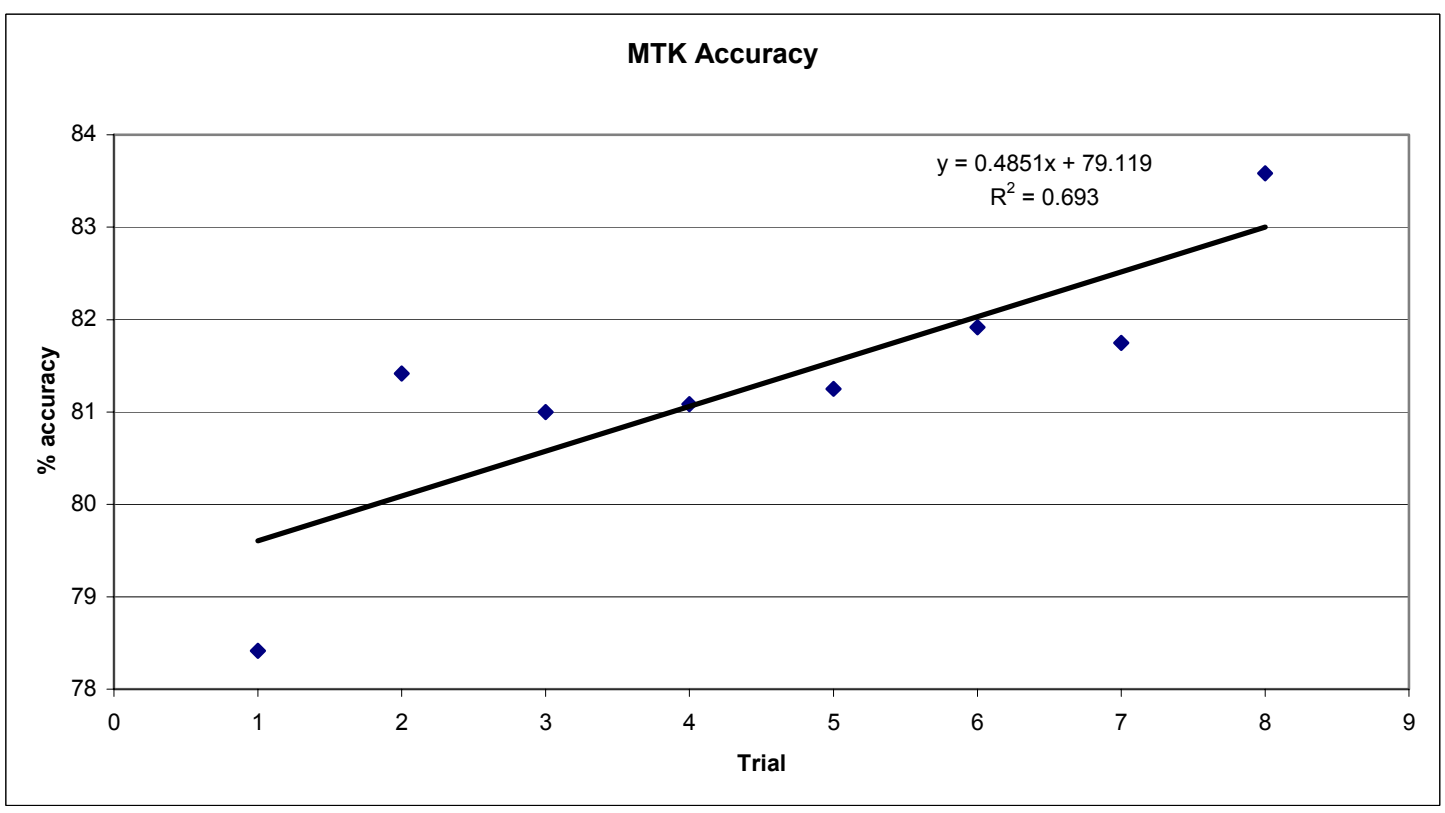

Figure 4.6. Linear regression of percent accuracy and typing trial 


\subsubsection{Wrist Posture}

Mean flexion and extension wrist deviation in the conventional keyboard condition (Figure 4.7) was significantly higher than those in the MTK condition $\left(\mathrm{F}_{1,11}=10.205, \mathrm{p}=0.000\right)$. There was no significant difference in mean radial and ulnar deviation between the CK and the MTK (Figure 4.7). The wrist goniometer recorded flexion and ulnar deviation as negative numbers and extension and radial deviation as positive numbers. In order to avoid means of 0 degrees, the absolute values of each wrist position were used for each of the calculations in this section.

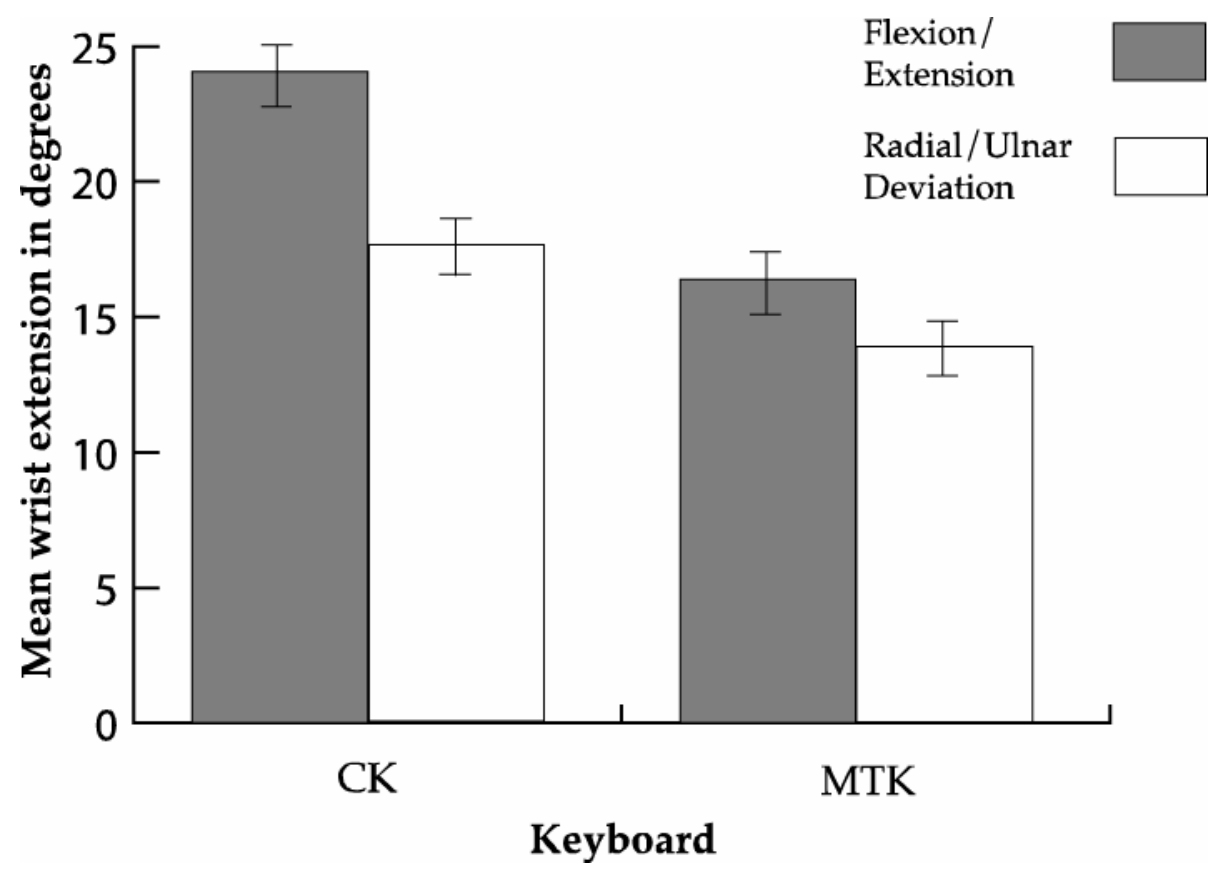

Figure 4.7. Mean wrist extension (Mean \pm Standard Error)

The percentage of flexion and extension that fell in the safe range of 0 to 10 degrees (Figure 4.8) was significantly higher in the MTK condition $\left(F_{1,11}=12.947\right.$, $\mathrm{p}=0.004$ ), indicating that subjects spent more time in a neutral wrist position while using the MTK. Subjects also spent more time in the range of flexion and extension 
above 10 degrees to 15 degrees while using the MTK, and this difference was found to be almost significant $\left(\mathrm{F}_{1,11}=3.933, \mathrm{p}=0.073\right)$. Conversely, the greatest percentage of the highest-risk flexion and extension above 20 degrees was found in the conventional keyboard condition $\left(\mathrm{F}_{1,11}=6.437, \mathrm{p}=0.028\right)$, indicating that subjects were more likely to be in an unsafe wrist position while using the conventional keyboard. No significant difference between the keyboards was found for the third zone of flexion and extension wrist postures above 15 degrees to 20 degrees.

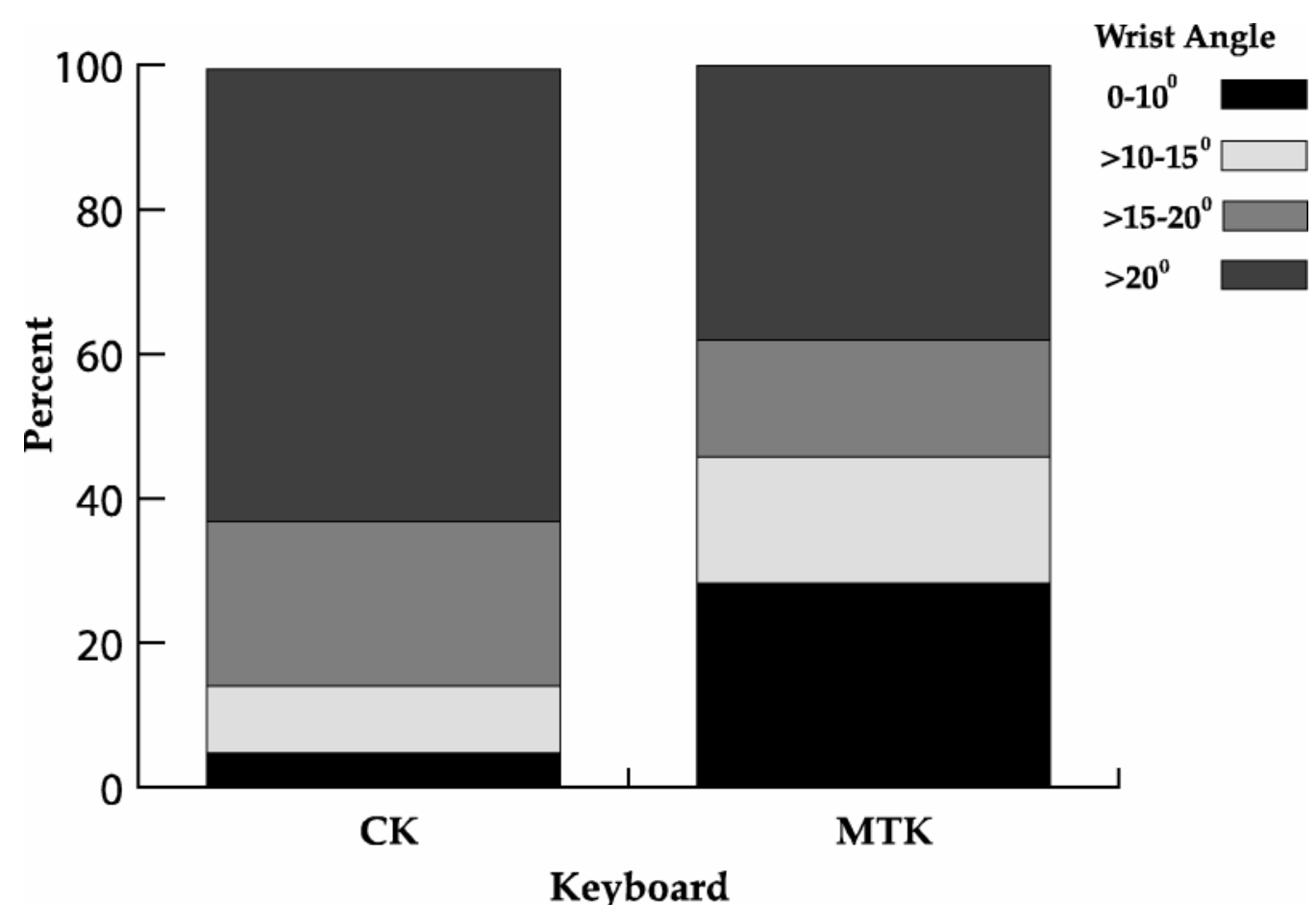

Figure 4.8. Percentage of flexion/extension wrist postures in risk zones

The percentage of radial and ulnar wrist deviation in the zone of 0 to 10 degrees did not differ significantly between the conventional keyboard and the MTK (Figure 4.9). Keyboard type did not affect the percentage of radial and ulnar devation 
for the other three zones of radial and ulnar deviation (above 10 to 15 degrees, above 15 to 20 degrees, and above 20 degrees).

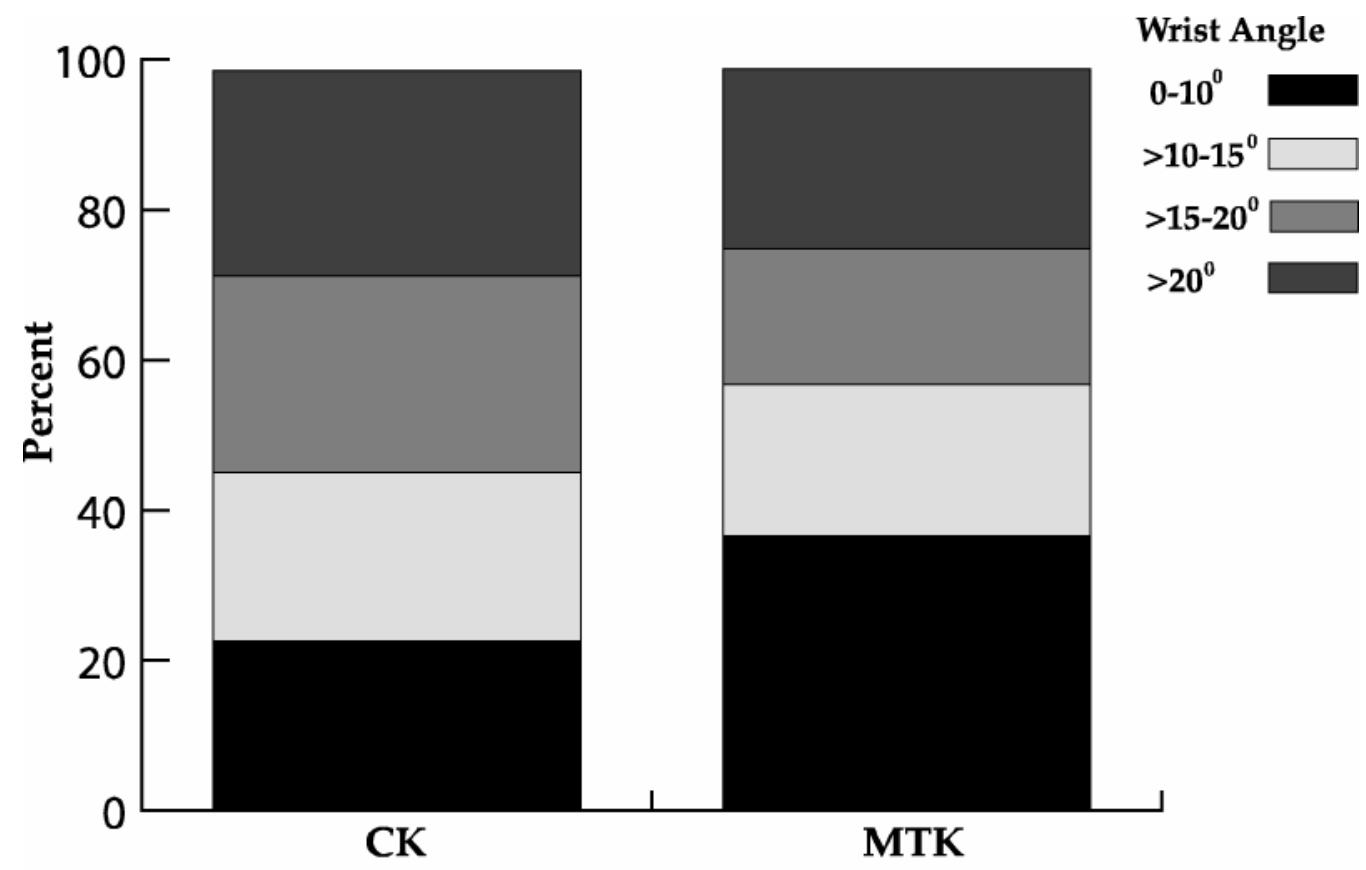

Keyboard

Figure 4.9. Percentage of radial/ulnar deviation wrist postures in risk zones

\subsection{Subjective Measures}

The following subjective measures were gathered from the self-report questionnaires administered during the experimental tasks.

\subsubsection{Enjoyment}

Subjects expressed more enjoyment using the conventional keyboard rather than the MTK for the typing tasks $\left(\mathrm{F}_{1,11}=51.120, \mathrm{p}=0.000\right.$ : Figure 4.10$)$. 


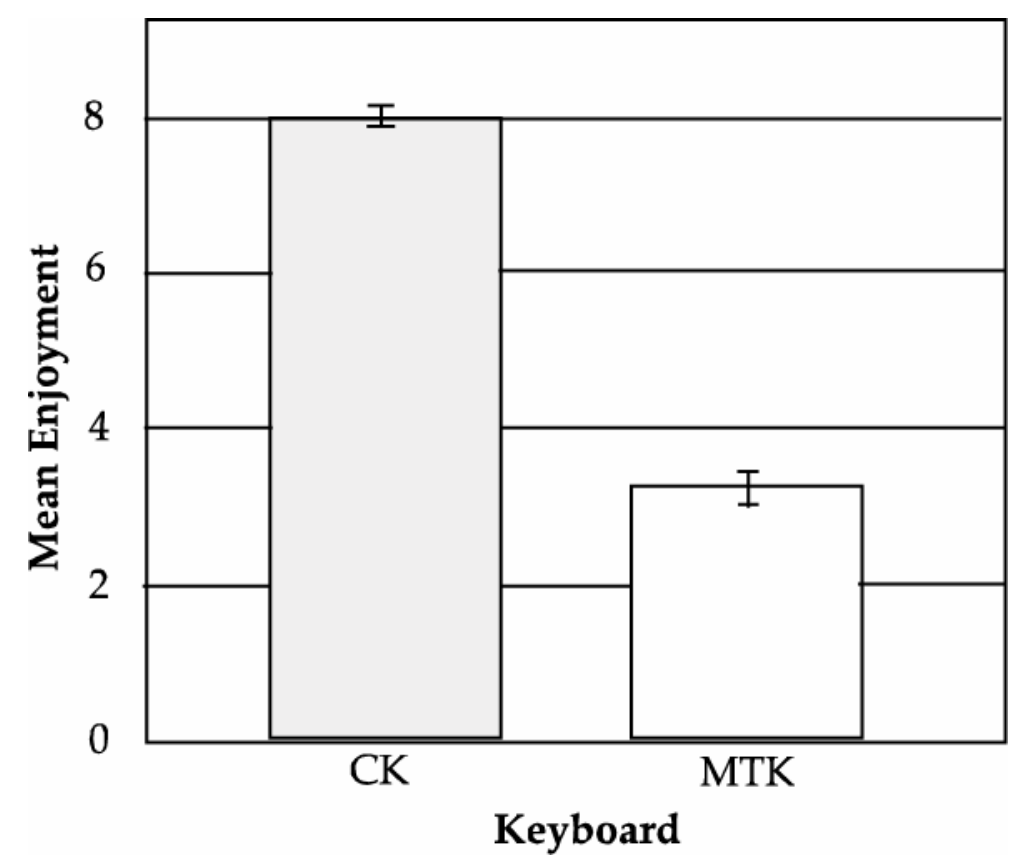

Figure 4.10. Keyboard Use Enjoyment (Mean \pm Standard Error)

\subsubsection{Ease}

Subjects reported that it was easier to use the conventional keyboard than the MTK to complete the typing tasks $\left(\mathrm{F}_{1,11}=49.732, \mathrm{p}=0.000\right.$ : Figure 4.11). 


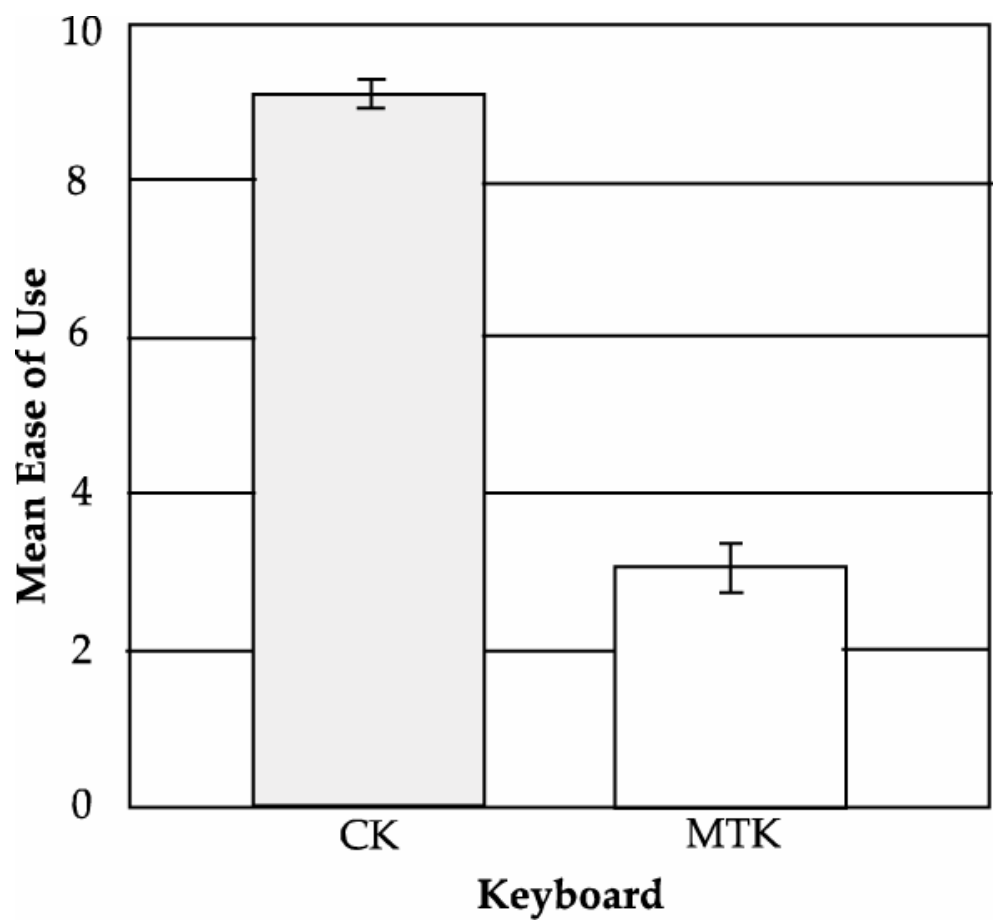

Figure 4.11. Keyboard Ease of Use (Mean \pm Standard Error)

\subsubsection{Comfort}

Subjects felt more comfortable using the conventional keyboard than the MTK for the typing tasks $\left(\mathrm{F}_{1,11}=14.113, \mathrm{p}=0.003\right.$ : Figure 4.12$)$. 


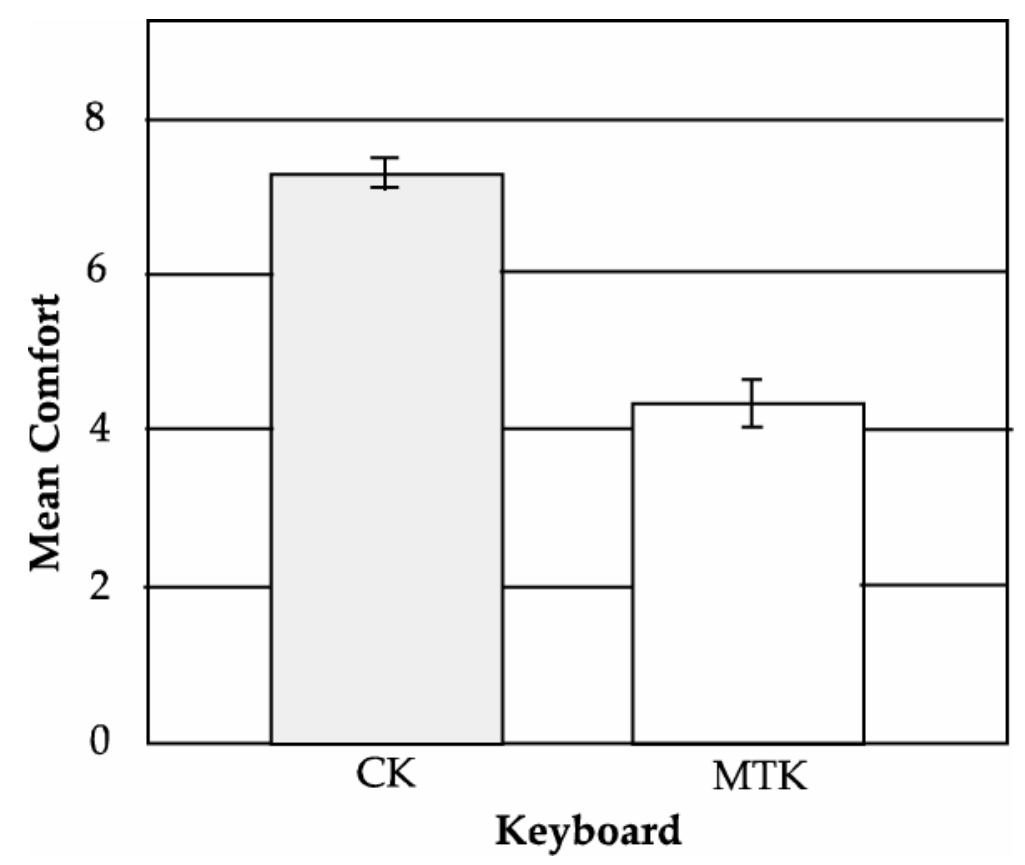

Figure 4.12. Self-report keyboard comfort (Mean \pm Standard Error)

\subsubsection{Fatigue}

There was no significant effect of keyboard on physical fatigue. However, when within-subjects effects were examined, the data revealed a significant effect of trial in fatigue levels for the body parts listed in Table 4.1. The upward trends suggested a fatigue effect as subjects progressed through the typing tasks for each condition. 
Table 4.1. Mean fatigue scores for CK

\begin{tabular}{|l|l|l|l|l|l|l|l|l|l|}
\hline & & Trial & & & & & & & \\
\hline $\begin{array}{l}\text { Body } \\
\text { part }\end{array}$ & $\begin{array}{l}\text { Pre- } \\
\text { task }\end{array}$ & 1 & 2 & 3 & 4 & 5 & 6 & 7 & 8 \\
\hline $\begin{array}{l}\text { Right } \\
\text { hand }\end{array}$ & 1.08 & 1.33 & 1.50 & 1.67 & 1.67 & 1.67 & 1.83 & 1.83 & 1.83 \\
\hline $\begin{array}{l}\text { Right } \\
\text { wrist }\end{array}$ & 1.17 & 1.58 & 1.67 & 1.92 & 1.83 & 1.75 & 1.92 & 2.00 & 2.17 \\
\hline $\begin{array}{l}\text { Right } \\
\text { forearm }\end{array}$ & 1.25 & 1.33 & 1.58 & 1.75 & 1.83 & 1.72 & 1.83 & 2.00 & 1.83 \\
\hline $\begin{array}{l}\text { Right } \\
\text { shoulder }\end{array}$ & 1.00 & 1.08 & 1.08 & 1.08 & 1.17 & 1.25 & 1.08 & 1.33 & 1.42 \\
\hline $\begin{array}{l}\text { Left } \\
\text { hand }\end{array}$ & 1.00 & 1.17 & 1.25 & 1.50 & 1.67 & 1.67 & 1.67 & 1.67 & 1.67 \\
\hline $\begin{array}{l}\text { Left } \\
\text { wrist }\end{array}$ & 1.00 & 1.33 & 1.50 & 1.42 & 1.58 & 1.67 & 1.75 & 1.83 & 1.75 \\
\hline $\begin{array}{l}\text { Left } \\
\text { forearm }\end{array}$ & 1.00 & 1.08 & 1.25 & 1.50 & 1.42 & 1.42 & 1.58 & 1.75 & 1.75 \\
\hline Neck & 1.00 & 1.00 & 1.08 & 1.08 & 1.17 & 1.33 & 1.33 & 1.58 & 1.58 \\
\hline $\begin{array}{l}\text { Upper } \\
\text { back }\end{array}$ & 1.00 & 1.00 & 1.17 & 1.17 & 1.25 & 1.17 & 1.25 & 1.33 & 1.50 \\
\hline $\begin{array}{l}\text { Lower } \\
\text { back }\end{array}$ & 1.08 & 1.17 & 1.33 & 1.42 & 1.50 & 1.67 & 1.58 & 1.75 & 1.75 \\
\hline
\end{tabular}


Table 4.2. Mean fatigue scores for MTK

\begin{tabular}{|l|l|l|l|l|l|l|l|l|l|}
\hline & & Trial & & & & & & & \\
\hline $\begin{array}{l}\text { Body } \\
\text { segment }\end{array}$ & Base & 1 & 2 & 3 & 4 & 5 & 6 & 7 & 8 \\
\hline $\begin{array}{l}\text { Right } \\
\text { hand }\end{array}$ & 1.08 & 1.25 & 1.29 & 1.42 & 1.42 & 1.54 & 1.83 & 1.75 & 1.83 \\
\hline $\begin{array}{l}\text { Right } \\
\text { wrist }\end{array}$ & 1.17 & 1.33 & 1.54 & 1.62 & 1.63 & 1.71 & 1.92 & 2.00 & 2.00 \\
\hline $\begin{array}{l}\text { Right } \\
\text { forearm }\end{array}$ & 1.00 & 1.25 & 1.37 & 1.54 & 1.54 & 1.45 & 1.50 & 1.83 & 1.96 \\
\hline $\begin{array}{l}\text { Right } \\
\text { shoulder }\end{array}$ & 1.00 & 1.17 & 1.25 & 1.25 & 1.33 & 1.33 & 1.33 & 1.33 & 1.33 \\
\hline $\begin{array}{l}\text { Left } \\
\text { hand }\end{array}$ & 1.00 & 1.08 & 1.33 & 1.33 & 1.42 & 1.50 & 1.75 & 1.75 & 1.83 \\
\hline $\begin{array}{l}\text { Left } \\
\text { wrist }\end{array}$ & 1.00 & 1.25 & 1.33 & 1.42 & 1.67 & 1.58 & 1.75 & 1.92 & 1.92 \\
\hline $\begin{array}{l}\text { Left } \\
\text { forearm }\end{array}$ & 1.00 & 1.00 & 1.00 & 1.17 & 1.17 & 1.37 & 1.33 & 1.50 & 1.58 \\
\hline Neck & 1.00 & 1.33 & 1.33 & 1.33 & 1.50 & 1.50 & 1.33 & 1.33 & 1.50 \\
\hline $\begin{array}{l}\text { Upper } \\
\text { back }\end{array}$ & 1.00 & 1.33 & 1.17 & 1.25 & 1.42 & 1.17 & 1.42 & 1.58 & 1.58 \\
\hline $\begin{array}{l}\text { Lower } \\
\text { back }\end{array}$ & 1.08 & 1.17 & 1.33 & 1.38 & 1.38 & 1.54 & 1.67 & 1.67 & 1.75 \\
\hline
\end{tabular}


Table 4.3. Effect of trial on fatigue levels.

\begin{tabular}{|l|l|l|l|}
\hline $\begin{array}{l}\text { Body } \\
\text { part }\end{array}$ & $\mathrm{F}$ & $\mathrm{df}$ & $\mathrm{p}$ \\
\hline $\begin{array}{l}\text { Right } \\
\text { hand }\end{array}$ & 8.29 & 88 & 0.00 \\
\hline $\begin{array}{l}\text { Right } \\
\text { wrist }\end{array}$ & 9.92 & 88 & 0.00 \\
\hline $\begin{array}{l}\text { Right } \\
\text { forearm }\end{array}$ & 12.54 & 88 & 0.01 \\
\hline $\begin{array}{l}\text { Right } \\
\text { shoulder }\end{array}$ & 2.61 & 88 & 0.00 \\
\hline $\begin{array}{l}\text { Left } \\
\text { hand }\end{array}$ & 7.85 & 88 & 0.00 \\
\hline $\begin{array}{l}\text { Left } \\
\text { wrist }\end{array}$ & 6.27 & 88 & 0.00 \\
\hline $\begin{array}{l}\text { Left } \\
\text { forearm }\end{array}$ & 7.12 & 88 & 0.00 \\
\hline Neck & 3.89 & 88 & 0.001 \\
\hline $\begin{array}{l}\text { Upper } \\
\text { back }\end{array}$ & 3.60 & 88 & 0.001 \\
\hline $\begin{array}{l}\text { Lower } \\
\text { back }\end{array}$ & 6.25 & 88 & 0.00 \\
\hline
\end{tabular}

\subsubsection{Subject Comments}

Subjects were asked to "provide additional comments" regarding the MTK

(Table 4.4). Many of the comments alluded to the unfamiliarity of the keyboard while a few subjects expressed frustration with using the MTK for typing tasks. 
Table 4.4. Subjects' comments regarding the MTK

\begin{tabular}{|c|c|}
\hline Positive & Negative \\
\hline $\begin{array}{l}\text { It was fun to use a new technology. } \\
\text { With practice, I could see my speed and } \\
\text { accuracy improving. }\end{array}$ & $\begin{array}{l}\text { MTK was cumbersome and } \\
\text { uncomfortable to hold fingers in the air. } \\
\text { I encountered difficulty in becoming } \\
\text { familiar with the MTK. } \\
\text { The lack of tactile clues and ultra- } \\
\text { sensitivity made it frustrating. } \\
\text { It would have helped to have more } \\
\text { resistance and feedback while typing. } \\
\text { MTK was hard to get used to - too } \\
\text { sensitive and responded to unintended } \\
\text { pressure. }\end{array}$ \\
\hline
\end{tabular}




\section{Chapter V. DISCUSSION}

\subsection{Key Travel and Key Force}

Contrary to the original hypothesis, text-entry using the MTK did not prove to be faster than text entry using the conventional keyboard. Despite the lack of key travel inherent with the MTK, the average words per minute typed during the tasks were significantly lower in the keyless keyboard condition. This may contradict the belief that key force and displacement may not have an effect on the throughput of experienced touch typists (Alden et al., 1972), such as the present subjects, but the difference in typing speeds may stem from other factors, such as learning, practice and feedback. In addition, it may also be possible that key travel could be reduced by using a different kind of typing motion such as simply touching the keys on the MTK instead of using a ballistic finger movement.

Again, the present findings on typing accuracy diverge from the research hypothesis. Subjects were significantly more accurate on the typing tasks during the conventional keyboard condition, despite the presence of key travel. This finding is consistent with past research suggesting that light resistance, low-hysteresis linearspring keyboards with less key travel are prone to inadvertent errors by typists (Brunner \& Richardson, 1984).

Although not directly measured in the present study, key force and its relationship to fingertip exertion may be important for comfort rather than speed and accuracy. The Dell AT101W requires 0.60-0.82 N make force to activate key depression while the MTK requires $0 \mathrm{~N}$, due to the sensor arrays used to detect electrical fields rather than force to depress keys (Fingerworks, 2004). By decreasing key make force from $0.71 \mathrm{~N}$ to $0.31 \mathrm{~N}$, Radwin and Ruffalo (1999) demonstrated a corresponding decrease of $0.35 \mathrm{~N}$ in peak force used to depress keys. 
However, with no objective measure of subjects' key strike force, it is difficult to determine whether or not a decreased key make force will cause users to decrease their strike force when using the MTK. Past research has shown that there was no significant difference in finger force or EMG activity when typists used a keyboard with a make force of $0.43 \mathrm{~N}$ and a keyboard with a make force of $0.47 \mathrm{~N}$ (Rempel et al., 1997). When a keyboard of $1.02 \mathrm{~N}$ make force was introduced, fingertip force and EMG activity increased significantly $(\mathrm{p}<0.05)$ by $40 \%$ and $20 \%$ respectively. Comments observed by the experimenter seem to indicate that some subjects were using a lighter touch for better typing performance due to the keyboard's sensitivity (Table 4.4) but without objective measures of applied finger force readings, it is impossible to verify the relationship between the lack of force required to operate the MultiTouch and the applied force used by subjects in the keyless keyboard condition. As mentioned previously, performance differences may be a function of learning a new typing technique for the MTK, where the keys are simply touched instead of conventionally typed.

\subsection{Fatigue}

While there was no effect of keyboard on fatigue, there was a within-subjects effect of trial $(p<0.001)$, suggesting that there was a fatigue effect occurring in the course of the experiment. This is consistent with the assertion that the musculature of the hand limits the ability of the fingers to perform typing tasks over a period of time (Alden et al., 1972).

There was no effect of right-hand side or left-hand side on fatigue as well, as both sides became progressively more fatigued during the typing tasks. This differs from previous research that suggest that the QWERTY layout overloads the left hand, 
which is the non-preferred hand for the majority of the user population (Greenstein \& Arnaut, 1987). All subjects in the present study were right-handed.

However, only subjective self-report were used to measure fatigue in this research and another objective measure of fatigue may have provided a clearer picture of fatigue effects. Recent research conducted by Balogh et al. (2004) compared the use of self-report activity diaries in office workers and cleaners with technical measures of activity, such as heart rate and steps taken during the course of the day, showed that subjects with posture complaints were more likely to over-report their activity levels in the self-report diaries $(\mathrm{p}<0.05)$.

\subsection{Feedback}

The visual, auditory and kinesthetic feedback afforded by each keyboard may have played a role in the performance differences between the CK and the MTK. The following sections discuss each type of feedback as it relates to the current study as well as past research.

\subsubsection{Visual Feedback}

Visual feedback is thought to assist in the self-detection of errors (Klemmer, 1971) and the software display that presented the typing task did offer visual cues of screen font color when a user mistake was made. Subjects were told, however, that they should try not to correct their errors, which makes the relationship between visual feedback and error self-detection difficult to ascertain in this study. Additionally, all subjects were pre-screened touch typists who normally do not need to look at the keyboard while typing but it is possible the cognitive load of using a new device may have caused subjects to look down at the MTK during the keyless keyboard conditions. 
Since the MTK is a relatively new technology and the model tested was a prototype, the possibility of a longer lag between the keyless keyboard and typed task appearing on the monitor did exist. Both the subjects and the experimenter did not notice a difference between lag times with the MTK and the conventional keyboard.

\subsubsection{Auditory Feedback}

The conventional keyboard provided auditory feedback as the keys were depressed while the MTK did not. The Dell AT101W is described by keyboard vendors as a "clicky" keyboard, meaning the auditory feedback is similar to the staccato sounds of a typewriter. The MultiTouch surface does provide an auditory feedback feature; however, it was not used during the present study. It is not clear that additional electronically generated feedback would produce as much of a performance benefit as the naturally occurring sounds of conventional keys being pressed (Pollard

\& Cooper, 1979). Subject comments indicate that auditory feedback would have been preferable during the keyless keyboard condition.

\subsubsection{Kinesthetic Feedback}

As a keyless keyboard, the MTK did not offer kinesthetic feedback, in terms of feeling a key depress and rebound beyond its make point. This lack of feedback may have contributed to the lower speed and accuracy scores, a finding that would be consistent with Roe et al.'s (1984) research stating the performance benefits of pairing auditory and kinesthetic feedback.

Almost all of the subjects in the present study did not prefer the lack of kinesthetic feedback offered by the MTK. In fact, a few felt the MTK was too sensitive and this lack of feedback caused them to make unintended errors while resting their fingers on the home row. Additionally, as touch typists, subjects missed 
having the raised bars on the $\mathrm{F}$ and $\mathrm{J}$ keys, so that they could find the home row quickly without looking down at the keyboard, a design feature recommended by the BSR/HFES 100 guidelines (2002).

\subsection{Wrist Posture}

The findings in the present study indicate that mean wrist extension was significantly lower for the MTK, which suggests that the ultra low-profile design of the keyless keyboard may reduce wrist extension. Extension decreases in an almost linear pattern as keyboard slope decreases (Woldstad \& Jedriewski, 1993) and the $0^{\circ}$ degree slope of the MTK may have contributed to the difference in extension between the keyboard conditions. Both the MTK and the conventional keyboard possessed a QWERTY layout and an effect of keyboard on mean radial/ulnar deviation was not expected, nor was it observed in the present research.

Subjects during the MTK condition spent significantly less time in risky $\left(15^{\circ}\right.$ and above) flexion and extension wrist postures, and conversely were more likely to have flexion and extension wrist postures in the safer zone of $0^{\circ}$ to $15^{\circ}$. The MTK may help to decrease the likelihood of MSDs by reducing the amount of time spent in awkward wrist postures while engaged in repetitive work, a guideline endorsed in previous research (NIOSH, 1997).

The mean wrist flexion/extension angle for the MTK was $17.56^{\circ}$, which is comparable to the $17^{\circ} \pm 5$ mean wrist extension for a split keyboard (Tittiranonda et al., 1999). As expected, the mean radial/ulnar deviation of $13.87^{\circ}$ for the Fingerworks Ultra was similar to past investigation of a conventional QWERTY keyboard with mean right wrist radial/ulnar deviation of $16.8^{\circ}$ (Marklin et al., 1999). To decrease wrist extension, workstation design may be altered by using a negatively sloped keyboard tray (Hedge \& Powers, 1995), instead of the flat adjustable table used in the 
present study. A reduction in radial/ulnar deviation may be accomplished if the key design of the MTK would be shifted into a split configuration (Marklin et al., 1999), which is an existing product that is currently offered to consumers.

\subsection{Learning Curve}

All subjects in the present study were naïve to the MultiTouch surface and the MTK keyboard. To familiarize users with the MultiTouch surface and lessen the learning effect, subjects were able to practice on the new technology for 5 minutes before starting the experimental typing tasks. Chen et al. (1994) used a similar practice period of 3 minutes before introducing a new keyboard to subjects, which resulted in an increase of $16.75 \%$ in mean typing speed over 4 typing sessions.

Subjects' unfamiliarity with the MultiTouch surface of the MTK remains one of the most important factors in the interpretation of the results (Detwiler et al., 2000). The significant upward linear trend found in the average words per minute $(p=0.011)$ and percent accuracy $(\mathrm{p}=0.005)$ in the MTK condition of the present study were consistent with MacKenzie and Zhang's (2001) investigation of a soft keyboard, where the familiar keyboard did not show improvement over trials but the unfamiliar input device resulted in more dramatic increases in performance. In a follow-up study using 7 of the 12 subjects from an original study about the MultiTouch surface as a gestural input, text-editing time decreased an average of $39.6 \%$ on the fourth time using MultiTouch during the second experiment (Shanis, 2002).

Using the regression equations developed in an earlier section (Figure 4.5 and Figure 4.6), it may be possible to forecast the amount of time needed for users to become familiar enough with the MTK so as to perform at the same level as the CK. To reach the CK average typing speed of 53 wpm, a user would need to perform 25 typing trials or 187.5 minutes of typing on the MTK. For the mean CK accuracy level 
of 97 percent, a user should undergo 36 typing trials or 270 minutes of typing on the MTK. By allowing users additional exposure to the MultiTouch surface, it may be possible to lessen familiarity effects in future research.

\subsection{Limitations of Present Study}

While the dependent measures used in the present study were chosen for their appropriateness for the tasks and input devices evaluated, additional measures may offer further insight regarding the two keyboards tested. Finger force data, used in Rempel et al. (1997) should be collected to show the actual key strike force applied to the keyboard by the subjects. This would be especially helpful in determining whether a no-force keyboard causes users to decrease key strike force.

Additional posture analysis may strengthen the present research as well. The malfunction of the left-hand wrist goniometer did not allow for collection of left-hand side posture data, which is a detriment due to the two-handed nature of typing. While preliminary analysis showed no significant difference in left-hand wrist postures on the data collected on one pilot subject (Table 3.1), past research has shown that the QWERTY keyboard does tax the left hand disproportionately (Greenstein \& Arnaut, 1987) and this may have affected the results as well. In addition, monitoring changes in body posture may provide a fuller picture of the advantages and disadvantages of each keyboard.

The reluctance to adapt to a new technology may have affected the results. Since all subjects were experienced touch typists, the frustration of learning a new text-input paradigm may have confounded their performance. This frustration was noted in the subject comments given on the post-experiment questionnaire and seems to have affected the preference ratings given to the MTK. Alden et al. (1972) noted 
that the increased cognitive load of using a new input device may affect a user's perception of that device.

Extraneous error is almost a certainty in experimental research. The prototype nature of the MTK may have possessed less reliability than a heavily tested established keyboard. There may have been a lag between key strike and visual feedback, which would have degraded user performance. The keyboard driver was also unpredictable at times and the keyboard would have to be removed and reinserted into the USB drive between tasks occasionally.

\subsection{Future Research and Design Directions}

To fully investigate user acceptance of the MultiTouch surface, further study that integrates a substantial period of familiarization with the input device should be conducted. In addition, while typing is solely investigated in the current study, textentry and gestural commands, which were evaluated in previous research (Shanis, 2002; Browne et al., 2000), could be combined in an omnibus experimental task to best simulate real-world use of the MTK.

An in-depth examination of user finger key strike force should be conducted to evaluate the muscular and postural benefits of MultiTouch's no-force keying surface. The effects of fatigue may be investigated to determine the changes in force exerted by users over a period of time. This data may prove helpful in the continued study of risky repetitive finger, hand and wrist motions.

As Fingerworks continues to expand the MultiTouch surface into a product line of full-sized keyboards, the sensitivity and the no-force nature of the typing surface can lead to user frustration for the experienced touch typist. Subjects reported that resting fingers on the home row resulted in unwanted text entry while typing at great speed may cause the occasional placement of 2 simultaneous fingers, which 
reads as a pointing movement and results in a misdirection of the cursor. This sensitivity balance should be investigated to refine further iterations of the MultiTouch product.

A compelling design property of the MultiTouch surface is its scalability. While tabletop devices of a large size have been developed (Browne et al., 2000), MultiTouch for small, portable devices, such as cell phones and cameras, has not been fully explored yet. In addition, the material flexibility of MultiTouch would allow for its use in irregularly shaped or non-flat surfaces. The versatility of the MultiTouch system could also have design implications for special groups of users. For example, the Browne et al. (2000) tabletop painting device was primarily targeted to children. As the number of American elderly who use computing devices and connect to the Internet increases dramatically (Pew Internet and American Life Project, 2004), the no-force pointing capabilities of the MultiTouch surface may prove more comfortable for older users.

The MultiTouch surface, with its gestural and typing capabilities, may also allow for multi-modal interfaces that would allow for collaborative work in workgroups, especially those involved in the design process. A tabletop workspace may help to facilitate discussion and innovative visualization techniques, which has been implemented in recent research on a room furniture layout application on a gestural surface (Wu \& Balakrishnan, 2003). Gestural surfaces have also become apparent in distributed tangible interfaces, such as the Distributed Designer's Outpost, where the physical movement of Post-it notes on an electronic whiteboard is tracked by cameras so that notes that are physical in one area are electronic in the next (Everitt, Klemmer, Lee, \& Landay, 2003). The use of MultiTouch surfaces in a similar tangible interface as an additional form of input may add another layer of richness to the user experience. 
The MTK and the MultiTouch surface appear to be an example of promising input technology. With further research on the full set of its gestural capabilities combined with its keyboard input properties, a more comprehensive picture of the MultiTouch's potential will be captured. The scalability aspect of the surface should provide designers with a broader toolkit for input methods to be used in portable devices. As computing becomes even more integrated into the fabric of users' daily lives, mechanisms which reduce postural strain and bodily stress as well as offer novel interaction methods should become essential to the design of new products. 
Appendix A. Experimental Setup with Conventional Keyboard Condition

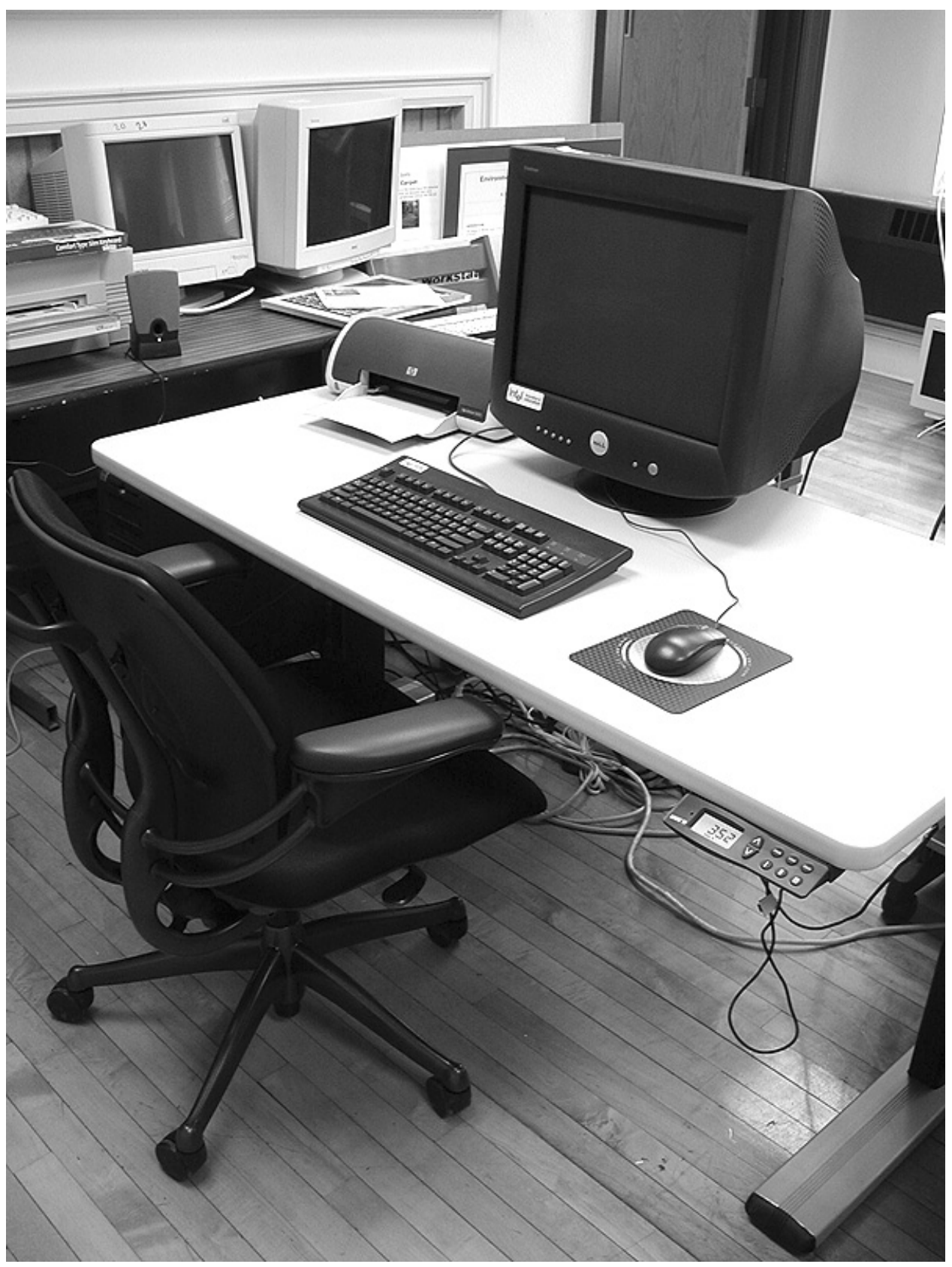


Appendix B. Experimental Setup with MTK Condition

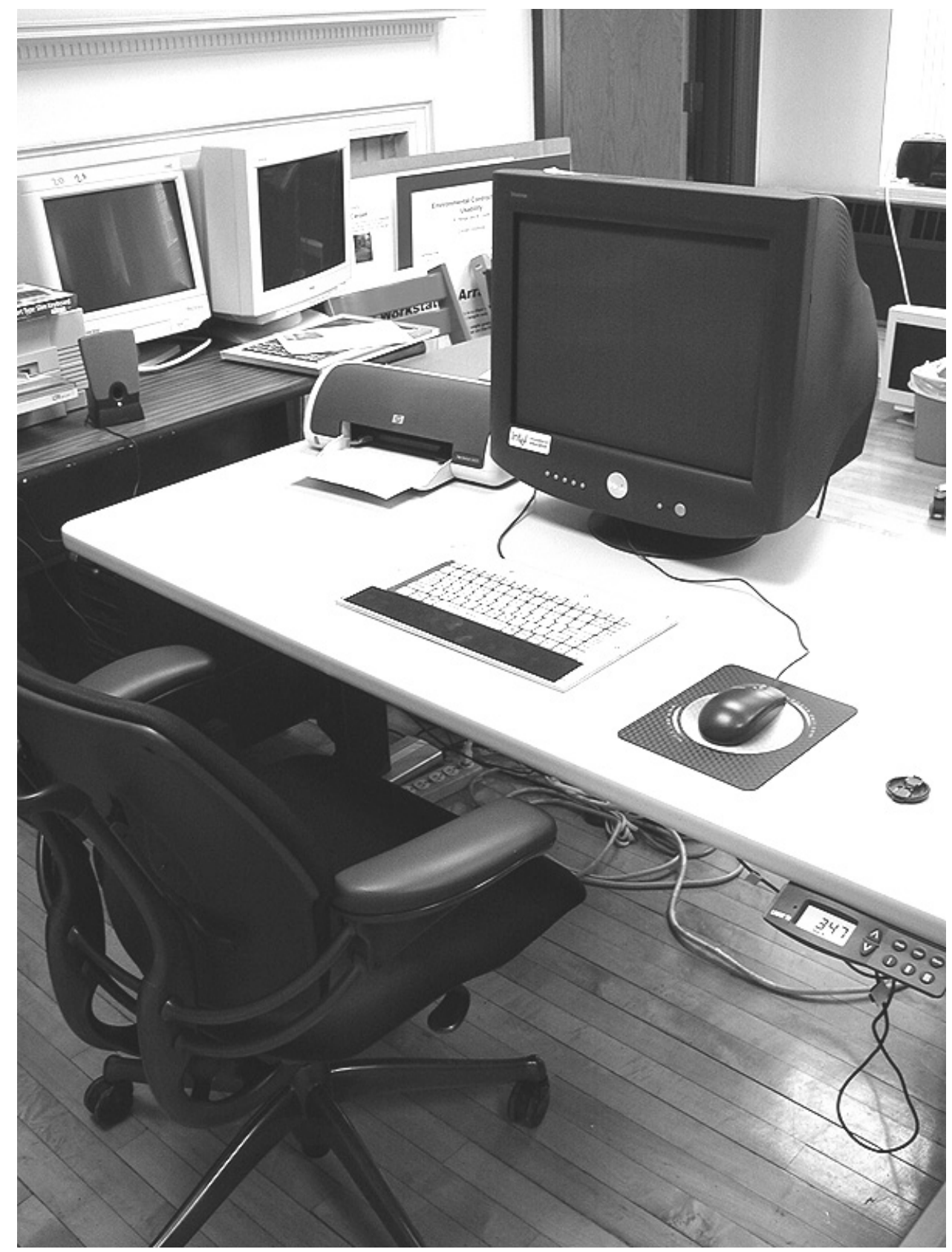




\section{Appendix C. Passages used for text-entry}

Passage 1. From Rybczynski, W. (2002, September). The Bilbao effect. The Atlantic Monthly, 290, 138-143.

In 1955 Le Corbusier built the chapel of Notre-Dame-du-Haut in Ronchamp, a remote site in the Jura Mountains near the Swiss border. The building had curved, roughly plastered concrete walls and a swelling roof that resembled a nun's wimple. These sculptural features challenged the functionalist dogma-to a large extent devised by the architect himself-of the white-shoebox International Style. After Ronchamp modern architecture was never quite the same.

Frank O. Gehry's Bilbao Guggenheim is equally iconoclastic. With its ballooning shapes and titanium swirls, its colliding forms and unusual spaces, it has been described variously as a "postrationalist vision," an "inter-galactic spaceship," and a "titanium artichoke." There is a major difference, however, between the museum and the chapel. When I went to Ronchamp, in 1964, there were few other visitors. Most, judging by their cameras and sketchbooks, were architectural-not religious-pilgrims, students like myself. Corbu, as we called him, was one of the most important architects in the world. Yet his was hardly a household name; most Americans, pressed to identify a contemporary architect, would probably have named Frank Lloyd Wright, who had been dead for five years. People did go out of their way to visit buildings, but they were usually ancient works of art like Chartres Cathedral, or historical monuments like the Tower of London. Buildings by modern architects were objects of veneration for students, but they were not paid much attention by the public.

Today's public definitely knows about the Bilbao Guggenheim; since its opening, in 1997, it has attracted almost five million visitors. According to the Financial Times, in its first three years the museum has helped to generate about $\$ 500$ million in economic activity and about $\$ 100$ million in new taxes. On seeing the titanium artichoke, other cities have been saying, "We want one of those."

Seattle got off the mark early. In 1996, before the Bilbao Guggenheim was even complete, Paul Allen, a cofounder of Microsoft and a Jimi Hendrix fan, commissioned Gehry to design a rock-and-roll museum and performance venue in Seattle called the Experience Music Project. Gehry delivered a striking building whose bulbous shapes are variously covered in shimmering gold, silver, and purple stainless steel, and in red and blue aluminum shingles. These forms resemble the fragments of a giant, multicolored, broken guitar after a particularly violent rock concert.

Two years after the Bilbao Guggenheim opened, the Corcoran Gallery of Art announced that Gehry would build a large addition to its century-old building in Washington, D.C. The new design is a composition of sail-like metallic forms. Construction is slated to begin in late 2003, probably before the groundbreaking for Gehry's other major museum project: a forty-story-high Guggenheim on the East 
River in Lower Manhattan, with yet more titanium swirls. A Guggenheim museum in New York City designed by Frank Gehry would no doubt attract millions of visitors. But will people really flock to New Orleans to see the Grammy Hall of Fame-a recently announced project that, according to its backers, "will have the 'wow factor'

Passage 2. From Rybczynski, W. (2002, September). The Bilbao effect. The Atlantic Monthly, 290, 138-143.

Will the new addition to the Milwaukee Art Museum, by the Spanish architect Santiago Calatrava, which features a giant kinetic sunshade resembling a flapping pair of pterodactyl wings, bring in throngs? Will Toronto, soon to have a dramatic addition to its Royal Ontario Museum designed by Daniel Libeskind (whose Jewish Museum in Berlin attracted 350,000 visitors in two years before it even had any exhibits), be the new Bilbao? Maybe, maybe not. A year and a half after the opening of the Experience Music Project attendance was down by more than a third, leading to a layoff of 124 employees. This may be partly because of September 11, but it is worth noting that during the same period the number of visitors to the local art museum increased by more than a third.

Whatever effect the Bilbao phenomenon will have on the way that tourists choose their destinations, it has already had a major influence on the way that clients, especially museums, choose their architects. In 1967, when the National Gallery of Art, in Washington, D.C., was planning an addition to its building, it solicited portfolios from a dozen prominent architects, and after narrowing the list down to four (Kevin Roche, Philip Johnson, Louis I. Kahn, and I. M. Pei), museum officials visited the finalists' buildings as well as their offices. Only after the choice was made did the winner, Pei-get down to work on a design. Three years ago, when the Corcoran went looking for an architect, it, too, had a short list: Gehry, Libeskind, and Calatrava. Where Gehry billows, Libeskind zigs and zags. The Jewish Museum, his first major building, resembles a fragmented Star of David. This seemed to many a stroke of genius when the building was completed, in 1999, but it turns out that Libeskind is simply partial to spiky, agitated forms. His winning design for an extension to the Denver Art Museum was described by The New York Times as a "dramatic glassandtitanium jumble of rectangles and triangles." Calatrava's stylishly engineered structures, in contrast, resemble sunbleached skeletons; they are "technoGothic;' according to one commentator.

Rather than merely ponder the previous work of the three architects, the Corcoran commissioned each one to prepare a specific design This kind of select competition, now the preferred way for choosing the architects of high-profile buildings, resembles a beauty pageant. With great fanfare a list of invited architects is announced. Their proposals are often exhibited, and sometimes the architects themselves give public presentations. The ranks of the competitors are winnowed. The anticipation is an important part of the publicity surrounding the proposed new building. When the Los 
Angeles County Museum of Art planned a major renovation and expansion, it invited five noteworthy architects to submit designs, including the ubiquitous Libeskind; Steven Holl, who was recently called "America's best architect" by Time magazine; and Thom Mayne, an avant-garde architect based in Los Angeles. Their proposals were eliminated in the first round of judging, leaving those of the Frenchman Jean Nouvel, whose best-known

Passage 3. From Rybczynski, W. (2002, September). The Bilbao effect. The Atlantic Monthly, 290, 138-143.

Finally Koolhaas, who recently won a competition to design Seattle's new public library, was declared the winner.

I have no objection to architects' duking it out, and I think it's great that architecture is attracting so much attention. But I am skeptical that designing in the full glare of public competitions encourages architects to produce better buildings. The charged atmosphere promotes flamboyance rather than careful thought, and favors the glib and obvious over the subtle and nuanced. Architects have always entered competitions, but they have usually seasoned their talents first by doing commissioned work. Libeskind, Nouvel, Koolhaas, and other young architects of today have built their reputations almost entirely by participating in competitions; a friend of mine calls them "competition show dogs." And show dogs are rarefied creatures, often refined and styled to the point of caricature.

Some years ago, in Learning From Las Vega (1972), Robert Venturi, Denise Scott Brown, and Steven Izenour differentiated between buildings whose architectural image was chiefly the result of surface ornament applied to structures shaped by their functions and buildings whose image was the result of unusual forms. They called the former "decorated sheds" and the latter "ducks;' a reference to a roadside stand on Long Island that sold poultry and was shaped like a duck. Italian Renaissance palazzi, for example, which are essentially straightforward buildings with exquisitely ornamented exteriors and interiors, are decorated sheds; Gothic cathedrals, with their flying buttresses, pinnacles, and steeples, are ducks.

The point was less that one approach was better than the other-Learning From Las Vegas allowed that "both kinds of architecture are valid"-than that, historically speaking, ducks are few and far between. Venturi and his co-authors argued that clients are better served by decorated sheds than by dramatically modeled buildings, no matter how exciting. After all, it is the former approach that has produced some of our most memorable public buildings-Philadelphia's Academy of Music, New York's Metropolitan Museum, and the Boston Public Library.

Yet ducks are clearly in season, and Venturi himself has suffered the consequences of this trend. Some years ago his firm was commissioned to design a new concert hall for Philadelphia. The resulting proposal was a sensible building with an attractive 
performance space but a relatively modest exterior. However, as more and more cities announced plans for trophy buildings, the concert-hall backers decided that a decorated shed simply would not do. They dismissed the Venturi firm, increased the budget from $\$ 60$ million to $\$ 265$ million, and hired the New York-based Rafael Vinoly, who delivered the requisite "wow factor": an immense glass vault.

Vinoly's concert hall, known as the Kimmel Center for the Performing Arts, illustrates another aspect of the Bilbao effect. Show-dog architecture, especially in a signature style, is unlikely to pay much attention to its surroundings. Venturi's design was carefully inserted into its site on Broad Street, and its conservative exterior suited Quakerish Philadelphia, his home town. Vinoly's glass vault, however impressive its drama, is an alien presence. Yet ducks are clearly in season

Passage 4. From Rybczynski, W. (2002, September). The Bilbao effect. The Atlantic Monthly, 290, 138-143.

One of the greatest American architects of the twentieth century was Louis I. Kahn. His best work, such as the Kimbell Art Museum, in Fort Worth; the Salk Institute, in La Jolla; and the Yale Center for British Art, was always directly commissioned. Although Kahn entered numerous competitions, he won only one, and in his later career he avoided competitions altogether. They did not suit him, because he developed his designs slowly, refining them in the process; his early sketches bear little resemblance to his finished buildings. Moreover, the qualities that made his architecture so good were poorly communicated in drawings and models. The buildings had to be experienced whole.

Japanese architect Tadao Ando, whose accomplished designs earned him the 1995 Pritzker Prize. His first public building in the United States, the Pulitzer Foundation for the Arts, in St. Louis, opened last year. Ando is a minimalist whose modest buildings depend on modulated natural light falling on simple materials-particularly concrete, which in his hands acquires a silky, sensuous texture. The forms of his buildings are uncomplicated; this is not eye-popping architecture. Benjamin Forgey, the architecture critic of The Washington Post, wrote of the Pulitzer Foundation, "It is almost dumbfounding in the United States to find an art museum whose interiors possess both the austerity and serenity of a Zen garden."

Emily Rauh Pulitzer, the president of the foundation, has said that the choice of Ando was based purely on aesthetics. Undoubtedly other architects were considered, but no design competition was involved. The question was who should be the architect, and the design came later. Indeed, the site of the museum was not yet final when Ando was commissioned. (His building, despite being abstract and minimalist in appearance, responds to its urban context very well.) To a degree that is not well understood, remarkable architecture is almost always the result of a dialogue between architect and client. Cut loose from this sort of creative conversation, few architects do their best work. The British architect Sir Edwin Lutyens once said, "There will never be great 
architects or architecture without great patrons." From the architect's point of view, the ideal project is not one with a magnanimous absent client. It is one with a magnanimous thoughtful client. In the Pulitzer Foundation, Ando had a thoughtful client; and he worked with Richard Serra and Ellsworth Kelly, two of the three artists whose works make up the permanent collection of this tiny museum. "My goal was to take to the limit the relationship between the works of art and the volume of the building's space," Ando has said.

The Pulitzer Foundation for the Arts is a small building that was not meant to attract a vast public. Yet it would be nice to think that the building signals at least an alternative, if not an end, to the Bilbao effect. The chief aim of architecture should not be to entertain, titillate, or shock viewers. After the third example of swirling titanium and colliding prisms, the effect

Passage 5. From Shreeve, J. (2003, October.) From Oliver's travels. The Atlantic Monthly, 292, 94-101.

On April 1, 1996, a truck carrying twelve chimpanzees backed up to the delivery gate at Primarily Primates, an animal sanctuary north of San Antonio. The chimps on the truck had come from a Pennsylvania research company called the Buckshire Corporation, and their delivery to Primarily Primates represented one of the first attempts anywhere to retire chimps to a sanctuary after they've been used in medical experiments. Wally Swett, the director of Primarily Primates, had been negotiating for eight months to take custody of them.

Swett came out to oversee the unloading of the animals. He was eager to get a glimpse of one in particular. The paperwork from Buckshire indicated that the shipment included an elderly primate named Oliver. Twenty years before, a chimp by that name had enjoyed a brief, feverish celebrity as a purported "missing link" between apes and men. This extraordinary claim was based on several behavioral and morphological peculiarities, especially Oliver's determined preference for walking upright on two legs. Preliminary genetic tests were said to indicate that he had forty-seven chromosomes, whereas human beings have forty-six, and common chimpanzees fortyeight. The tests were unconfirmed, however, and the media soon lost interest. After drifting for a decade from one California theme park to another, Oliver faded from view. Most of those who remembered him at all presumed he was dead. Wally Swett believed he might be alive, and crouching in one of the cages in the back of the truck.

Oliver became a celebrity in January of 1976, when he was approximately sixteen years old. There is no question that he was odd. His head was bald and abnormally small in proportion to his body, with a cranium more rounded than a typical chimp's. His lower face lacked the usual pronounced forward jut. His ears were high and pointed, his skin pale and freckled, and his aspect unusually gende and intelligent. His body odor was said to be strangely sharp, wholly atypical of chimpanzees. And he walked on two legs all the time. When he lived under the care of Frank and Janet 
Burger, the animal trainers who raised him, Oliver occasionally fed the dogs and did other chores, relaxing afterward with a cup of coffee. In the evening he might sit and watch TV with the couple, sometimes preparing a nightcap for Frank and himself of whiskey and 7UP. He did not get along with other chimps, and separation from his human companions was said to bring him to tears. When he reached sexual maturity, he was interested only in human females.

During Wally Swett's negotiations with Buckshire Corporation, Sharon Hursh, the company's president, had insisted that there was no reason to link the aged ape in her possession with the freakish creature whose likeness had once appeared in the pages of Time. But even in the darkness of the truck Swett, who as a young man had followed Oliver's story closely, thought he could recognize the ape's Mr. Spock ears and other distinctive features.

Passage 6. From Shreeve, J. (2003, October.) From Oliver's travels. The Atlantic Monthly, 292, 94-101.

He was not completely sure, however, until the animals had been unloaded and released from their transport cages.

The moment was recorded on film. The first few chimps to emerge, their limbs weakened from inactivity, knuckle-walk gingerly around their new enclosure looking frightened and confused. Then Oliver appears and immediately begins striding around on two legs, his body hair bristling with excitement. For a moment he, too, seems disoriented, his steps directionless. But at the sound of Swett's voice-"Hi, Ollie! Wow, Ollie, you stand up!"-the ape turns and rushes toward the human observers, eager and a little stiff-legged, like a passenger after a long flight catching sight of waiting friends.

According to news reports when Oliver first came into public view, he had been obtained by agents of Frank Burger as an infant in "the Congo River region." Considering that the Congo River drains an area of about 1.5 million square miles, much of it dense rain forest, the reports might as well have said he came from darkest Africa. Oliver spent his formative years with the Burgers in Blackwood, New Jersey, a stone's throw from the traffic whizzing by on Route 42. The Burgers were circus performers whose dog, pony, and chimp act had been featured on The Ed Sullivan Show in the early 1960s. They intended to train Oliver to join the act. He ended up with a far more unusual career.

Frank Burger died a few years ago, but Janet, at seventy-five, was still actively training animals on the same property in Blackwood when I visited her there late last year. (Since then she has given away her last chimpanzees, to Primarily Primates, and she is preparing to move to Florida.) Burger is a small, energetic woman with a platinum-blonde ponytail, indifferently painted-on eyebrows, and hands rough from work. "I've had forty chimps in my day," she told me. "But Oliver, he was altogether 
different. A real oddball. This guy walked all over the place. He lived out in the barn with the others, but as soon as it was morning, he'd want to come in the house. He'd sit around watching television, maybe have a jelly sandwich. That made him happy. He loved TV. But he didn't like the violence. If he saw two men fighting, he'd go over and punch the screen. He was peaceful. Kind of a loner. He liked helping Frank with the chores, like loading sawdust into a wheelbarrow. In the evening we would put him back out in the barn. But you couldn't put him with the other guys. They hated him."

In a photo of Oliver from that time, his face is flat, its contours almost human in appearance, and his pate is peach-fuzzed and liver-spotted, like that of an old courtier without his wig. He is staring back at the viewer with the half hopeful, half resigned expression of someone who has always relied on the kindness of strangers but is used to being disappointed.

"Deep down in my

Passage 7. From Shreeve, J. (2003, October.) From Oliver's travels. The Atlantic Monthly, 292, 94-101.

"Myself, I think he's some kind of throwback."

Burger remembers Oliver most of all for his persistent amorous advances toward her and her female friends. "He'd get aroused, and want to kiss you and so forth," she said. "I'd tell him, 'I love you, but I'm not going to have sex with you."'

Because of the animosity of the other chimps, the Burgers never succeeded in integrating Oliver into their animal act. But Frank would trot him out on a leash afterward as a sort of encore, and say a few words about the mysterious ape who walked like a man. Following one of these appearances a short article in an obscure magazine caught the attention of a thirty-three-year-old Manhattan appellate lawyer named Michael Miller. Miller found himself so obsessed with the notion of an uprightwalking ape that he tracked the Burgers down at their place in New Jersey and asked if he could meet Oliver in person. In December of 1975 Frank invited Miller and his wife to dinner. After loosening them up for a few hours with tales of his adventures with the chimpanzees, he took Miller out to the barn. He sat him down in an easy chair, excused himself, and came back with Oliver on a tether. As soon as Oliver caught sight of the visitor, he threw his shoulders back, and with every hair on his body erect, he strode over to Miller, cocked an eye to get a better look at him, and reached out to shake his hand, grasping his elbow with the other hand.

"It was a transforming experience," Miller told me recently. "I thought I was seeing the missing link. I was seeing Australopithecus. And I felt a terrible sense that if this creature was so important to science, he shouldn't be with a carnival guy." 
Miller decided on the spot that Oliver should be with a Manhattan appellate lawyer instead. At first Frank refused to sell, claiming that Oliver was like a son. It was then after midnight, so Miller and his wife said good-bye, and the Burgers led them to the highway. But just as they reached it, Frank and Janet waved them over and offered to sell Oliver for eight thousand dollars. They wrote out the agreement on a piece of paper on the hood of the car.

"In my heart, I felt destiny was pointing," Miller told me. "Here I was, Michael Miller, just a guy, with the opportunity to present to the world this extraordinary creature. I felt I was the fisherman who finds the coelacanth in his net, or the shepherd who discovers the Dead Sea scrolls. The earth has many secrets, and I was privileged to find a living one. My life was moved off the rails that night. I couldn't go back to practicing law."

Having bought Oliver, Miller had to figure out what to do with him. Obviously, the lawyer and his wife could not have an ape living with them in

Passage 8. From Shreeve, J. (2003, October.) From Oliver's travels. The Atlantic Monthly, 292, 94-101.

Miller's plan, to the extent he had one, was to present his discovery to experts at the American Museum of Natural History, who would probably want to keep Oliver in their custody, he thought, while they delved into the myriad questions raised by his existence. "I thought they would say thanks very much, here's a bronze plaque, we'll take it from here," he told me.

The museum, however, had no interest in even meeting Oliver, much less taking him in for research purposes. Miller decided to go back to the Burgers' and arrange to board Oliver there, which Frank was glad to do for \$500 a month. Miller then began inviting experts to travel to Blackwood and examine Oliver. Some were highly reputable scientists-among them George Schaller, of the Wildlife Conservation Society, one of the world's best-known field biologists, and Clifford Jolly, a physical anthropologist at New York University. Others were authorities on the Bigfoot legend and its African manifestations-tales of mysterious, apelike creatures known by such names as Agogwe, Apamandi, and Sehite.

"I made everybody sign a secrecy agreement about what they saw and where it was located," Miller said. "Not because I wanted to manipulate things but because I knew the story was huge." In spite of his efforts, in January of 1976 a reporter got wind of the news, and his story was picked up by the UPI wire. Miller was obliged to hold a press conference, and there he produced photos of Oliver, which appeared in newspapers around the world the next day and in Time a couple of days later. With the media vying for a chance to see the missing link, Miller scheduled a full-scale coming out at the Explorers Club, in New York City. The press release for the event made no definite claims about Oliver's species identity, but it did drop a number of hints: his 
erect posture was "a total mystery," his chromosomes "abnormal," and his place of origin in Africa known to be inhabited by both human beings and chimpanzees, which the press took as an implication that Oliver was perhaps half one and half the other. Oliver was otherwise described as light-skinned, myopic, and virtually toothless, the last condition as yet to be explained. (Janet Burger told me that Oliver had developed a gum disease when he was younger, and had pulled out his own teeth as they became loose.) His body odor was "extraordinarily pungent," and he was known to make a warbling noise in his throat that "occasionally breaks into a scream." Reporters were warned that although Oliver was normally docile, he was extremely strong, and their safety could not be guaranteed.

On the day of the event the police cordoned off the street outside the Explorers Club. Inside, with security officers holding back a wall of photographers, Oliver, guided by Frank Burger's leash, appeared-stopping on command to pose with his arms outstretched, his legs spread wide apart, and his enormous chimp testicles in full view. The

Passage 9. From Shreeve, J. (2003, October.) From Oliver's travels. The Atlantic Monthly, 292, 94-101.

The curtain rises, and Burger, dressed in a powder-blue leisure suit, trots out with Oliver, who is strolling along beside him in bowlegged, easygoing cowpoke style. At one point he breaks into a goofy, toothless grimace, but otherwise he seems as coolly indifferent to the audience's gasps and applause as a fashion model on a runway.

By this time the scientists had reported the results of their examinations of Oliver. Miller heard what he wanted to hear and ignored the rest. Meanwhile, officials from the Nippon Television Network, in Japan, had approached him with an offer: they would pay him a small fee and fund additional scientific studies to be carried out in Japan, including genetic tests, in exchange for the right to reveal the results in a nationally televised program. This seemed to Miller like a perfect opportunity to determine Oliver's true nature, to increase his public exposure, and to make a little money.

Oliver spent three weeks on tour in Japan, with Nippon's cameras following his every move: at a banquet, dressed in a tux; enjoying a cigar and an outsize can of beer; in a kimono, getting ready for bed. In the center of Tokyo a billboard bearing his image rotated above the rush-hour traffic. The Japanese made good on their promise to conduct an elaborate scientific examination, Nippon's ubiquitous camera crews recording every step. At one point scientists placed Oliver on a device called a "gravicoder," which indicated that his center of gravity resembled a human being's more than a chimpanzee's. In most other respects, however, Oliver fell toward the chimp side of the spectrum. Karyotypes were worked up on forty of his cells; most seemed to indicate the presence of forty-eight chromosomes, but the results were ambiguous enough to keep the possibility of forty-seven alive for anyone who wanted 
to believe that. Reportedly, some 26 million people watched the Japanese television broadcast.

How was Oliver dealing with all this? In the broadcast, or at least in the segments reaired this past June on the Discovery Channel, he appears to be thoroughly enjoying himself, bestowing hugs and handshakes all around. But according to Miller, there were less happy moments in Japan-such as the time Oliver turned white with rage when he was pushed into a tiny house his hosts had built for him to pretend to live in, and the time he grabbed hold of a little girl's hair and wouldn't let go. And he had to be sedated before undergoing x-rays, blood tests, and other scientific probing. In order to administer an injectable sedative, researchers placed him in a "squeeze cage"-a box with one side that can be cranked inward until the animal inside is unable to move.

"Oliver screamed very loud, because he was frightened," Miller told me. "It was very disturbing to me then. It disturbs me to think about it now." Miller himself was growing increasingly uncomfortable on the Japan tour. Far from rescuing Oliver from the life of a circus freak,

Passage 10. From Kummer, C. (2002, September). Maine certified. The Atlantic Monthly, 292, 131-136.

\section{FOOD}

In fifteen years or so of farm forays I have watched potatoes come and go in the gourmet revival of heirloom everything. Novelty candy stripes and blue or purple potatoes appear one season and vanish the next, as growers learn which kinds best suit their soil and cooks realize that color seldom indicates better flavor. Chefs discover that the secret of the best puree they ever tasted was not the Ratte variety that Parisian chefs swear by but the equal weight of butter whipped in before serving. In my experiments dark-horse varieties have often turned out to taste far better than touted ones. As always, variety counts less than climate and the care the farmer takes.

I was always puzzled, though, as to why so little potato news came from Maine, which for even longer than Idaho has been synonymous with potatoes in this country. It is also part of my heritage: my grandfather traveled every fall from Connecticut to northern Maine, where he bought the state's famous seed potatoes to sell to southern New England farmers. I learned on a recent visit to Aroostook County, one of my grandfather's destinations, that Maine has kept its reputation among the country's most reliable suppliers of disease-resistant seed potatoes even as the state's potato industry has otherwise diminished.

Few small farmers have stepped in to claim Maine's unused potato fields and grow the old varieties for which chefs and home cooks pay a premium. But on my trip I did find what might be the country's best source of those heirloom potatoes worth growing and eating: a strictly organic farm in the heart of what was once traditional potato-growing 
territory. It is run by an earthy, sympathetic couple whose entrepreneurial spirit and canny respect for the land my grandfather would have appreciated-even if their founding philosophy, and their hairstyles, would have baffled him.

When I drove into Wood Prairie Farm, a few miles from the several potato cooperatives remaining along a stretch of Route 1 in northern Aroostook County, Jim Gerritsen was leaning over a curious tractor painted pea green. He had rigged its trailer as a potato planter, with a few homemade parts jutting from the base and sides. "Two eyes apiece," he said, cutting a long seed potato into four chunks. "It's the eyes that sprout.' He laid the chunks, some of which had already sprouted, on a black rubber conveyor belt at the back of the planter. "We put this on;' he said, pointing to a spadeshaped length of metal at the front, "because our soil is so rocky it could break an ordinary potato planter."

Aroostook hardly resembles the Maine that draws tourists from all over the world, the Maine of lobster boats and evergreen-dotted seascapes. The county is vast, as big as Connecticut and Rhode Island combined; it has sky-wide open plains, and hills covered with pines. It's easy to see why some New Englanders have an almost visceral annual longing to go north, for the

Passage 11. From Kummer, C. (2002, September). Maine certifited. The Atlantic Monthly, 292, 131-136.

They also discovered that the soil, however rocky, was better than what they had left behind; "caribou loam;' as in the native reindeer that once lived in the Maine woods, has just the right mixture of clay, silt, and sand. Through the 1940s Maine was the country's largest potato producer, and Aroostook County produced 90 percent of Maine potatoes.

Today the Maine woods are being methodically logged by Canadian and American timber companies, and the chief planting in what once was the chief agricultural county in New England has become trees. The acreage devoted to potatoes shrank from 200,000 in the late 1940 s to 64,000 in 2000 , a loss of nearly 70 percent. The soil is still just as good for potatoes. But the big buyers don't want Maine potatoes anymore, because, like all potatoes grown without steady, controlled irrigation, they are uneven in shape. The widespread use of irrigation in the West-and, especially, the standards of uniformity that McDonald's set in the 1950s for its french fries-made the industry move.

Running a farm in Aroostook County was an unusual career choice for a young man who grew up in San Francisco. But farming ran in Gerritsen's blood: both his parents had been raised on farms and were part of the postwar migration from country to city. ("My grandfather kept telling my dad that farming was hard, that there wasn't much money in it" Gerritsen told me. "My dad listened.") While studying forestry at a 
California college, Gerritsen decided that his place was on a farm, not in school. From the look of him today, that decision was inevitable: his craggy features, deep-set green eyes, and wind-etched face immediately identify him as a man of the land. The graywhite beard and shoulder-length hair identify him as a child of the 1960s.

The decline of potato farming in Maine was what made Gerritsen think he could afford good farmland there, and get a head start on the organic farming he intended to practice. Land was cheap, and Aroostook County was too remote to attract developers. Farmland was still dear: former potato farmers had not yet planted it all with trees, a low-maintenance crop, and new-growth forests had not yet covered abandoned farmland. The lapsed time without any kind of planting meant that much Aroostook farmland would more than meet the requirements of organic farming. Gerritsen told me that he was also drawn by Maine's reputation for having "good, friendly, down-toearth people living an outdoor tradition."

In 1976 Gerritsen bought Wood Prairie Farm, in Bridgewater, a short drive down Route 1 from the town of Presque Isle, the effective capital of Aroostook County, and only a few miles from the Canadian border. At first he grew what he thought the organic market wanted: vegetables, apples for cider, pumpkins. He also raised cattle and lambs for organic meat. But none of these paid well enough to support the farm.

Potatoes seemed the least likely solution. What market remains is mostly for "chipping" potatoes-unbeautiful

Passage 12. From Kummer, C. (2002, September). Maine certified. The Atlantic Monthly, 292, 131-136.

Potatoes left over from the previous year's harvest are likely to be plagued by bacteria, viruses, or fungi; late blight, which caused the Irish potato famine, remained a danger to the U.S. crop through the 1980s. Starting in the 1920s, Maine set itself up as the country's most scrupulous producer of seed potatoes. "Maine certified" meant the best and safest potatoes when my grandfather was buying and selling them, and the phrase still carries great weight in the potato world. Gerritsen could fill a big gap by producing certified organic seed potatoes, and the most appealing varieties would be heirlooms and traditional Maine potatoes that had fallen out of use.

To find these, and for inspiration on reaching customers directly instead of losing profits to middlemen, Gerritsen listened carefully to Chris Holmes, a Maine farmer who through the late 1980s sold historical potato varieties by way of a "potato-of-themonth club." When I was first sampling heirloom potatoes, I spoke with Holmes, who thought he might be the only farmer growing them in Maine; on my recent trip I visited him in his apartment near Presque Isle, where, though sidelined by Parkinson's disease, he tries to convince farmers of the economic benefits of growing heirlooms. He didn't have the chance on his own farm, he told me, to see through the full potential of his idea, and he was somewhat discouraged that few farmers had taken his 
lead. He was proud, though, of Gerritsen, who has been his prize pupil, and told me how much he hopes that other farmers will copy Wood Prairie's success.

Gerritsen was helped greatly by his wife, Megan, a nearly local girl (although she grew up in New York State, she had worked on nearby farms and has family in Maine). Megan's hair, parted down the middle with a braid around her head, may be as hippie-ish as her husband's, but it would be less surprising to my grandfather, whose own father moved to the small Connecticut town where I grew up in hopes of emulating the agricultural success and familial closeness of the plain-living, plain-dressing members of a colony of the Swiss Apostolic Church, which still flourishes there. The Gerritsens have three small children, who help try out potato recipes, and many cats and a few dogs to finish off leftovers; during my visit all of them, along with several of the neighbors who work at the farm, wandered in and out of the cozy, pine-paneled Wood Prairie office, which is above the temperature-controlled storage and packing cellar. Megan cooks new heirlooms as Jim plants and harvests them, and everyone offers an opinion.

The couple decided at the outset to go for inner beauty. Even the organic market, which is becoming increasingly industrialized, grows "faceless, nameless potatoes that yield well and look pretty but don't have very good flavor," Megan says. The Gerritsens came to the same conclusion as anyone does who tastes a lot of heirlooms: yellow-fleshed potatoes have a fuller, richer, more

Passage 13. From Kummer, C. (2003, October). Big organic, small organic. The Atlantic Monthly, 292, 143-146.

It used to be that buyers of organic food could make some safe assumptions: the food was made close to where it was bought, by someone the buyer could visit or call up; the farmer or food producer cared about the environment and the importance of locally grown food; producer and consumer were likely to read alternative weeklies and listen to the same radio stations.

Once federal standards were passed, in 2000, that picture changed. Large industries, seeing that there was real money to be made, moved in. In supermarkets and food coops alike paper bags and bulk containers are giving way to slickly designed boxes of cereal and even frozen dinners, whose ingredients can be assembled from vast farms in California or the Midwest-or, for that matter, anywhere in the world that meets U.S. organic requirements. They may include synthesized flavorings just as artificialtasting as the ones in anything else in the supermarket: under the new standards flavorings need not be organic if they are used in sufficiently small quantities.

Buying and judging organic products has thus become considerably more complicated, as a recent comparison of several organic yogurts showed me. I liked yogurt well enough before; I love it now, having found a yogurt made with the milk of a "closed herd" of cows fed only on grain grown at the farm that makes it. That farm is strictly 
organic-and so are the producers of other yogurts that may be admirable but are by no means revelatory.

Passage 14. From Kummer, C. (2003, October). Big organic, small organic. The Atlantic Monthly, 292, 143-146.

Flavor, in fact, seems to have fallen fairly far down the list of what motivates consumers and producers of organic food: health concerns and simple market share are taking priority, not only over flavor but also over the environment. Market growth and adoption of the national standards have, of course, brought good things: a wider range of organic products, and attractive rather than gnarled and frankly old-looking fruits and vegetables. As industry encroaches on what was once the domain of artisans, consumers of organic food must decide whether they care about the ideological trappings that used to come with it or simply want organic food to be reliably free of chemicals and pesticides-and the less expensive and easier to find, the better.

I recently visited two New England yogurt producers I admire: the maker of that yogurt I love, and the country's largest producer of organic yogurt. Both are fervent supporters of family farms and a spectrum of environmental causes. The similarities between them pretty much stop there. The head of the big organic company has created a pioneering and successful model that I hope other large producers of organic food will study closely and copy. I fear they won't. As for flavor, I had to conclude that in this case, at least, small organic still tastes better than big.

With his bushy silver beard and bright blue eyes and denim overalls, Jack Lazor looks like an organic Santa Claus. When Lazor, a late-1960s radical, met his future wife, Anne, they

Passage 15. From Kummer, C. (2003, October). Big organic, small organic. The Atlantic Monthly, 292, 143-146.

The two decided to use Anne's graduate-school money to buy a farm in Vermont's Northeast Kingdom, near the Canadian border. Their idea was to raise dairy cattle and grow enough corn, wheat, and barley to feed their livestock and themselves (dense, dark bread was a talisman of the era; think of the added prestige home-grown grain conferred). Butterworks Farm may or may not be "Vermont's original organic dairy," as its label claims, but it is still held up as the small-scale ideal-a place where young people dream of apprenticing so they can learn how to make land sustainable and support themselves doing it.

The achievement the Lazors are proudest of is nurturing their soil. Everything flows from that, Lazor told me: the milk is sweet because they have spent more than twenty years returning the land to rich health, and because the compost they spread 
encourages particularly fine clover. Luckily, milk tastes the way forage smells and not the way it tastes. I was reminded of this during my Vermont visit by a young farmer, Earl Ransom, of Strafford Organic Creamery, whose subtle and wonderfully fullflavored ice cream has given rise to a Northeast Kingdom cult, and was the reason I called him up. Ransom told me that as the summer goes by, he can trace the forage progression from dandelion to red clover and orchard grass in his ice cream.

In the yogurt Lazor makes for himself (whole-milk, of course; I have yet to meet a yogurt producer who likes anything less), I sampled the full range of flavors in Butterworks milk, from herbal to slightly pungent The long pasteurization required for all commercial yogurt erases many but not all of the herbal and floral grass flavors, and not the pure, sweet flavor of Butterworks milk. The yogurt he spooned out of a big mason jar for me to try was straw-colored, with the texture and richness of soft sour cream. "This," Lazor said, taking a spoonful for himself, "is sort of divine."

I was already sold. The Butterworks Farm yogurt I regularly demolish-nonfat, which is almost the only kind I find in Boston stores, and is 80 percent of what Butterworks makes-is a thing of delicate beauty. It breaks into miniature canyons and bluffs, like junket. What Lazor calls a "tender set" results from the absence of the jelling agents that other manufacturers use-chiefly pectin (found in fruits and used in jams) and starch. The flavor is lightly sour, with none of the harsh vinegar sting of many unflavored yogurts. It's just tart enough to be refreshing.

I much prefer yogurt without pectin, which in excess can give a rubbery texture, and without starch, which often leaves a chalky flavor. But manufacturing yogurt without them is a high-wire act. Pectin helps keep the yogurt from separating to form a layer of whey-the liquid at the top of many yogurt containers. (My reflexive draining of the whey, I recently learned, throws out protein and minerals; for the full nutritional

Passage 16. From Kummer, C. (2003, October). Big organic, small organic. The Atlantic Monthly, 292, 143-146.

The makers of a newly available Greek yogurt I like very much, Total, also omit the pectin but strain out the liquid in advance, putting into small tubs a lightly tangy yogurt almost as thick as whipped cream cheese.

My visit was cut short by a call from Lazor's daughter. "I have to go and chase some cows," Lazor told me. He took me to the barn where his wife was doing the evening milking, helped by their future son-in-law. I saw what Lazor meant when he called their forty-odd Jersey cows "a bunch of pets": each has a name (Menorah, Vetch, Milkyway), and they are much smaller than Holsteins, the usual New England dairy cow. While the Lazors pulled the errant cows back to the barn by their collars, I quietly left with several containers from the big storage refrigerator. 
I was surprised by how firm the contents were. The knocking around that cartons get as they are loaded and unloaded (Butterworks Farm yogurt is sold on the East Coast as far south as Raleigh-Durham) disturbs the structure formed while the yogurt cools and sets. As Lazor had recommended, I took a pint, the smallest container Butterworks makes, of maple yogurt, made with New England syrup and no other flavoring. I had always thought that whole-milk yogurt was too rich to eat much of at a time, and of course sinful-although the new bad-guy status of trans fats, found in nearly every packaged baked or fried good, makes cream and butter seem positively virtuous. This was silken and sweet but not too sweet, with none of the blaring synthesized maple flavor we now take for granted. The taste was slightly smoky and reminiscent of butterscotch. The container was empty by the time I turned in.

Gary Hirshberg, the head of Stonyfield Farms, calls Jack Lazor his hero. When executives from Danone, the large France-based conglomerate that bought a 40 percent stake in Stonyfield two years ago, come to visit, Hirshberg's sister Nancy, the company's director of natural resources, drives them several hours each way to Butterworks Farm, so that they can see the kind of organic dairy farm Stonyfield is committed to supporting. Stonyfield, which is based in southern New Hampshire, began selling yogurt in 1983, a year before the Lazors did; for a very few years Hirshberg and his founding partner even had a few Jerseys. Briefly the companies were rivals for shelf space in co-ops and natural-foods stores. Then they went in very different directions.

Stonyfield sold its cows, bought the milk of many breeds from cooperative organic dairies, and pursued the goal of putting its product in every supermarket and convenience store in the land. In the late 1980s, when I first visited Stonyfield, I was surprised to find a low modern factory. Today Stonyfield is among the top five brands of yogurt in the United States, and the only one of the five that makes organic yogurt.

Hirshberg was after market share and the purchasing 


\section{Appendix D. Fatigue Index}

Pre and Post Trial Comfort Questionnaire

Please indicate your level of fatigue by circling the appropriate choice for each body part listed:

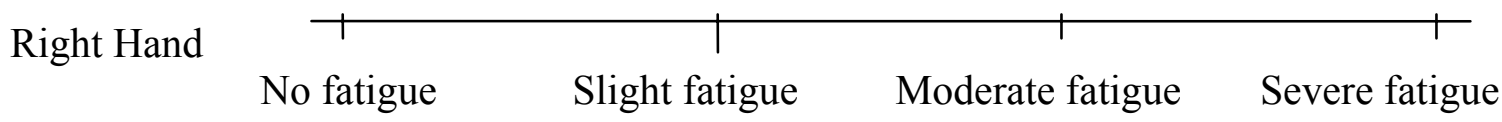

Right Wrist $\begin{aligned} & \\ & \text { No fatigue }\end{aligned}$

Right Forearm 1 Slight fatigue $\quad$ Moderate fatigue $\quad$ Severe fatigue

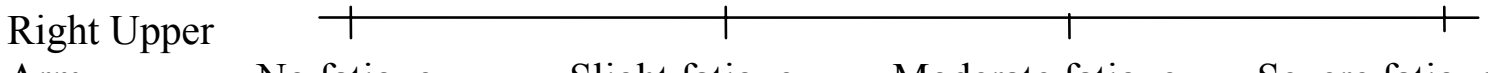

Arm No fatigue Slight fatigue Moderate fatigue Severe fatigue

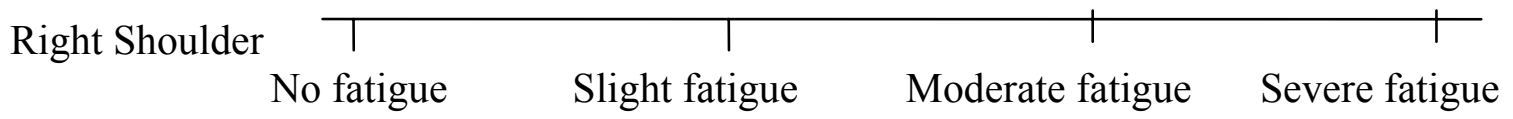

Left Hand

\begin{tabular}{cc|c|c}
\hline$T$ & & & \\
No fatigue & Slight fatigue & Moderate fatigue & Severe fatigue
\end{tabular}




\begin{tabular}{|c|c|c|c|c|}
\hline Left Wrist & $\begin{array}{c}7 \\
\text { No fatigue }\end{array}$ & \begin{tabular}{c|c} 
& \\
Slight fatigue
\end{tabular} & $\begin{array}{c} \\
\text { Moderate fatigue }\end{array}$ & $\begin{array}{c} \\
\text { Severe fatigue }\end{array}$ \\
\hline Left Forearm & $\begin{array}{c}\top \\
\text { No fatigue }\end{array}$ & $\begin{array}{c} \\
\text { Slight fatigue }\end{array}$ & $\begin{array}{c} \\
\text { Moderate fatigue }\end{array}$ & $\begin{array}{c} \\
\text { Severe fatigue }\end{array}$ \\
\hline $\begin{array}{l}\text { Left Upper } \\
\text { Arm }\end{array}$ & $\begin{array}{c}T \\
\text { No fatigue }\end{array}$ & $\begin{array}{c} \\
\text { Slight fatigue }\end{array}$ & $\begin{array}{c} \\
\text { Moderate fatigue }\end{array}$ & $\begin{array}{c}1 \\
\text { Severe fatigue }\end{array}$ \\
\hline
\end{tabular}

Left Shoulder

\begin{tabular}{cccc}
\hline & & 1 & 1 \\
No fatigue & Slight fatigue & Moderate fatigue & Severe fatigue
\end{tabular}

Neck

\begin{tabular}{cc|cc}
\hline$T$ & $\mid$ & & \\
No fatigue & Slight fatigue & Moderate fatigue & Severe fatigue
\end{tabular}

Upper back

\begin{tabular}{ll|ll}
\hline & & & \\
No fatigue & Slight fatigue & Moderate fatigue & Severe fatigue
\end{tabular}

Lower back

$\begin{array}{cccc}T & & & \\ \text { No fatigue } & \text { Slight fatigue } & \text { Moderate fatigue } & \text { Severe fatigue }\end{array}$




\section{Appendix E. Post-Trial Questionnaire}

1. After using both keyboards, indicate how much you enjoy using the following with your keyboard at your computer. Please rate each on a scale from 1-10 (1=least enjoyable, $10=$ most enjoyable).

Conventional Keyboard

Fingerworks Ultra

2. Overall, indicate how comfortable each technology was on a scale from 1-10 (1=least comfortable, $10=$ most comfortable).

Conventional Keyboard

Fingerworks Ultra

3. Indicate how easy each technology was to use on a scale from $1-10(1=$ most difficult, $10=$ easiest).

Conventional Keyboard

Fingerworks Ultra

4. How easy was it to type text with each keyboard? (1=most difficult, $10=$ easiest $)$

Conventional Keyboard

Fingerworks Ultra 
Please provide any additional comments:

5. Please circle the frequency with which you have used the following.

Split keyboard

never used sometimes used often used always used

Conventional keyboard

never used sometimes used often used always used

Notebook computer

never used sometimes used often used always used

Tablet PC

never used sometimes used often used always used

Personal Digital Assistant

never used sometimes used often used always used

Cell phone

never used sometimes used often used always used

Please estimate how much time (in hours) you use each on a typical day.

Split Keyboard

Conventional Keyboard

Notebook Computer

Tablet PC

Personal Digital Assistant

Cell phone 
Answer ALL questions in order and independently of others. Do NOT go back and check your answers. For each question choose ONE answer only. Write the answer number in the SCORE box.

6. What time would you get up if you were entirely free to plan your own day?

\begin{tabular}{|c|c|c|c|c|c|}
\hline $\begin{array}{l}5-6: 30 \\
\text { am }\end{array}$ & $\begin{array}{l}\text { 6:30-7:45 } \\
\text { am }\end{array}$ & $\begin{array}{l}7: 45-9: 45 \\
\text { am }\end{array}$ & $\begin{array}{l}9: 45-11: 00 \\
\text { am }\end{array}$ & $\begin{array}{l}11: 00-12 \\
\text { noon }\end{array}$ & SCORE \\
\hline 5 & 4 & 3 & 2 & 1 & \\
\hline
\end{tabular}

7. What time would you go to bed if you were entirely free to plan your evening?

\begin{tabular}{|c|c|c|c|c|c|}
\hline $\begin{array}{l}8-9: 00 \\
\text { pm }\end{array}$ & $\begin{array}{l}\text { 9-10:15 } \\
\text { pm }\end{array}$ & $\begin{array}{l}10: 15-12: 30 \\
\text { am }\end{array}$ & $\begin{array}{l}12: 30-1: 45 \\
\text { am }\end{array}$ & $\begin{array}{l}1: 45-3: 00 \\
\text { am }\end{array}$ & SCORE \\
\hline 5 & 4 & 3 & 2 & 1 & \\
\hline
\end{tabular}

8. How dependent are you on being woken up by an alarm clock?

\begin{tabular}{|c|c|c|c|c|}
\hline $\begin{array}{l}\text { Not at } \\
\text { all }\end{array}$ & $\begin{array}{l}\text { Slightly } \\
\text { dependent }\end{array}$ & $\begin{array}{l}\text { Fairly } \\
\text { dependent }\end{array}$ & $\begin{array}{l}\text { Very } \\
\text { dependent }\end{array}$ & SCORE \\
\hline 4 & 3 & 2 & 1 & \\
\hline
\end{tabular}

9. How easy do you find getting up in the mornings?

\begin{tabular}{|c|c|c|c|c|}
\hline $\begin{array}{l}\text { Not at } \\
\text { all }\end{array}$ & Not very easy & Fairly easy & Very easy & SCORE \\
\hline 1 & 2 & 3 & 4 & \\
\hline
\end{tabular}

10. How alert do you feel during the first half-hour after having woken in the morning?

\begin{tabular}{|c|c|c|c|c|}
\hline $\begin{array}{l}\text { Not at } \\
\text { all }\end{array}$ & Not very alert & Fairly alert & Very alert & SCORE \\
\hline 1 & 2 & 3 & 4 & \\
\hline
\end{tabular}

11. How is your appetite during the first half-hour after having woken in the morning?

\begin{tabular}{|c|c|c|c|c|}
\hline $\begin{array}{l}\text { Very } \\
\text { Poor }\end{array}$ & Fairly poor & Fairly good & Very good & SCORE \\
\hline 1 & 2 & 3 & 4 & \\
\hline
\end{tabular}


12. During the first half-hour after having woken in the morning, how tired do you feel?

\begin{tabular}{|c|c|l|l|c|}
\hline $\begin{array}{l}\text { Very } \\
\text { tired }\end{array}$ & Fairly tired & $\begin{array}{l}\text { Fairly } \\
\text { refreshed }\end{array}$ & $\begin{array}{l}\text { Very } \\
\text { refreshed }\end{array}$ & SCORE \\
\hline 1 & 2 & 3 & 4 & \\
\hline
\end{tabular}

13. When you have no commitments the next day, at what time do you go to bed compared to your usual bedtime?

\begin{tabular}{|c|c|c|c|c|}
\hline $\begin{array}{l}\text { Seldom } \\
\text { or } \\
\text { never } \\
\text { later }\end{array}$ & $\begin{array}{l}\text { Less than one } \\
\text { hour later }\end{array}$ & $\begin{array}{l}1-2 \text { hours } \\
\text { later }\end{array}$ & $\begin{array}{l}\text { More than } \\
\text { two hours } \\
\text { later }\end{array}$ & SCORE \\
\hline 4 & 3 & 2 & 1 & \\
\hline
\end{tabular}

14. How well would you perform one hour's physical exercise between 7-8:00am?

\begin{tabular}{|c|l|c|l|c|}
\hline $\begin{array}{l}\text { Would be } \\
\text { in good } \\
\text { form }\end{array}$ & $\begin{array}{l}\text { Would be } \\
\text { in } \\
\text { reasonable } \\
\text { form }\end{array}$ & $\begin{array}{l}\text { Would find } \\
\text { it difficult }\end{array}$ & $\begin{array}{l}\text { Would find } \\
\text { it very } \\
\text { difficult }\end{array}$ & SCORE \\
\hline 4 & 3 & 2 & 1 & \\
\hline
\end{tabular}

15. When do you feel tired and in need of sleep?

\begin{tabular}{|c|l|c|c|c|c|}
\hline $\begin{array}{l}8-9: 00 \\
\mathrm{pm}\end{array}$ & $\begin{array}{l}9-10: 15 \\
\mathrm{pm}\end{array}$ & $\begin{array}{l}10: 15 \mathrm{pm}- \\
12: 30 \mathrm{am}\end{array}$ & $\begin{array}{l}12: 30-1: 45 \\
\text { am }\end{array}$ & $\begin{array}{l}1: 45-3: 00 \\
\mathrm{am}\end{array}$ & SCORE \\
\hline 5 & 4 & 3 & 2 & 1 & \\
\hline
\end{tabular}

16. Which ONE of the four testing times would you choose to take a 2 hour test?

\begin{tabular}{|l|c|c|c|c|}
\hline $\begin{array}{l}8-10: 00 \\
\text { am }\end{array}$ & $\begin{array}{l}11: 00 \mathrm{am}- \\
1: 00 \mathrm{pm}\end{array}$ & $\begin{array}{l}3: 00-5: 00 \\
\mathrm{pm}\end{array}$ & $\begin{array}{l}7: 00-9: 00 \\
\mathrm{pm}\end{array}$ & SCORE \\
\hline 4 & 3 & 2 & \multicolumn{1}{|c|}{1} & \\
\hline
\end{tabular}

17. If you went to bed at 11:00 pm. how tired would you be?

\begin{tabular}{|c|c|c|c|c|}
\hline $\begin{array}{l}\text { Not at } \\
\text { all }\end{array}$ & A little tired & Fairly tired & Very tired & SCORE \\
\hline 0 & 2 & 3 & 5 & \\
\hline
\end{tabular}


18. If you go to bed much later than usual, but don't need to get up at any particular time the next morning, which ONE of the following events are you most likely to experience?

\begin{tabular}{|l|l|l|l|l|}
\hline $\begin{array}{l}\text { Will wake } \\
\text { up at usual } \\
\text { time and } \\
\text { will NOT } \\
\text { fall asleep }\end{array}$ & $\begin{array}{l}\text { Will wake } \\
\text { time but } \\
\text { will doze }\end{array}$ & $\begin{array}{l}\text { Will wake } \\
\text { up at usual } \\
\text { time but } \\
\text { will fall } \\
\text { asleep } \\
\text { again }\end{array}$ & $\begin{array}{l}\text { Will NOT } \\
\text { wake up at } \\
\text { usual time }\end{array}$ & SCORE \\
\hline 4 & 3 & 2 & 1 & \\
\hline
\end{tabular}

19. If you had to stay awake between 4:00 - 6:00 am and you had no commitments the next day. Which ONE of the following alternatives would you choose?

\begin{tabular}{|l|l|l|l|l|}
\hline $\begin{array}{l}\text { Would } \\
\text { NOT go to } \\
\text { bed until } \\
\text { after 6 am }\end{array}$ & $\begin{array}{l}\text { Would take } \\
\text { a nap before } \\
4 \text { am and } \\
\text { then sleep } \\
\text { after }\end{array}$ & $\begin{array}{l}\text { Would take } \\
\text { a good } \\
\text { sleep before } \\
\text { 4am and } \\
\text { then nap } \\
\text { after }\end{array}$ & $\begin{array}{l}\text { Would take } \\
\text { ALL sleep } \\
\text { before 4am }\end{array}$ & SCORE \\
\hline 1 & \multicolumn{1}{|c|}{2} & 3 & 4 & \\
\hline
\end{tabular}

20. You have to do two hours of hard physical work. Now you are entirely free to plan your day. Which ONE of the following times would you choose MOST to do stuff?

\begin{tabular}{|c|c|c|l|l|}
\hline $\begin{array}{l}\text { 8-10:00 } \\
\text { am }\end{array}$ & $\begin{array}{l}11: 00 \mathrm{am}- \\
1: 00 \mathrm{pm}\end{array}$ & $\begin{array}{l}\text { 3:00-5:00 } \\
\mathrm{pm}\end{array}$ & $\begin{array}{l}\text { 7:00-9:00 } \\
\mathrm{pm}\end{array}$ & SCORE \\
\hline 4 & 3 & 2 & 1 & \\
\hline
\end{tabular}

21. You are planning a hard physical workout with a friend. You will do this for one hour twice a week. The best time for your friend is between 10:00-11:00pm. How well do you think you would perform at this time?

\begin{tabular}{|c|l|c|l|c|}
\hline $\begin{array}{l}\text { Would be } \\
\text { in good } \\
\text { form }\end{array}$ & $\begin{array}{l}\text { Would be in } \\
\text { reasonable } \\
\text { form }\end{array}$ & $\begin{array}{l}\text { Would find } \\
\text { it difficult }\end{array}$ & $\begin{array}{l}\text { Would find } \\
\text { it very } \\
\text { difficult }\end{array}$ & SCORE \\
\hline 1 & 2 & 3 & 4 & \\
\hline
\end{tabular}


22. Suppose that you've graduated High School and you can choose your own work hours. Assume you work a FIVE-hour day (including breaks) at an interesting job and are paid by your results. Which FIVE CONSECUTIVE HOURS would you select?

\begin{tabular}{|l|c|l|l|l|l|}
\hline $\begin{array}{l}\text { 3:00- } \\
7: 30 \mathrm{am}\end{array}$ & $\begin{array}{l}7: 30 \mathrm{am}- \\
12: 30 \mathrm{pm}\end{array}$ & $\begin{array}{l}\text { Between } \\
9: 00 \mathrm{am}- \\
2: 00 \mathrm{pm}\end{array}$ & $\begin{array}{l}\text { Between } \\
2-7: 00 \mathrm{pm}\end{array}$ & $\begin{array}{l}\text { Between } \\
5: 00 \mathrm{pm}- \\
3: 00 \mathrm{am}\end{array}$ & SCORE \\
\hline 5 & 4 & 3 & 2 & 1 & \\
\hline
\end{tabular}

23. At what time of the day do you think that you reach your "feeling best" peak?

\begin{tabular}{|l|l|l|l|l|l|}
\hline $4-7: 30$ & $7: 30-$ & Between & Between & $9: 30 \mathrm{pm}-$ & SCORE \\
am & $9: 30$ & $9: 30 \mathrm{am}-$ & $4: 30-9: 30$ & $4: 00 \mathrm{am}$ & \\
& am- & $4: 30 \mathrm{pm}$ & $\mathrm{pm}$ & & \\
\hline \multicolumn{1}{|l|}{5} & 4 & 3 & 2 & 1 & \\
\hline
\end{tabular}

24. Do you think you are a "morning" or "evening" type of person?

\begin{tabular}{|c|l|l|l|l|}
\hline $\begin{array}{l}\text { Definitely a } \\
\text { "morning" } \\
\text { type }\end{array}$ & $\begin{array}{l}\text { Probably a } \\
\text { "morning" } \\
\text { type }\end{array}$ & $\begin{array}{l}\text { Probably an } \\
\text { "evening" } \\
\text { type }\end{array}$ & $\begin{array}{l}\text { Definitely an } \\
\text { "evening" } \\
\text { type }\end{array}$ & SCORE \\
\hline 6 & 3 & 2 & 1 & \\
\hline
\end{tabular}




\section{Appendix F. Subject Condition and Task Order}

\begin{tabular}{|c|c|c|}
\hline Subject 1 & $\begin{array}{c}\text { A } \\
1234 \\
5678\end{array}$ & $\begin{array}{ccc} & \mathrm{B} \\
91011 & 12 \\
1314 & 1516\end{array}$ \\
\hline Subject 2 & $\begin{array}{c}\text { B } \\
3219 \\
1361011\end{array}$ & $\begin{array}{c}\mathrm{A} \\
164815 \\
571412\end{array}$ \\
\hline Subject 3 & $\begin{array}{c}\mathrm{A} \\
168215 \\
31194\end{array}$ & $\begin{array}{c}\text { B } \\
11265 \\
1371410\end{array}$ \\
\hline Subject 4 & \begin{tabular}{cc}
\multicolumn{1}{c}{$\mathrm{B}$} \\
145911 \\
410712 \\
\end{tabular} & $\begin{array}{c}\text { A } \\
13136 \\
216815\end{array}$ \\
\hline Subject 5 & $\begin{array}{c}\text { A } \\
51391 \\
111526\end{array}$ & $\begin{array}{c}\text { B } \\
16847 \\
1410312\end{array}$ \\
\hline Subject 6 & $\begin{array}{c}\text { B } \\
710214 \\
59111 \\
\end{array}$ & $\begin{array}{c}\text { A } \\
151638 \\
641312 \\
\end{array}$ \\
\hline Subject 7 & $\begin{array}{c}\text { A } \\
21263 \\
111645\end{array}$ & $\begin{array}{rl} & \text { B } \\
7119 & 10 \\
13 & 81415\end{array}$ \\
\hline Subject 8 & $\begin{array}{cc}\text { B } \\
161368 \\
104111 \\
\end{array}$ & $\begin{array}{c}\mathrm{A} \\
21439 \\
151275 \\
\end{array}$ \\
\hline Subject 9 & $\begin{array}{c}\text { A } \\
514127 \\
1361015 \\
\end{array}$ & $\begin{array}{c}\text { B } \\
1843 \\
111629 \\
\end{array}$ \\
\hline Subject 10 & $\begin{array}{c}\text { B } \\
13952 \\
10714 \\
\end{array}$ & $\begin{array}{c}\text { A } \\
163118 \\
1214156 \\
\end{array}$ \\
\hline Subject 11 & $\begin{array}{c}\text { A } \\
9671 \\
1014216 \\
\end{array}$ & 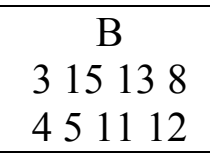 \\
\hline Subject 12 & $\begin{array}{c}\text { B } \\
14267 \\
915411 \\
\end{array}$ & \begin{tabular}{llll} 
& \multicolumn{1}{c}{$A$} \\
13 & 1 & 5 & 16 \\
3 & 10 & 12 & 8 \\
\end{tabular} \\
\hline
\end{tabular}
A: Conventional Keyboard
B: MTK 


\section{Appendix G. Raw Data: Typing Speed}

\section{Typing Speed}

\begin{tabular}{|c|c|c|c|c|c|c|c|c|c|c|c|c|}
\hline & $1 \mathrm{~F}$ & $2 \mathrm{~F}$ & $3 \mathrm{~F}$ & $4 \mathrm{~F}$ & $5 \mathrm{~F}$ & $6 \mathrm{~F}$ & $7 \mathrm{M}$ & $8 \mathrm{M}$ & $9 \mathrm{M}$ & $\begin{array}{l}10 \\
\mathrm{M}\end{array}$ & $\begin{array}{l}11 \\
\mathrm{M}\end{array}$ & $12 \mathrm{M}$ \\
\hline \multicolumn{13}{|l|}{ Avg wpm } \\
\hline \multirow[t]{8}{*}{ CK } & 45 & 61 & 57 & 54 & 53 & 36 & 44 & 50 & 34 & 77 & 47 & 34 \\
\hline & 51 & 58 & 60 & 57 & 53 & 35 & 44 & 53 & 31 & 73 & 47 & 34 \\
\hline & 55 & 58 & 65 & 55 & 57 & 35 & 46 & 49 & 34 & 78 & 49 & 33 \\
\hline & 55 & 64 & 64 & 56 & 55 & 33 & 46 & 53 & 35 & 76 & 50 & 37 \\
\hline & 56 & 58 & 67 & 56 & 56 & 35 & 43 & 53 & 36 & 77 & 50 & 35 \\
\hline & 54 & 61 & 66 & 56 & 55 & 35 & 41 & 51 & 35 & 75 & 50 & 34 \\
\hline & 61 & 59 & 68 & 53 & 56 & 36 & 47 & 51 & 34 & 73 & 48 & 33 \\
\hline & 58 & 59 & 67 & 55 & 53 & 36 & 40 & 49 & 36 & 77 & 48 & 32 \\
\hline \multirow[t]{8}{*}{ MTK } & 23 & 18 & 43 & 33 & 33 & 12 & 20 & 39 & 16 & 23 & 34 & 60 \\
\hline & 24 & 26 & 43 & 38 & 33 & 17 & 22 & 38 & 21 & 24 & 33 & 66 \\
\hline & 26 & 32 & 44 & 39 & 34 & 21 & 23 & 45 & 20 & 27 & 38 & 65 \\
\hline & 28 & 34 & 47 & 40 & 35 & 28 & 22 & 41 & 22 & 27 & 39 & 65 \\
\hline & 33 & 35 & 47 & 39 & 32 & 29 & 20 & 41 & 25 & 27 & 41 & 62 \\
\hline & 31 & 40 & 46 & 41 & 35 & 29 & 23 & 42 & 26 & 28 & 40 & 60 \\
\hline & 33 & 34 & 46 & 43 & 36 & 29 & 25 & 44 & 24 & 26 & 38 & 62 \\
\hline & 34 & 40 & 46 & 38 & 38 & 30 & 26 & 42 & 26 & 28 & 40 & 57 \\
\hline
\end{tabular}


Appendix H. Raw Data: Percent Accuracy

Percent Accuracy

\begin{tabular}{|c|c|c|c|c|c|c|c|c|c|c|c|c|}
\hline & $1 \mathrm{~F}$ & $2 \mathrm{~F}$ & $3 \mathrm{~F}$ & $4 \mathrm{~F}$ & $5 \mathrm{~F}$ & $6 \mathrm{~F}$ & $7 \mathrm{M}$ & $8 \mathrm{M}$ & $9 \mathrm{M}$ & $\begin{array}{l}10 \\
M\end{array}$ & $\begin{array}{l}11 \\
\mathrm{M}\end{array}$ & $\begin{array}{l}12 \\
M\end{array}$ \\
\hline \multicolumn{13}{|l|}{ Accu } \\
\hline \multirow[t]{8}{*}{$\mathrm{CK}$} & 96 & 100 & 95 & 94 & 93 & 99 & 97 & 99 & 97 & 99 & 98 & 96 \\
\hline & 97 & 100 & 96 & 94 & 95 & 98 & 98 & 99 & 97 & 99 & 96 & 96 \\
\hline & 96 & 100 & 96 & 95 & 93 & 99 & 97 & 99 & 98 & 100 & 97 & 95 \\
\hline & 95 & 100 & 94 & 94 & 93 & 99 & 99 & 99 & 97 & 99 & 97 & 94 \\
\hline & 96 & 100 & 95 & 94 & 90 & 99 & 100 & 99 & 98 & 100 & 97 & 96 \\
\hline & 95 & 100 & 94 & 91 & 88 & 99 & 98 & 100 & 97 & 99 & 96 & 95 \\
\hline & 95 & 100 & 93 & 93 & 94 & 98 & 98 & 100 & 97 & 100 & 96 & 94 \\
\hline & 94 & 100 & 92 & 94 & 92 & 98 & 98 & 100 & 96 & 98 & 98 & 95 \\
\hline \multirow[t]{8}{*}{ MTK } & 86 & 84 & 79 & 76 & 80 & 88 & 91 & 92 & 83 & 49 & 84 & 49 \\
\hline & 92 & 93 & 82 & 81 & 79 & 96 & 75 & 95 & 76 & 75 & 84 & 49 \\
\hline & 90 & 91 & 78 & 84 & 75 & 97 & 69 & 92 & 89 & 67 & 84 & 56 \\
\hline & 86 & 90 & 77 & 83 & 82 & 98 & 60 & 94 & 82 & 71 & 79 & 71 \\
\hline & 93 & 91 & 79 & 84 & 69 & 97 & 68 & 95 & 82 & 72 & 84 & 61 \\
\hline & 95 & 96 & 80 & 84 & 79 & 95 & 72 & 95 & 88 & 57 & 85 & 57 \\
\hline & 93 & 90 & 80 & 83 & 81 & 95 & 76 & 94 & 79 & 58 & 81 & 71 \\
\hline & 90 & 97 & 79 & 81 & 89 & 97 & 80 & 96 & 86 & 66 & 85 & 57 \\
\hline
\end{tabular}




\section{Appendix I. Raw Data: Wrist Data, CK Task 1}

\section{Wrist Data for Conventional Keyboard Condition, Task 1}

\begin{tabular}{|r|l|l|l|l|r|r|r|r|r|r|}
\hline & $\begin{array}{l}\mathrm{F} / \mathrm{E} \\
\text { Mean }\end{array}$ & $\begin{array}{l}\mathrm{R} / \mathrm{U} \\
\text { Mean }\end{array}$ & $\begin{array}{l}\mathrm{F} / \mathrm{E} \\
0-10 \\
\%\end{array}$ & $\begin{array}{l}\mathrm{R} / \mathrm{U} \\
0-10 \\
\%\end{array}$ & $\begin{array}{l}\mathrm{F} / \mathrm{E} \\
>10- \\
15 \%\end{array}$ & $\begin{array}{l}\mathrm{R} / \mathrm{U}> \\
10- \\
15 \%\end{array}$ & $\begin{array}{l}\mathrm{F} / \mathrm{E} \\
>15- \\
20 \%\end{array}$ & $\begin{array}{l}\mathrm{R} / \mathrm{U} \\
>15- \\
20 \%\end{array}$ & $\begin{array}{l}\mathrm{F} / \mathrm{E} \\
>20\end{array} \%$ & $\begin{array}{l}\mathrm{R} / \mathrm{U} \\
>20 \\
\%\end{array}$ \\
\hline $2 \mathrm{~F}$ & 26.52 & 3.77 & 0.13 & 92.60 & 0.37 & 3.83 & 5.20 & 2.87 & 94.30 & 0.70 \\
\hline $3 \mathrm{~F}$ & 26.73 & 11.04 & 0.00 & 37.40 & 0.00 & 55.73 & 3.00 & 6.80 & 97.00 & 0.07 \\
\hline $4 \mathrm{~F}$ & 17.64 & 31.13 & 2.13 & 0.50 & 11.63 & 0.03 & 70.23 & 0.03 & 16.00 & 99.43 \\
\hline $5 \mathrm{~F}$ & 20.34 & 10.95 & 7.93 & 39.57 & 17.57 & 44.97 & 31.63 & 15.10 & 42.87 & 0.37 \\
\hline $6 \mathrm{~F}$ & 15.05 & 25.01 & 9.70 & 0.00 & 27.27 & 0.07 & 60.87 & 3.03 & 2.17 & 96.90 \\
\hline $7 \mathrm{M}$ & 21.88 & 18.15 & 0.73 & 1.30 & 3.83 & 9.90 & 25.03 & 65.77 & 70.40 & 23.03 \\
\hline $8 \mathrm{M}$ & 45.09 & 4.60 & 0.00 & 90.37 & 0.00 & 8.20 & 0.00 & 1.13 & 100.00 & 0.30 \\
\hline $9 \mathrm{M}$ & 14.64 & 14.56 & 7.03 & 3.83 & 47.90 & 54.60 & 43.07 & 41.13 & 2.00 & 0.43 \\
\hline $10 \mathrm{M}$ & 18.85 & 15.62 & 0.53 & 5.43 & 11.23 & 33.37 & 59.20 & 54.03 & 29.03 & 7.17 \\
\hline $11 \mathrm{M}$ & 25.77 & 22.64 & 0.00 & 0.00 & 1.10 & 0.00 & 8.63 & 21.60 & 90.27 & 78.40 \\
\hline $12 \mathrm{M}$ & 42.90 & 10.73 & 4.23 & 50.20 & 0.80 & 13.73 & 0.80 & 30.97 & 94.17 & 5.10 \\
\hline
\end{tabular}


Appendix J. Raw Data: Wrist Data, CK Task 2

Wrist Data for Conventional Keyboard Condition, Task 2

\begin{tabular}{|c|c|c|c|c|c|c|c|c|c|c|}
\hline & $\begin{array}{r}\mathrm{F} / \mathrm{E} \\
\text { Mean }\end{array}$ & $\begin{array}{r}\mathrm{R} / \mathrm{U} \\
\text { Mean }\end{array}$ & $\begin{array}{r}\mathrm{F} / \mathrm{E} \\
0-10 \\
\%\end{array}$ & $\begin{array}{r}\mathrm{R} / \mathrm{U} \\
0-10 \\
\%\end{array}$ & $\begin{array}{r}\mathrm{F} / \mathrm{E} \\
>10- \\
15 \%\end{array}$ & $\begin{array}{c}\mathrm{R} / \mathrm{U} \\
>10- \\
15 \%\end{array}$ & $\begin{array}{r}\mathrm{F} / \mathrm{E}> \\
15- \\
20 \%\end{array}$ & $\begin{array}{r}\mathrm{R} / \mathrm{U}> \\
15- \\
20 \%\end{array}$ & $\begin{array}{r}\mathrm{F} / \mathrm{E} \\
>20 \%\end{array}$ & $\begin{array}{r}\mathrm{R} / \mathrm{U} \\
>20 \%\end{array}$ \\
\hline $1 \mathrm{~F}$ & 26.05 & 15.70 & 0.93 & 0.90 & 3.23 & 34.57 & 10.83 & 60.70 & 85.00 & 3.83 \\
\hline $2 \mathrm{~F}$ & 23.60 & 4.19 & 1.30 & 91.90 & 2.93 & 4.87 & 17.67 & 2.33 & 78.10 & 0.90 \\
\hline $3 \mathrm{~F}$ & 27.89 & 10.80 & 0.00 & 38.43 & 0.00 & 56.47 & 1.93 & 4.90 & 98.07 & 0.20 \\
\hline $4 \mathrm{~F}$ & 25.27 & 35.19 & 0.17 & 0.00 & 0.10 & 0.07 & 4.13 & 0.13 & 95.60 & 99.80 \\
\hline $5 \mathrm{~F}$ & 17.76 & 12.81 & 4.23 & 22.50 & 23.90 & 48.10 & 48.07 & 27.50 & 23.80 & 1.90 \\
\hline $6 \mathrm{~F}$ & 12.54 & 25.83 & 23.50 & 0.00 & 46.33 & 0.00 & 29.67 & 1.80 & 0.50 & 98.20 \\
\hline $7 \mathrm{M}$ & 21.64 & 17.84 & 1.30 & 0.93 & 5.00 & 12.77 & 26.20 & 64.87 & 67.50 & 21.43 \\
\hline $8 \mathrm{M}$ & 47.75 & 5.57 & 0.00 & 86.10 & 0.00 & 10.43 & 0.00 & 3.20 & 100.00 & 0.27 \\
\hline $9 \mathrm{M}$ & 15.52 & 13.14 & 6.03 & 7.13 & 35.83 & 78.07 & 49.50 & 14.07 & 8.63 & 0.73 \\
\hline $10 \mathrm{M}$ & 18.35 & 14.62 & 0.80 & 4.87 & 8.53 & 51.27 & 68.60 & 39.93 & 22.07 & 3.93 \\
\hline $11 \mathrm{M}$ & 18.06 & 8.39 & 16.37 & 74.03 & 17.27 & 18.50 & 22.33 & 3.30 & 44.03 & 4.17 \\
\hline $12 \mathrm{M}$ & 40.82 & 12.58 & 0.53 & 17.40 & 0.40 & 59.60 & 0.77 & 21.77 & 98.30 & 1.23 \\
\hline
\end{tabular}




\section{Appendix K. Raw Data: Wrist Data, CK Task 3}

\section{Wrist Data for Conventional Keyboard Condition, Task 3}

\begin{tabular}{|c|c|c|c|c|c|c|c|c|c|c|}
\hline & $\begin{array}{r}\mathrm{F} / \mathrm{E} \\
\text { Mean }\end{array}$ & $\begin{array}{r}\mathrm{R} / \mathrm{U} \\
\text { Mean }\end{array}$ & $\begin{array}{r}\mathrm{F} / \mathrm{E} \\
0-10 \\
\%\end{array}$ & $\begin{array}{r}\mathrm{R} / \mathrm{U} \\
0-10 \\
\%\end{array}$ & $\begin{array}{r}\mathrm{F} / \mathrm{E} \\
>10- \\
15 \%\end{array}$ & $\begin{array}{c}\mathrm{R} / \mathrm{U} \\
>10- \\
15 \%\end{array}$ & $\begin{array}{r}\mathrm{F} / \mathrm{E} \\
>15- \\
20 \%\end{array}$ & $\begin{array}{c}\mathrm{R} / \mathrm{U} \\
>15- \\
20 \%\end{array}$ & $\begin{array}{r}\mathrm{F} / \mathrm{E} \\
>20 \%\end{array}$ & $\begin{array}{r}\mathrm{R} / \mathrm{U} \\
>20 \%\end{array}$ \\
\hline $1 \mathrm{~F}$ & 23.55 & 16.21 & 0.57 & 0.80 & 4.13 & 28.30 & 18.60 & 64.57 & 76.70 & 6.33 \\
\hline $2 \mathrm{~F}$ & 23.00 & 7.20 & 0.20 & 76.60 & 3.67 & 11.87 & 22.83 & 7.47 & 73.30 & 4.07 \\
\hline $3 \mathrm{~F}$ & 25.58 & 13.65 & 0.00 & 9.37 & 0.33 & 60.00 & 7.70 & 29.17 & 91.97 & 1.47 \\
\hline $4 \mathrm{~F}$ & 20.05 & 34.30 & 14.47 & 0.00 & 5.07 & 0.00 & 8.93 & 0.17 & 71.53 & 99.83 \\
\hline $5 \mathrm{~F}$ & 20.81 & 12.07 & 3.80 & 30.30 & 19.17 & 40.43 & 37.33 & 25.93 & 39.70 & 3.33 \\
\hline $6 \mathrm{~F}$ & 15.32 & 25.59 & 19.40 & 0.00 & 21.30 & 0.23 & 42.93 & 3.40 & 16.37 & 96.37 \\
\hline $7 \mathrm{M}$ & 20.98 & 16.34 & 11.47 & 12.23 & 6.60 & 14.63 & 13.97 & 54.53 & 67.97 & 18.60 \\
\hline $8 \mathrm{M}$ & 43.10 & 3.96 & 0.00 & 92.47 & 0.03 & 5.63 & 0.13 & 1.67 & 99.83 & 0.23 \\
\hline $9 \mathrm{M}$ & 17.72 & 15.02 & 2.70 & 5.57 & 15.37 & 51.03 & 58.67 & 36.17 & 23.27 & 7.23 \\
\hline $10 \mathrm{M}$ & 18.81 & 11.53 & 0.90 & 33.10 & 8.70 & 55.87 & 61.17 & 10.33 & 29.23 & 0.70 \\
\hline $11 \mathrm{M}$ & 22.70 & 20.80 & 0.07 & 0.27 & 2.83 & 1.00 & 16.43 & 48.27 & 72.33 & 42.13 \\
\hline $12 \mathrm{M}$ & 34.73 & 17.10 & 1.43 & 2.70 & 0.07 & 17.77 & 0.57 & 68.30 & 97.93 & 11.23 \\
\hline
\end{tabular}




\section{Appendix L. Raw Data: Wrist Data, CK Task 4}

\section{Wrist Data for Conventional Keyboard Condition, Task 4}

\begin{tabular}{|r|r|r|r|r|r|r|r|r|r|r|}
\hline & F/E & $\begin{array}{r}\mathrm{R} / \mathrm{U} \\
\text { Mean }\end{array}$ & $\begin{array}{r}\mathrm{F} / \mathrm{E} \\
0-10 \\
\%\end{array}$ & $\begin{array}{r}\mathrm{R} / \mathrm{U} \\
0-10 \\
\%\end{array}$ & $\begin{array}{r}\mathrm{F} / \mathrm{E} \\
>10- \\
15 \%\end{array}$ & $\begin{array}{r}\mathrm{R} / \mathrm{U} \\
>10- \\
15 \%\end{array}$ & $\begin{array}{r}\mathrm{F} / \mathrm{E} \\
>15- \\
20 \%\end{array}$ & $\begin{array}{r}\mathrm{R} / \mathrm{U} \\
>15- \\
20 \%\end{array}$ & $\begin{array}{r}\mathrm{F} / \mathrm{E} \\
>20 \%\end{array}$ & $\begin{array}{r}\mathrm{R} / \mathrm{U} \\
>20 \%\end{array}$ \\
\hline $1 \mathrm{~F}$ & 22.91 & 15.90 & 0.33 & 0.03 & 4.23 & 35.83 & 21.53 & 60.20 & 73.90 & 3.93 \\
\hline $2 \mathrm{~F}$ & 21.47 & 5.69 & 3.63 & 85.50 & 9.03 & 6.43 & 25.53 & 4.10 & 61.80 & 3.97 \\
\hline $3 \mathrm{~F}$ & 22.91 & 15.90 & 0.33 & 0.03 & 4.23 & 35.83 & 21.53 & 60.20 & 73.90 & 3.93 \\
\hline $4 \mathrm{~F}$ & 17.68 & 35.74 & 17.67 & 0.00 & 14.27 & 0.00 & 16.53 & 0.07 & 51.53 & 99.93 \\
\hline $5 \mathrm{~F}$ & 13.20 & 15.45 & 23.63 & 7.27 & 41.10 & 34.83 & 30.30 & 50.27 & 4.97 & 7.63 \\
\hline $6 \mathrm{~F}$ & 17.13 & 24.43 & 9.57 & 0.23 & 15.57 & 0.50 & 50.37 & 7.80 & 24.50 & 91.47 \\
\hline $7 \mathrm{M}$ & 21.79 & 16.90 & 2.10 & 4.83 & 6.40 & 17.47 & 23.50 & 61.27 & 68.00 & 16.43 \\
\hline $8 \mathrm{M}$ & 40.31 & 5.09 & 7.83 & 85.93 & 0.20 & 8.33 & 1.63 & 5.60 & 90.33 & 0.13 \\
\hline $9 \mathrm{M}$ & 18.40 & 14.53 & 1.93 & 5.17 & 11.43 & 56.87 & 59.20 & 35.20 & 27.43 & 2.77 \\
\hline $10 \mathrm{M}$ & 22.38 & 13.78 & 0.07 & 8.57 & 1.03 & 62.90 & 14.50 & 25.33 & 84.40 & 3.20 \\
\hline $11 \mathrm{M}$ & 28.22 & 21.53 & 0.07 & 0.47 & 0.07 & 3.40 & 2.17 & 31.67 & 97.70 & 64.47 \\
\hline $12 \mathrm{M}$ & 38.24 & 12.27 & 0.20 & 22.57 & 0.27 & 54.07 & 2.37 & 21.63 & 97.17 & 1.73 \\
\hline
\end{tabular}




\section{Appendix M. Raw Data: Wrist Data, CK Task 5}

\section{Wrist Data for Conventional Keyboard Condition, Task 5}

\begin{tabular}{|c|c|c|c|c|c|c|c|c|c|c|}
\hline & $\begin{array}{r}\mathrm{F} / \mathrm{E} \\
\text { Mean }\end{array}$ & $\begin{array}{r}\mathrm{R} / \mathrm{U} \\
\text { Mean }\end{array}$ & $\begin{array}{r}\mathrm{F} / \mathrm{E} \\
0-10 \\
\%\end{array}$ & $\begin{array}{r}\mathrm{R} / \mathrm{U} \\
0-10 \\
\%\end{array}$ & $\begin{array}{r}\mathrm{F} / \mathrm{E} \\
>10- \\
15 \%\end{array}$ & $\begin{array}{r}\mathrm{R} / \mathrm{U} \\
>10- \\
15 \%\end{array}$ & $\begin{array}{r}\mathrm{F} / \mathrm{E} \\
>15- \\
20 \%\end{array}$ & $\begin{array}{l}\mathrm{R} / \mathrm{U} \\
>15- \\
20 \%\end{array}$ & $\begin{array}{r}\mathrm{F} / \mathrm{E} \\
>20 \%\end{array}$ & $\begin{array}{r}\mathrm{R} / \mathrm{U} \\
>20 \%\end{array}$ \\
\hline $1 \mathrm{~F}$ & 16.28 & 16.37 & 10.73 & 0.07 & 24.43 & 24.47 & 47.53 & 70.00 & 17.30 & 5.47 \\
\hline $2 \mathrm{~F}$ & 20.28 & 12.12 & 4.80 & 45.93 & 8.73 & 29.37 & 33.73 & 11.97 & 52.73 & 12.73 \\
\hline $3 \mathrm{~F}$ & 27.49 & 12.07 & 0.00 & 21.73 & 0.10 & 65.73 & 2.53 & 11.07 & 97.37 & 1.47 \\
\hline $4 \mathrm{~F}$ & 22.41 & 37.64 & 0.63 & 0.00 & 1.47 & 0.00 & 12.50 & 0.00 & 85.40 & 100.00 \\
\hline $5 \mathrm{~F}$ & 13.27 & 15.54 & 23.23 & 7.23 & 40.63 & 34.23 & 31.07 & 49.90 & 5.07 & 8.63 \\
\hline $6 \mathrm{~F}$ & 18.66 & 28.15 & 4.50 & 0.33 & 11.67 & 1.40 & 44.83 & 7.17 & 39.00 & 91.10 \\
\hline $7 \mathrm{M}$ & 24.51 & 20.68 & 1.30 & 2.60 & 1.97 & 2.73 & 11.47 & 39.70 & 85.27 & 54.97 \\
\hline $8 \mathrm{M}$ & 40.19 & 4.89 & 0.03 & 90.43 & 0.83 & 7.67 & 0.90 & 1.27 & 98.23 & 0.63 \\
\hline $9 \mathrm{M}$ & 20.09 & 16.37 & 1.40 & 2.20 & 5.53 & 17.33 & 40.30 & 76.00 & 52.77 & 4.47 \\
\hline $10 \mathrm{M}$ & 19.47 & 15.07 & 0.53 & 3.67 & 5.33 & 47.60 & 56.13 & 43.90 & 38.00 & 4.83 \\
\hline $11 \mathrm{M}$ & 26.88 & 20.00 & 0.37 & 1.03 & 0.43 & 8.17 & 4.83 & 50.17 & 91.03 & 37.30 \\
\hline $12 \mathrm{M}$ & 31.50 & 15.07 & 6.47 & 18.47 & 2.77 & 16.17 & 5.87 & 57.27 & 84.90 & 8.10 \\
\hline
\end{tabular}




\section{Appendix N. Raw Data: Wrist Data, CK Task 6}

\section{Wrist Data for Conventional Keyboard Condition, Task 6}

\begin{tabular}{|r|r|r|r|r|r|r|r|r|r|r|}
\hline & $\begin{array}{r}\mathrm{F} / \mathrm{E} \\
\text { Mean }\end{array}$ & $\begin{array}{r}\mathrm{R} / \mathrm{U} \\
\mathrm{Mean}\end{array}$ & $\begin{array}{r}\mathrm{F} / \mathrm{E} \\
0-10 \\
\%\end{array}$ & $\begin{array}{r}\mathrm{R} / \mathrm{U} \\
0-10 \\
\%\end{array}$ & $\begin{array}{r}\mathrm{F} / \mathrm{E} \\
>10- \\
15 \%\end{array}$ & $\begin{array}{r}\mathrm{R} / \mathrm{U} \\
>10- \\
15 \%\end{array}$ & $\begin{array}{r}\mathrm{F} / \mathrm{E} \\
>15- \\
20 \%\end{array}$ & $\begin{array}{r}\mathrm{R} / \mathrm{U} \\
>15- \\
20 \%\end{array}$ & $\begin{array}{r}\mathrm{F} / \mathrm{E} \\
>20 \%\end{array}$ & $\begin{array}{r}\mathrm{R} / \mathrm{U} \\
>20 \%\end{array}$ \\
\hline $1 \mathrm{~F}$ & 19.88 & 19.37 & 4.13 & 0.07 & 12.23 & 1.37 & 38.80 & 70.10 & 44.83 & 28.47 \\
\hline $2 \mathrm{~F}$ & 23.19 & 8.39 & 0.83 & 68.30 & 2.13 & 16.57 & 21.63 & 7.23 & 75.40 & 7.90 \\
\hline $3 \mathrm{~F}$ & 26.29 & 12.43 & 0.00 & 32.37 & 0.07 & 41.47 & 1.40 & 21.67 & 98.53 & 4.50 \\
\hline $4 \mathrm{~F}$ & 23.10 & 37.29 & 1.57 & 0.77 & 5.73 & 2.57 & 9.90 & 0.77 & 82.80 & 95.90 \\
\hline $5 \mathrm{~F}$ & 13.81 & 14.44 & 18.47 & 13.90 & 45.00 & 39.60 & 29.37 & 39.67 & 7.17 & 6.83 \\
\hline $6 \mathrm{~F}$ & 17.39 & 23.99 & 7.90 & 0.00 & 15.17 & 1.07 & 49.43 & 7.70 & 27.50 & 91.23 \\
\hline $7 \mathrm{M}$ & 22.70 & 21.61 & 0.50 & 0.23 & 3.50 & 1.20 & 20.83 & 31.50 & 75.17 & 67.07 \\
\hline $8 \mathrm{M}$ & 44.62 & 4.27 & 0.10 & 92.13 & 0.07 & 6.47 & 0.10 & 1.33 & 99.73 & 0.07 \\
\hline $9 \mathrm{M}$ & 21.29 & 14.94 & 0.63 & 4.43 & 3.53 & 47.83 & 25.33 & 43.87 & 70.50 & 3.87 \\
\hline $10 \mathrm{M}$ & 19.85 & 11.90 & 0.30 & 23.10 & 4.27 & 64.87 & 51.13 & 11.87 & 44.30 & 0.17 \\
\hline $11 \mathrm{M}$ & 26.78 & 20.33 & 0.37 & 1.00 & 0.43 & 4.33 & 4.77 & 48.10 & 84.43 & 36.57 \\
\hline $12 \mathrm{M}$ & 41.42 & 6.66 & 2.57 & 76.83 & 1.63 & 20.50 & 1.43 & 1.60 & 94.37 & 1.07 \\
\hline
\end{tabular}




\section{Appendix O. Raw Data: Wrist Data, CK Task 7}

\section{Wrist Data for Conventional Keyboard Condition, Task 7}

\begin{tabular}{|c|c|c|c|c|c|c|c|c|c|c|}
\hline & $\begin{array}{r}\mathrm{F} / \mathrm{E} \\
\text { Mean }\end{array}$ & $\begin{array}{r}\mathrm{R} / \mathrm{U} \\
\text { Mean }\end{array}$ & $\begin{array}{r}\mathrm{F} / \mathrm{E} \\
0-10 \\
\%\end{array}$ & $\begin{array}{r}\mathrm{R} / \mathrm{U} \\
0-10 \\
\%\end{array}$ & $\begin{array}{r}\mathrm{F} / \mathrm{E} \\
>10- \\
15 \%\end{array}$ & $\begin{array}{c}\mathrm{R} / \mathrm{U} \\
>10- \\
15 \%\end{array}$ & $\begin{array}{r}\mathrm{F} / \mathrm{E} \\
>15- \\
20 \%\end{array}$ & $\begin{array}{c}\mathrm{R} / \mathrm{U} \\
>15- \\
20 \%\end{array}$ & $\begin{array}{r}\mathrm{F} / \mathrm{E} \\
>20 \%\end{array}$ & $\begin{array}{r}\mathrm{R} / \mathrm{U} \\
>20 \%\end{array}$ \\
\hline $1 \mathrm{~F}$ & 16.96 & 21.17 & 10.37 & 0.00 & 23.20 & 0.00 & 42.67 & 38.83 & 23.77 & 61.17 \\
\hline $2 \mathrm{~F}$ & 19.71 & 6.81 & 0.77 & 78.23 & 10.37 & 9.47 & 49.50 & 5.60 & 39.37 & 6.70 \\
\hline $3 \mathrm{~F}$ & 26.57 & 13.21 & 0.00 & 28.80 & 0.03 & 34.77 & 2.43 & 27.80 & 97.53 & 8.63 \\
\hline $4 \mathrm{~F}$ & 8.76 & 33.10 & 66.13 & 0.00 & 30.70 & 0.03 & 2.90 & 0.20 & 0.27 & 99.77 \\
\hline $5 \mathrm{~F}$ & 14.45 & 14.81 & 18.20 & 10.63 & 37.40 & 39.27 & 32.83 & 43.17 & 11.57 & 6.93 \\
\hline $6 \mathrm{~F}$ & 18.06 & 21.51 & 11.47 & 3.50 & 9.87 & 7.13 & 28.77 & 18.00 & 43.23 & 64.70 \\
\hline $7 \mathrm{M}$ & 23.95 & 23.73 & 0.20 & 0.13 & 2.50 & 0.43 & 15.80 & 15.07 & 81.50 & 84.37 \\
\hline $8 \mathrm{M}$ & 41.56 & 6.91 & 0.00 & 77.10 & 0.07 & 16.10 & 0.10 & 6.00 & 99.83 & 0.80 \\
\hline $9 \mathrm{M}$ & 23.54 & 13.06 & 0.70 & 10.77 & 1.70 & 70.53 & 11.03 & 17.47 & 86.57 & 1.23 \\
\hline $10 \mathrm{M}$ & 20.28 & 10.33 & 0.00 & 53.90 & 1.67 & 39.43 & 44.37 & 6.67 & 53.97 & 0.00 \\
\hline $11 \mathrm{M}$ & 26.23 & 18.06 & 0.00 & 0.10 & 0.10 & 14.43 & 5.60 & 65.57 & 94.30 & 19.90 \\
\hline $12 \mathrm{M}$ & 30.31 & 15.33 & 0.13 & 18.17 & 0.43 & 23.63 & 2.50 & 44.93 & 96.93 & 13.27 \\
\hline
\end{tabular}




\section{Appendix P. Raw Data: Wrist Data, CK Task 8}

\section{Wrist Data for Conventional Keyboard Condition, Task 8}

\begin{tabular}{|r|r|r|r|r|r|r|r|r|r|r|}
\hline & $\begin{array}{r}\mathrm{F} / \mathrm{E} \\
\text { Mean }\end{array}$ & $\begin{array}{r}\mathrm{R} / \mathrm{U} \\
\mathrm{Mean}\end{array}$ & $\begin{array}{r}\mathrm{F} / \mathrm{E} \\
0-10 \\
\%\end{array}$ & $\begin{array}{r}\mathrm{R} / \mathrm{U} \\
0-10 \\
\%\end{array}$ & $\begin{array}{r}\mathrm{F} / \mathrm{E} \\
>10- \\
15 \%\end{array}$ & $\begin{array}{r}\mathrm{R} / \mathrm{U} \\
>10- \\
15 \%\end{array}$ & $\begin{array}{r}\mathrm{F} / \mathrm{E} \\
>15- \\
20 \%\end{array}$ & $\begin{array}{r}\mathrm{R} / \mathrm{U} \\
>15 \\
20 \%\end{array}$ & $\begin{array}{r}\mathrm{F} / \mathrm{E} \\
>20 \%\end{array}$ & $\begin{array}{r}\mathrm{R} / \mathrm{U} \\
>20 \%\end{array}$ \\
\hline $1 \mathrm{~F}$ & 17.27 & 22.06 & 8.93 & 2.93 & 23.53 & 0.67 & 42.63 & 12.20 & 24.90 & 84.20 \\
\hline $2 \mathrm{~F}$ & 22.94 & 12.58 & 0.23 & 40.70 & 3.37 & 30.63 & 25.60 & 15.00 & 70.80 & 13.67 \\
\hline $3 \mathrm{~F}$ & 23.68 & 21.08 & 0.00 & 0.90 & 0.63 & 2.43 & 9.50 & 41.10 & 89.87 & 55.57 \\
\hline $4 \mathrm{~F}$ & 23.37 & 36.63 & 2.40 & 0.00 & 14.20 & 0.00 & 7.27 & 0.00 & 76.13 & 100.00 \\
\hline $5 \mathrm{~F}$ & 13.29 & 14.84 & 26.90 & 12.60 & 43.23 & 36.83 & 21.53 & 42.33 & 8.33 & 8.23 \\
\hline $6 \mathrm{~F}$ & 19.09 & 19.91 & 3.70 & 1.67 & 10.23 & 11.50 & 44.10 & 36.90 & 41.97 & 49.93 \\
\hline $7 \mathrm{M}$ & 23.90 & 23.53 & 0.13 & 0.10 & 2.20 & 0.40 & 14.77 & 14.53 & 82.90 & 84.97 \\
\hline $8 \mathrm{M}$ & 40.09 & 8.97 & 0.23 & 62.00 & 0.67 & 23.93 & 1.23 & 10.70 & 97.87 & 3.37 \\
\hline $9 \mathrm{M}$ & 23.72 & 11.19 & 0.90 & 28.93 & 1.73 & 65.77 & 12.77 & 5.27 & 84.60 & 0.03 \\
\hline $10 \mathrm{M}$ & 18.19 & 13.24 & 0.97 & 12.87 & 10.07 & 60.83 & 69.27 & 25.20 & 19.70 & 1.10 \\
\hline $11 \mathrm{M}$ & 26.12 & 18.23 & 0.00 & 0.07 & 0.10 & 10.13 & 5.00 & 58.40 & 81.57 & 18.07 \\
\hline 32.11 & 16.99 & 1.10 & 10.23 & 0.80 & 16.27 & 2.03 & 49.27 & 96.07 & 24.23 \\
\hline
\end{tabular}




\section{Appendix Q. Raw Data: Wrist Data, MTK Task 1}

\section{Wrist Data for MTK Condition, Task 1}

\begin{tabular}{|r|r|r|r|r|r|r|r|r|r|r|}
\hline & $\begin{array}{r}\mathrm{F} / \mathrm{E} \\
\mathrm{Mean}\end{array}$ & $\begin{array}{r}\mathrm{R} / \mathrm{U} \\
\mathrm{Mean}\end{array}$ & $\begin{array}{r}\mathrm{F} / \mathrm{E} \\
0-10 \\
\%\end{array}$ & $\begin{array}{r}\mathrm{R} / \mathrm{U} \\
0-10 \\
\%\end{array}$ & $\begin{array}{r}\mathrm{F} / \mathrm{E} \\
>10- \\
15 \%\end{array}$ & $\begin{array}{r}\mathrm{R} / \mathrm{U} \\
>10- \\
15 \%\end{array}$ & $\begin{array}{r}\mathrm{F} / \mathrm{E} \\
>15- \\
20 \%\end{array}$ & $\begin{array}{r}\mathrm{R} / \mathrm{U} \\
>15- \\
20 \%\end{array}$ & $\begin{array}{r}\mathrm{F} / \mathrm{E} \\
>20 \%\end{array}$ & $\begin{array}{r}\mathrm{R} / \mathrm{U} \\
>20 \%\end{array}$ \\
\hline $1 \mathrm{~F}$ & 25.24 & 2.08 & 1.30 & 99.50 & 7.10 & 0.40 & 19.13 & 0.10 & 72.47 & 0.00 \\
\hline $2 \mathrm{~F}$ & 16.73 & 11.01 & 21.07 & 44.03 & 25.83 & 29.77 & 20.47 & 21.03 & 32.63 & 5.17 \\
\hline $3 \mathrm{~F}$ & 11.46 & 7.37 & 40.20 & 82.20 & 41.47 & 14.73 & 15.27 & 2.43 & 3.07 & 0.63 \\
\hline $4 \mathrm{~F}$ & 9.27 & 20.34 & 58.93 & 5.47 & 31.73 & 7.40 & 7.80 & 38.20 & 1.53 & 48.93 \\
\hline $5 \mathrm{~F}$ & 14.15 & 15.89 & 28.13 & 19.80 & 29.70 & 26.03 & 21.10 & 23.37 & 21.07 & 30.80 \\
\hline $6 \mathrm{~F}$ & 7.07 & 14.40 & 68.43 & 10.43 & 17.00 & 35.63 & 5.83 & 47.43 & 5.40 & 3.17 \\
\hline $7 \mathrm{M}$ & 27.13 & 26.13 & 2.50 & 0.97 & 2.90 & 2.17 & 8.77 & 7.37 & 85.83 & 89.50 \\
\hline $8 \mathrm{M}$ & 29.81 & 6.57 & 0.00 & 78.77 & 0.90 & 12.97 & 4.27 & 6.27 & 94.83 & 2.00 \\
\hline $9 \mathrm{M}$ & 19.99 & 13.67 & 2.77 & 14.67 & 5.17 & 53.07 & 41.60 & 27.73 & 50.47 & 4.53 \\
\hline $10 \mathrm{M}$ & 9.18 & 11.54 & 57.43 & 35.17 & 33.00 & 49.30 & 9.03 & 14.63 & 0.53 & 0.90 \\
\hline $11 \mathrm{M}$ & 11.84 & 13.46 & 37.77 & 8.60 & 42.83 & 66.17 & 14.20 & 23.87 & 5.20 & 1.37 \\
\hline $12 \mathrm{M}$ & 25.07 & 2.51 & 0.23 & 98.77 & 3.23 & 0.87 & 10.87 & 0.37 & 85.67 & 0.00 \\
\hline
\end{tabular}




\section{Appendix R. Raw Data: Wrist Data, MTK Task 2}

\section{Wrist Data for MTK Condition, Task 2}

\begin{tabular}{|r|r|r|r|r|r|r|r|r|r|r|}
\hline & $\begin{array}{r}\mathrm{F} / \mathrm{E} \\
\text { Mean }\end{array}$ & $\begin{array}{r}\mathrm{R} / \mathrm{U} \\
\mathrm{Mean}\end{array}$ & $\begin{array}{r}\mathrm{F} / \mathrm{E} \\
0-10 \\
\%\end{array}$ & $\begin{array}{r}\mathrm{R} / \mathrm{U} \\
0-10 \\
\%\end{array}$ & $\begin{array}{r}\mathrm{F} / \mathrm{E} \\
>10- \\
15 \%\end{array}$ & $\begin{array}{r}\mathrm{R} / \mathrm{U} \\
>10- \\
15 \%\end{array}$ & $\begin{array}{r}\mathrm{F} / \mathrm{E} \\
>15- \\
20 \%\end{array}$ & $\begin{array}{r}\mathrm{R} / \mathrm{U} \\
>15- \\
20 \%\end{array}$ & $\begin{array}{r}\mathrm{F} / \mathrm{E} \\
>20 \%\end{array}$ & $\begin{array}{r}\mathrm{R} / \mathrm{U} \\
>20 \%\end{array}$ \\
\hline $1 \mathrm{~F}$ & 23.45 & 3.63 & 1.90 & 97.70 & 11.73 & 2.03 & 23.93 & 0.27 & 62.43 & 0.00 \\
\hline $2 \mathrm{~F}$ & 12.69 & 13.64 & 36.07 & 29.33 & 35.67 & 27.33 & 16.80 & 28.50 & 11.47 & 14.83 \\
\hline $3 \mathrm{~F}$ & 10.95 & 10.24 & 46.10 & 51.33 & 36.53 & 43.27 & 14.60 & 4.63 & 2.77 & 0.77 \\
\hline $4 \mathrm{~F}$ & 12.21 & 20.61 & 28.00 & 0.57 & 49.43 & 5.53 & 20.27 & 38.60 & 2.30 & 55.30 \\
\hline $5 \mathrm{~F}$ & 9.42 & 15.74 & 59.23 & 20.83 & 22.03 & 26.47 & 11.57 & 27.67 & 7.17 & 25.03 \\
\hline $6 \mathrm{~F}$ & 6.25 & 19.91 & 78.67 & 0.40 & 16.40 & 4.23 & 4.73 & 46.80 & 0.20 & 48.57 \\
\hline $7 \mathrm{M}$ & 29.51 & 23.17 & 1.03 & 0.87 & 1.60 & 4.67 & 4.93 & 17.13 & 92.43 & 77.33 \\
\hline $8 \mathrm{M}$ & 29.80 & 6.54 & 0.13 & 79.57 & 1.03 & 12.43 & 4.60 & 6.00 & 94.23 & 2.00 \\
\hline $9 \mathrm{M}$ & 20.14 & 13.15 & 1.63 & 17.63 & 5.27 & 60.13 & 43.73 & 17.27 & 49.37 & 4.97 \\
\hline $10 \mathrm{M}$ & 9.69 & 8.21 & 58.00 & 78.87 & 33.67 & 17.20 & 7.27 & 3.43 & 1.07 & 0.50 \\
\hline $11 \mathrm{M}$ & 18.06 & 8.39 & 16.37 & 74.03 & 17.27 & 18.50 & 22.33 & 3.30 & 44.03 & 4.17 \\
\hline $12 \mathrm{M}$ & 30.01 & 7.98 & 0.00 & 72.03 & 0.03 & 22.60 & 1.23 & 3.73 & 98.73 & 1.63 \\
\hline
\end{tabular}




\section{Appendix S. Raw Data: Wrist Data, MTK Task 3}

Wrist Data for MTK Condition, Task 3

\begin{tabular}{|r|r|r|r|r|r|r|r|r|r|r|}
\hline & $\begin{array}{r}\mathrm{F} / \mathrm{E} \\
\mathrm{Mean}\end{array}$ & $\begin{array}{r}\mathrm{R} / \mathrm{U} \\
\mathrm{Mean}\end{array}$ & $\begin{array}{r}\mathrm{F} / \mathrm{E} \\
0-10 \\
\%\end{array}$ & $\begin{array}{r}\mathrm{R} / \mathrm{U} \\
0-10 \\
\%\end{array}$ & $\begin{array}{r}\mathrm{F} / \mathrm{E} \\
>10- \\
15 \%\end{array}$ & $\begin{array}{r}\mathrm{R} / \mathrm{U} \\
>10- \\
15 \%\end{array}$ & $\begin{array}{r}\mathrm{F} / \mathrm{E} \\
>15- \\
20 \%\end{array}$ & $\begin{array}{r}\mathrm{R} / \mathrm{U} \\
>15- \\
20 \%\end{array}$ & $\begin{array}{r}\mathrm{F} / \mathrm{E} \\
>20 \%\end{array}$ & $\begin{array}{r}\mathrm{R} / \mathrm{U} \\
>20 \%\end{array}$ \\
\hline $1 \mathrm{~F}$ & 27.35 & 4.69 & 1.17 & 92.53 & 4.30 & 6.43 & 13.80 & 1.03 & 80.73 & 0.00 \\
\hline $2 \mathrm{~F}$ & 10.45 & 12.67 & 54.27 & 30.80 & 26.13 & 36.20 & 13.17 & 27.83 & 6.43 & 5.17 \\
\hline $3 \mathrm{~F}$ & 10.69 & 14.11 & 58.50 & 14.93 & 29.27 & 46.67 & 5.23 & 31.00 & 7.00 & 7.40 \\
\hline $4 \mathrm{~F}$ & 13.65 & 21.28 & 20.70 & 1.47 & 42.70 & 3.77 & 30.87 & 36.17 & 5.73 & 58.60 \\
\hline $5 \mathrm{~F}$ & 10.73 & 15.55 & 49.63 & 20.03 & 26.57 & 30.57 & 17.80 & 27.20 & 6.00 & 22.20 \\
\hline $6 \mathrm{~F}$ & 9.47 & 21.86 & 56.90 & 0.03 & 21.70 & 0.47 & 17.73 & 22.50 & 3.67 & 77.00 \\
\hline $7 \mathrm{M}$ & 29.51 & 23.17 & 1.03 & 0.87 & 1.60 & 4.67 & 4.93 & 17.13 & 92.43 & 77.33 \\
\hline $8 \mathrm{M}$ & 28.64 & 5.59 & 0.17 & 85.17 & 1.23 & 12.13 & 6.30 & 2.60 & 92.30 & 0.10 \\
\hline $9 \mathrm{M}$ & 21.03 & 14.15 & 0.73 & 10.70 & 4.43 & 56.13 & 32.60 & 27.20 & 62.23 & 5.97 \\
\hline $10 \mathrm{M}$ & 9.74 & 10.55 & 54.37 & 48.67 & 35.13 & 39.03 & 10.00 & 10.60 & 0.50 & 1.70 \\
\hline $11 \mathrm{M}$ & 17.57 & 11.43 & 24.37 & 47.60 & 12.40 & 22.33 & 22.73 & 23.50 & 40.50 & 6.57 \\
\hline $12 \mathrm{M}$ & 28.52 & 2.98 & 0.07 & 96.47 & 0.63 & 2.80 & 2.03 & 0.33 & 97.27 & 0.40 \\
\hline
\end{tabular}


Appendix T. Raw Data: Wrist Data, MTK Task 4

Wrist Data for MTK Condition, Task 4

\begin{tabular}{|c|c|c|c|c|c|c|c|c|c|c|}
\hline & $\begin{array}{r}\mathrm{F} / \mathrm{E} \\
\text { Mean }\end{array}$ & $\begin{array}{r}\mathrm{R} / \mathrm{U} \\
\text { Mean }\end{array}$ & $\begin{array}{r}\mathrm{F} / \mathrm{E} \\
0-10 \\
\%\end{array}$ & $\begin{array}{r}\mathrm{R} / \mathrm{U} \\
0-10 \\
\%\end{array}$ & $\begin{array}{r}\mathrm{F} / \mathrm{E} \\
>10- \\
15 \%\end{array}$ & $\begin{array}{c}\mathrm{R} / \mathrm{U} \\
>10- \\
15 \%\end{array}$ & $\begin{array}{c}\mathrm{F} / \mathrm{E} \\
>15- \\
20 \%\end{array}$ & $\begin{array}{c}\mathrm{R} / \mathrm{U} \\
>15- \\
20 \%\end{array}$ & $\begin{array}{r}\mathrm{F} / \mathrm{E} \\
>20 \%\end{array}$ & $\begin{array}{r}\mathrm{R} / \mathrm{U} \\
>20 \%\end{array}$ \\
\hline $1 \mathrm{~F}$ & 36.36 & 7.94 & 4.10 & 70.90 & 8.30 & 9.67 & 17.77 & 14.63 & 69.83 & 4.80 \\
\hline $2 \mathrm{~F}$ & 11.54 & 17.09 & 43.87 & 11.83 & 32.80 & 22.03 & 16.40 & 37.00 & 6.93 & 29.13 \\
\hline $3 \mathrm{~F}$ & 8.72 & 12.39 & 71.67 & 29.87 & 21.53 & 44.60 & 3.50 & 22.87 & 3.30 & 2.67 \\
\hline $4 \mathrm{~F}$ & 9.60 & 25.40 & 57.20 & 0.37 & 34.30 & 1.07 & 7.80 & 7.73 & 0.70 & 90.83 \\
\hline $5 \mathrm{~F}$ & 8.70 & 16.72 & 63.93 & 15.30 & 20.90 & 20.43 & 11.53 & 35.33 & 3.63 & 28.93 \\
\hline $6 \mathrm{~F}$ & 11.23 & 20.89 & 41.83 & 0.00 & 27.23 & 0.00 & 25.40 & 35.63 & 5.53 & 64.37 \\
\hline $7 \mathrm{M}$ & 27.48 & 17.64 & 10.03 & 16.67 & 0.47 & 7.37 & 3.47 & 30.47 & 86.03 & 45.50 \\
\hline $8 \mathrm{M}$ & 26.43 & 3.92 & 0.80 & 96.13 & 1.03 & 3.30 & 7.77 & 0.43 & 90.40 & 0.13 \\
\hline $9 \mathrm{M}$ & 16.94 & 9.90 & 4.27 & 56.63 & 21.37 & 32.83 & 59.60 & 6.17 & 14.77 & 4.37 \\
\hline $10 \mathrm{M}$ & 10.58 & 9.31 & 45.97 & 60.53 & 38.73 & 32.67 & 14.27 & 6.47 & 1.03 & 0.33 \\
\hline $11 \mathrm{M}$ & 17.78 & 9.94 & 8.53 & 56.53 & 26.30 & 38.13 & 29.83 & 3.90 & 35.33 & 1.43 \\
\hline $12 \mathrm{M}$ & 26.87 & 4.13 & 0.03 & 96.33 & 1.00 & 2.40 & 3.10 & 0.80 & 95.87 & 0.47 \\
\hline
\end{tabular}




\section{Appendix U. Raw Data: Wrist Data, MTK Task 5}

Wrist Data for MTK Condition, Task 5

\begin{tabular}{|r|r|r|r|r|r|r|r|r|r|r|}
\hline & $\begin{array}{r}\mathrm{F} / \mathrm{E} \\
\text { Mean }\end{array}$ & $\begin{array}{r}\mathrm{R} / \mathrm{U} \\
\mathrm{Mean}\end{array}$ & $\begin{array}{r}\mathrm{F} / \mathrm{E} \\
0-10 \\
\%\end{array}$ & $\begin{array}{r}\mathrm{R} / \mathrm{U} \\
0-10 \\
\%\end{array}$ & $\begin{array}{r}\mathrm{F} / \mathrm{E} \\
>10- \\
15 \%\end{array}$ & $\begin{array}{r}\mathrm{R} / \mathrm{U} \\
>10- \\
15 \%\end{array}$ & $\begin{array}{r}\mathrm{F} / \mathrm{E} \\
>15- \\
20 \%\end{array}$ & $\begin{array}{r}\mathrm{R} / \mathrm{U} \\
>15- \\
20 \%\end{array}$ & $\begin{array}{r}\mathrm{F} / \mathrm{E} \\
>20 \%\end{array}$ & $\begin{array}{r}\mathrm{R} / \mathrm{U} \\
>20 \%\end{array}$ \\
\hline $1 \mathrm{~F}$ & 21.70 & 5.48 & 7.63 & 83.80 & 17.33 & 14.43 & 27.73 & 1.67 & 47.30 & 0.10 \\
\hline $2 \mathrm{~F}$ & 6.80 & 18.97 & 78.90 & 9.73 & 13.57 & 12.13 & 5.40 & 31.63 & 2.13 & 46.50 \\
\hline $3 \mathrm{~F}$ & 10.16 & 16.15 & 48.30 & 2.27 & 41.00 & 31.20 & 9.63 & 58.47 & 1.07 & 8.07 \\
\hline $4 \mathrm{~F}$ & 9.71 & 32.88 & 55.07 & 0.20 & 39.00 & 0.37 & 5.63 & 1.57 & 0.30 & 97.87 \\
\hline $5 \mathrm{~F}$ & 8.99 & 15.54 & 60.77 & 17.97 & 23.60 & 32.67 & 12.13 & 30.43 & 3.50 & 18.93 \\
\hline $6 \mathrm{~F}$ & 14.56 & 23.35 & 29.23 & 0.00 & 20.50 & 0.00 & 27.20 & 6.50 & 23.07 & 93.50 \\
\hline $7 \mathrm{M}$ & 30.94 & 19.06 & 1.20 & 7.87 & 1.90 & 9.70 & 5.43 & 32.37 & 91.47 & 50.07 \\
\hline $8 \mathrm{M}$ & 27.01 & 5.33 & 0.33 & 88.43 & 2.27 & 9.10 & 7.57 & 2.10 & 89.83 & 0.37 \\
\hline $9 \mathrm{M}$ & 16.10 & 10.11 & 9.80 & 49.63 & 26.93 & 40.53 & 47.20 & 8.03 & 16.07 & 1.80 \\
\hline $10 \mathrm{M}$ & 15.28 & 9.47 & 10.77 & 56.70 & 36.60 & 36.53 & 41.47 & 6.53 & 11.17 & 0.23 \\
\hline $11 \mathrm{M}$ & 13.61 & 10.18 & 20.40 & 59.77 & 43.60 & 31.70 & 28.97 & 6.53 & 7.03 & 2.00 \\
\hline $12 \mathrm{M}$ & 29.15 & 9.47 & 0.10 & 60.93 & 0.40 & 37.77 & 3.10 & 1.13 & 96.40 & 0.17 \\
\hline
\end{tabular}




\section{Appendix V. Raw Data: Wrist Data, MTK Task 6}

Wrist Data for MTK Condition, Task 6

\begin{tabular}{|r|r|r|r|r|r|r|r|r|r|r|}
\hline & $\begin{array}{r}\mathrm{F} / \mathrm{E} \\
\mathrm{Mean}\end{array}$ & $\begin{array}{r}\mathrm{R} / \mathrm{U} \\
\mathrm{Mean}\end{array}$ & $\begin{array}{r}\mathrm{F} / \mathrm{E} \\
0-10 \\
\%\end{array}$ & $\begin{array}{r}\mathrm{R} / \mathrm{U} \\
0-10 \\
\%\end{array}$ & $\begin{array}{r}\mathrm{F} / \mathrm{E} \\
>10- \\
15 \%\end{array}$ & $\begin{array}{r}\mathrm{R} / \mathrm{U} \\
>10- \\
15 \%\end{array}$ & $\begin{array}{r}\mathrm{F} / \mathrm{E} \\
>15- \\
20 \%\end{array}$ & $\begin{array}{r}\mathrm{R} / \mathrm{U} \\
>15- \\
20 \%\end{array}$ & $\begin{array}{r}\mathrm{F} / \mathrm{E} \\
>20 \%\end{array}$ & $\begin{array}{r}\mathrm{R} / \mathrm{U} \\
>20 \%\end{array}$ \\
\hline $1 \mathrm{~F}$ & 5.23 & 5.17 & 82.90 & 11.60 & 13.07 & 26.53 & 3.33 & 56.70 & 0.70 & 0.10 \\
\hline $2 \mathrm{~F}$ & 16.40 & 64.23 & 16.77 & 20.13 & 25.00 & 9.70 & 30.33 & 5.93 & 27.90 & 46.50 \\
\hline $3 \mathrm{~F}$ & 17.74 & 34.50 & 1.47 & 31.37 & 18.77 & 25.83 & 57.27 & 8.30 & 22.50 & 8.07 \\
\hline $4 \mathrm{~F}$ & 32.42 & 56.93 & 0.00 & 36.00 & 0.13 & 6.60 & 1.30 & 0.47 & 98.57 & 97.87 \\
\hline $5 \mathrm{~F}$ & 14.30 & 70.80 & 25.13 & 16.53 & 30.03 & 9.30 & 28.47 & 3.37 & 16.37 & 18.93 \\
\hline $6 \mathrm{~F}$ & 20.84 & 7.20 & 0.27 & 13.97 & 0.50 & 27.53 & 35.53 & 51.30 & 63.70 & 93.50 \\
\hline $7 \mathrm{M}$ & 25.74 & 4.10 & 1.13 & 4.17 & 3.53 & 8.33 & 10.67 & 83.40 & 84.67 & 50.07 \\
\hline $8 \mathrm{M}$ & 5.74 & 0.17 & 84.83 & 0.90 & 11.43 & 4.87 & 2.87 & 94.07 & 0.87 & 0.37 \\
\hline $9 \mathrm{M}$ & 16.11 & 1.07 & 13.33 & 4.27 & 30.77 & 42.07 & 36.20 & 52.60 & 19.70 & 1.80 \\
\hline $10 \mathrm{M}$ & 11.90 & 0.30 & 23.10 & 4.27 & 64.87 & 51.13 & 11.87 & 44.30 & 0.17 & 0.23 \\
\hline $11 \mathrm{M}$ & 12.44 & 58.00 & 25.60 & 28.37 & 55.77 & 10.13 & 15.33 & 3.50 & 3.30 & 2.00 \\
\hline $12 \mathrm{M}$ & 9.47 & 0.10 & 56.30 & 0.40 & 35.73 & 3.07 & 1.13 & 89.77 & 0.17 & 0.17 \\
\hline
\end{tabular}




\section{Appendix W. Raw Data: Wrist Data, MTK Task 7}

\section{Wrist Data for MTK Condition, Task 7}

\begin{tabular}{|r|r|r|r|r|r|r|r|r|r|r|}
\hline & $\begin{array}{r}\mathrm{F} / \mathrm{E} \\
\text { Mean }\end{array}$ & $\begin{array}{r}\mathrm{R} / \mathrm{U} \\
\mathrm{Mean}\end{array}$ & $\begin{array}{r}\mathrm{F} / \mathrm{E} \\
0-10 \\
\%\end{array}$ & $\begin{array}{r}\mathrm{R} / \mathrm{U} \\
0-10 \\
\%\end{array}$ & $\begin{array}{r}\mathrm{F} / \mathrm{E} \\
>10- \\
15 \%\end{array}$ & $\begin{array}{r}\mathrm{R} / \mathrm{U} \\
>10- \\
15 \%\end{array}$ & $\begin{array}{r}\mathrm{F} / \mathrm{E} \\
>15- \\
20 \%\end{array}$ & $\begin{array}{r}\mathrm{R} / \mathrm{U} \\
>15- \\
20 \%\end{array}$ & $\begin{array}{r}\mathrm{F} / \mathrm{E} \\
>20 \%\end{array}$ & $\begin{array}{r}\mathrm{R} / \mathrm{U} \\
>20 \%\end{array}$ \\
\hline $1 \mathrm{~F}$ & 22.99 & 7.25 & 6.30 & 68.90 & 11.27 & 18.43 & 20.93 & 11.23 & 61.50 & 1.43 \\
\hline $2 \mathrm{~F}$ & 5.43 & 13.25 & 87.23 & 33.07 & 8.70 & 29.07 & 3.03 & 25.20 & 1.03 & 12.67 \\
\hline $3 \mathrm{~F}$ & 10.65 & 18.50 & 51.07 & 1.37 & 33.83 & 13.57 & 11.30 & 56.17 & 3.80 & 28.90 \\
\hline $4 \mathrm{~F}$ & 7.87 & 29.84 & 75.30 & 0.13 & 21.70 & 0.10 & 3.00 & 1.03 & 0.00 & 98.73 \\
\hline $5 \mathrm{~F}$ & 6.19 & 17.65 & 80.27 & 5.57 & 14.77 & 21.33 & 3.73 & 43.97 & 1.23 & 29.13 \\
\hline $6 \mathrm{~F}$ & 20.04 & 20.84 & 7.20 & 0.27 & 13.97 & 0.50 & 27.53 & 35.53 & 51.30 & 63.70 \\
\hline $7 \mathrm{M}$ & 31.33 & 26.28 & 1.87 & 2.73 & 2.03 & 2.07 & 3.60 & 2.93 & 92.50 & 92.27 \\
\hline $8 \mathrm{M}$ & 26.23 & 4.65 & 0.17 & 91.47 & 1.17 & 7.57 & 8.20 & 0.57 & 90.47 & 0.40 \\
\hline $9 \mathrm{M}$ & 19.23 & 16.82 & 1.67 & 1.77 & 9.20 & 32.67 & 49.67 & 49.93 & 39.47 & 15.63 \\
\hline $10 \mathrm{M}$ & 14.63 & 8.20 & 24.97 & 67.07 & 24.43 & 22.77 & 32.80 & 8.57 & 17.80 & 1.60 \\
\hline $11 \mathrm{M}$ & 11.01 & 8.90 & 53.27 & 61.90 & 19.33 & 29.33 & 17.77 & 6.93 & 9.63 & 1.83 \\
\hline $12 \mathrm{M}$ & 31.64 & 7.80 & 0.07 & 89.63 & 0.37 & 8.10 & 1.47 & 2.20 & 98.10 & 0.07 \\
\hline & & & & & & & & & \\
\hline
\end{tabular}




\section{Appendix X. Raw Data: Wrist Data, MTK Task 8}

Wrist Data for MTK Condition, Task 8

\begin{tabular}{|c|c|c|c|c|c|c|c|c|c|c|}
\hline & $\begin{array}{r}\mathrm{F} / \mathrm{E} \\
\text { Mean }\end{array}$ & $\begin{array}{r}\mathrm{R} / \mathrm{U} \\
\text { Mean }\end{array}$ & $\begin{array}{r}\mathrm{F} / \mathrm{E} \\
0-10 \\
\%\end{array}$ & $\begin{array}{r}\mathrm{R} / \mathrm{U} \\
0-10 \\
\% \\
\end{array}$ & $\begin{array}{r}\mathrm{F} / \mathrm{E} \\
>10- \\
15 \%\end{array}$ & $\begin{array}{c}\mathrm{R} / \mathrm{U} \\
>10- \\
15 \%\end{array}$ & $\begin{array}{r}\mathrm{F} / \mathrm{E} \\
>15- \\
20 \%\end{array}$ & $\begin{array}{r}\mathrm{R} / \mathrm{U} \\
>15- \\
20 \%\end{array}$ & $\begin{array}{r}\mathrm{F} / \mathrm{E} \\
>20 \%\end{array}$ & $\begin{array}{r}\mathrm{R} / \mathrm{U} \\
>20 \%\end{array}$ \\
\hline $1 \mathrm{~F}$ & 31.80 & 10.04 & 0.00 & 53.83 & 0.10 & 39.23 & 2.67 & 6.50 & 97.23 & 0.43 \\
\hline $2 \mathrm{~F}$ & 26.52 & 3.77 & 0.13 & 92.60 & 0.37 & 3.83 & 5.20 & 2.87 & 94.30 & 0.70 \\
\hline $3 \mathrm{~F}$ & 26.73 & 11.04 & 0.00 & 37.40 & 0.00 & 55.73 & 3.00 & 6.80 & 97.00 & 0.07 \\
\hline $4 \mathrm{~F}$ & 17.64 & 31.13 & 2.13 & 0.50 & 11.63 & 0.03 & 70.23 & 0.03 & 16.00 & 99.43 \\
\hline $5 \mathrm{~F}$ & 20.34 & 10.95 & 7.93 & 39.57 & 17.57 & 44.97 & 31.63 & 15.10 & 42.87 & 0.37 \\
\hline $6 \mathrm{~F}$ & 15.05 & 25.01 & 9.70 & 0.00 & 27.27 & 0.07 & 60.87 & 3.03 & 2.17 & 96.90 \\
\hline $7 \mathrm{M}$ & 21.88 & 18.15 & 0.73 & 1.30 & 3.83 & 9.90 & 25.03 & 65.77 & 70.40 & 23.03 \\
\hline $8 \mathrm{M}$ & 45.09 & 4.60 & 0.00 & 90.37 & 0.00 & 8.20 & 0.00 & 1.13 & 100.00 & 0.30 \\
\hline $9 \mathrm{M}$ & 14.64 & 14.56 & 7.03 & 3.83 & 47.90 & 54.60 & 43.07 & 41.13 & 2.00 & 0.43 \\
\hline $10 \mathrm{M}$ & 18.85 & 15.62 & 0.53 & 5.43 & 11.23 & 33.37 & 59.20 & 54.03 & 29.03 & 7.17 \\
\hline $11 \mathrm{M}$ & 25.77 & 22.64 & 0.00 & 0.00 & 1.10 & 0.00 & 8.63 & 21.60 & 90.27 & 78.40 \\
\hline $12 \mathrm{M}$ & 42.90 & 10.73 & 4.23 & 50.20 & 0.80 & 13.73 & 0.80 & 30.97 & 94.17 & 5.10 \\
\hline
\end{tabular}




\section{BIBLIOGRAPHY}

Alden, D., Daniels, R., \& Kanarick, A. (1972). Keyboard design and operation: A review of the major issues. Human Factors, 14, 275-293.

Balogh, I, Ørbæk, P., Ohlsson, K., Nordander, C., Unge, J., Winkel, J. et al. (2004). Self-assessed and directly measured occupational physical activities: Influence of musculoskeletal complaints, age and gender. Applied Ergonomics, 35, 4956.

Browne, H., Bederson, B., Druin, A., Sherman, L., \& Westerman, W. (2000). Designing a collaborative finger painting application for children. College Park: Human-Computer Interaction Laboratory, Institute for Advanced Computer Studies, University of Maryland.

Brunner, H., \& Richardson, R. M. (1984). Effects of keyboard design and typing skill on user keyboard preferences and throughput performance. In Proceedings of the 28th Annual Meeting of the Human Factors Society (pp. 267-270). Santa Monica, CA: Human Factors Society.

BSR \& HFES. (2002). Human factors engineering of computer workstations. Santa Monica, CA: HFES.

Cakir, A. (1995). Acceptance of the adjustable keyboard. Ergonomics, 38, 1728-1744.

Chen, C., Burastero, S., Tittiranonda, P., Hollerback, K., Shih, M., \& Denhoy, R. (1994). Quantitative evaluation of four computer keyboards: wrist posture and typing performance. In Proceedings of the Human Factors and Ergonomics Society 38th Annual Meeting (pp. 1094-1098). Santa Monica, CA: HFES.

Detwiler, B., Hun An, C., \& Choi, P. (2000). The battle of input devices: examining the FingerWorks FingerBoard. College Park: Human-Computer Interaction Laboratory, Institute for Advanced Computer Studies, University of Maryland.

Everitt, K., Klemmer, S., Lee, R., \& Landay, J. (2003). Between u and i: Two worlds apart: bridging the gap between physical and virtual media for distributed design collaboration. In Proceedings of CHI'03 Conference of Human Factors in Computing Systems (pp. 553-560). New York: ACM Press.

Fingerworks. (2004). MultiTouch overview. Retrieved October 15, 2003 from http://fingerworks.com/multoverview.html.

Folkard, S. (1979). Changes in immediate memory strategy under induced muscle tension and with time of day. Quarterly Journal of Experimental Psychology, 31, 621-633. 
Gerard, M. J., Jones, S. K., Smith, L. A., Thomas, R. E., \& Wang, T. (1994). An ergonomic evaluation of the Kinesis ergonomic computer keyboard. Ergonomics, 37, 1661-1668.

Goodwin, N. (1975). Cursor positioning on an electronic display using lightpen, lightgun, or keyboard for three basic tasks. Human Factors, 17, 289-295.

Green, G. K., \& Morgan, B. B. (1985). Task performances as functions of level of processing, morningness-eveningness, time of day, and gender. In R. E. Eberts \& C. G. Eberts (Eds.), Trends in Ergonomics/Human Factors II (pp. 139-145). Amsterdam: North-Holland.

Greenstein, J. S., \& Arnaut, L. Y. (1987). Human factors aspects of manual computer input devices. In G. Salvendy (Ed.), Handbook of Human Factors (pp. 14501489). New York: Wiley.

Hanes, L. (1975). Human factors in international keyboard arrangement. In A. Chapanis (Ed.), Ethnic Variables in Human Factors Engineering (pp. 189206). Baltimore, MD: Johns Hopkins University Press.

Hashimoto, M., \& Togasi, M. (1995). A virtual oval keyboard and a vector input method for pen-based character input. In Proceedings of CHI'95 Conference of Human Factors in Computing Systems (pp. 254-255). New York: ACM Press.

Hedge, A., Morimoto, S., \& McCrobie, D. (1999). Effects of keyboard tray geometry on upper body posture and comfort on upper body posture and comfort. Ergonomics, 42, 1333-1349.

Hedge, A., \& Powers, J. (1995). Wrist postures while keyboarding: Effects of a negative slope keyboard system and full motion forearm supports. Ergonomics, $38,508-517$.

Hill, D. W., Cureton, K. J., \& Collins, M. A. (1989). Circadian specificity in exercise training. Ergonomics, 32, 79-92.

Hirsch, R. (1970). Effects of standard versus alphabetical keyboard formats on typing performance. Journal of Applied Psychology, 54, 484-490.

Hobday, S. W. (1988). A keyboard to increase productivity and reduce postural stress. In F. Aghazadeh (Ed.), Trends in Ergonomics/Human Factors V (pp. 321-330). Amsterdam: Elsevier Science Publishers.

Hoffman, E., Tsang, K., \& Mu, A. (1995). Data entry keyboard geometry and keying movement times. Ergonomics, 38, 940-950. 
Horne, J. A., \& Ostberg, O. (1976). A self-assessment questionnaire to determine Morningness-Eveningness in human circadian rhythms. International Journal of Chronobiology, 4, 97-110.

ISO. (1998). Ergonomic requirements for office work with visual display terminals (VDTs). Part 4: Keyboard Requirements (ISO 9241-4: 1998). Geneva, Switzerland: ISO.

Klemmer, E. (1971). Keyboard entry. Applied Ergonomics, 2, 2-6.

Knight, L. W., \& Retter, D. (1989). Datahand: design, potential performance, and improvements in the computer keyboard and mouse. In Proceedings of the 33rd Annual Meeting of the Human Factors Society (pp. 450-454). Santa Monica, CA: Human Factors Society.

Kroemer, K. (1972). Human engineering the keyboard. Human Factors, 14, 51-63.

Kroemer, K. (2000). Publications Related to Keyboarding - in Chronological Order. Radford, VA: K.H.E. Kroemer Ergonomics Research Institute, Inc.

Kroemer, K., Fathallah, F., \& Langley, L. (1988). A new keyboard with chorded ternary keys. In Proceedings of the 32nd Annual Meeting of the Human Factors Society (pp. 724-726). Santa Monica, CA: Human Factors Society.

Lewis, J., Allard, D., \& Hudson, H. (1999). Membrane keyboards and human performance. In Proceedings of the 43rd Annual Meeting of the Human Factors Society (pp. 101-106). Santa Monica, CA: HFES.

Lowe, B., Moore, J., Swanson, N., Perez, L., \& Alderson, M. (2001). Relationships between upper limb loading, physical findings, and discomfort associated with keyboard use. In Proceedings of the 45th Annual Meeting of the Human Factors and Ergonomics Society (pp. 1087-1091). Santa Monica, CA: Human Factors and Ergonomics Society.

MacKenzie, I. S., \& Zhang, S. X. (2001). An empirical investigation of the novice experience with soft keyboards. Behaviour \& Information Technology, 20, 411-418.

Marklin, R., Simoneau, G., \& Monroe, J. (1999). Wrist and forearm posture from typing on split and vertically inclined computer keyboards. Human Factors, 41, 559-569.

Marks, M., \& Folkard, S. (1988). The effects of time of day on recall from Expository Test. In M. M. Gruneberg, P. E. Morris \& R. N. Sykes (Eds.), Practical 
Aspects of Memory: Current Research and Issues. (Vol. 2, pp. 471-476).

Chichester: Wiley.

Matias, E., MacKenzie, I. S., \& Buxton, W. (1994). Half-QWERTY: Typing with one hand using your two-handed skills. In Proceedings of CHI'94 Conference on Human Factors in Computing Systems (pp. 51-52). New York: ACM Press.

Michaels, S. E. (1971). Qwerty vs. alphabetic keyboards as a function of typing skill. Human Factors, 13, 419-426.

Muss, T., \& Hedge, A. (1999). Effects of a vertical split-keyboard on posture, comfort and performance. In Proceedings of the 43rd Annual Meeting of the Human Factors and Ergonomics Society (pp.496-500). Santa Monica, CA: HFES.

Nakaseko, M., Grandjean, E., Hunting, W., \& Gierer, R. (1985). Studies on ergonomically designed alphanumeric keyboards. Human Factors, 27, 175187.

National Academy of Sciences. (2001). Musculoskeletal disorders and the workplace : low back and upper extremities. Washington, D.C.: National Academy Press.

Nelson, J., Treaster, D., \& Marras, W. (2001). Finger motion, wrist motion and tendon travel as a function of keyboard angles. Clinical Biomechanics, 15, 489-498.

NIOSH. (1997). Musculoskeletal disorders (MSDs) and workplace factors: A critical review of epidemiologic evidence for work-related musculoskeletal disorders of the neck, upper extremity, and low back. Cincinnati, $\mathrm{OH}$ : Author.

Norman, D., \& Fisher, D. (1982). Why alphabetic keyboards are not easy to use: Keyboard layout doesn't much matter. Human Factors, 24, 509-519.

Pollard, D., \& Cooper, M. (1979). The effect of feedback on keying performance. Applied Ergonomics, 10, 277-281.

Pew Internet \& American Life Project. (2004, March 28). Older Americans and the Internet. Retrieved April 15, 2004 from the Pew Internet \& American Life Project Web site: http://www.pewinternet.org/PPF/r/117/report_display.asp

Radwin, R., \& Ruffalo, B. (1999). Computer key switch force-displacement characteristics and short-term effects on localized fatigue. Ergonomics, 42, 160-170.

Rempel, D., Serina, E., Klinenberg, E., Martin, B. J., \& Armstrong, T. (1997). The effects of keyboard keyswitch make force on applied force and finger flexor muscle activity. Ergonomics, 40, 800-808. 
Rempel, D. M., Bach, J., Gordon, L., \& Tal, R. (1998). Effects of forearm pronation/supination on carpal tunnel pressure. Journal of Hand Surgery, 23, $38-42$.

Rochester, N., Bequaert, F. C., \& Sharp, E. M. (1978). The chord keyboard. Computer, 57-63.

Roe, C. J., Muto, W. H., \& Blake, T. (1984). Feedback and discrimination on membrane keyboards. In Proceedings of the Human Factors Society 28th Annual Meeting (pp. 277-281). Santa Monica, CA: Human Factors Scoiety.

Rossignol, A., Morse, E., Summers, V., \& Pagnotto, L. (1987). Video display terminal use and reported health symptoms among Massachusetts clerical workers. Journal of Occupational Medicine, 29, 112-118.

Sanders, M. S., \& McCormick, E. J. (1993). Human factors in engineering and design. New York: McGraw Hill.

Shanis, J. (2002). An exploration of Multitouch technology: A comparison of a fixed angle split keyboard with Multitouch and current input technologies. Unpublished Master's Thesis, Cornell University, Ithaca.

Simoneau, G., \& Marklin, R. (1999). Relationship between computer keyboard slope and wrist extension angle. In Proceedings of the 43rd Annual Meeting of the Human Factors and Ergonomics Society (pp. 708-711). Santa Monica, CA: Human Factors Society.

Simoneau, G., \& Marklin, R. (2001). Effect of computer keyboard slope and height on wrist extension angle. Human Factors, 43, 287-298.

Stasser, H., Fleischer, R., \& Keller, E. (2000). Electromyographic evaluation of muscle strain of the hand-arm-shoulder system during alternating typing at a conventional and an ergonomic keyboard. In Proceedings of the IEA 2000/HFES 200 Congress (pp. 360-363). Santa Monica, CA: HFES.

Tittiranonda, P., Burastero, S., \& Rempel, D. (1999). Risk factors for musculoskeletal disorders among computer users. Occupational Medicine: State of the Art Reviews, 14, 17-38.

Tittiranonda, P., Rempel, D., Armstrong, T., \& Burastero, S. (1999). Workplace use of an adjustable keyboard: Adjustment preferences and effect on wrist posture. American Industrial Hygiene Association Journal, 60, 340-348. 
Treaster, D., \& Marras, W. (2000). An assessment of alternate keyboards using finger motion, wrist motion and tendon travel. Clinical Biomechanics, 15, 499-503.

Westerman, W., Elias, J. G., \& Hedge, A. (2001). Multi-touch: A new tactile 2-D gesture interface for human interaction. In Proceedings of the Human Factors and Ergonomics Society 45th Annual Meeting (pp. 632-636). Santa Monica, CA: HFES.

Wiklund, M. E., Dumas, J. S., \& Hoffman, L. R. (1987). Optimizing a portable terminal keyboard for combined one-handed and two-handed use. In Proceedings of the 31st Annual Meeting of the Human Factors Society (pp. 585-589). Santa Monica, CA: Human Factors Society.

Woldstad, J. C., \& Jedriewski, M. A. (1993). Initial wrist posture during typing for different keyboard heights and slopes. In Advances in Industrial Ergonomics and Safety V (pp. 257-262). London: Taylor \& Francis.

Wu, M., \& Balakrishnan, R. (2003). Multi-finger and whole hand gestural interaction techniques for multi-user tabletop displays. In Proceedings of the 16th annual ACM symposium on User interface software and technology, (pp. 193-202). New York: ACM Press.

Zecevic, A., Miller, D. I., \& Harburn, K. (2000). An evaluation of the ergonomics of three computer keyboards. Ergonomics, 43, 55-72.

Zipp, P., Haider, E., Halpern, N., \& Rohmert, W. (1983). Keyboard design through physiological strain measurements. Applied Ergonomics, 14, 117-122. 